\title{
Hanford Radiological Protection Support Services Annual Report for 1995
}
M. Lyon
J. J. Fix
D. E. Bihl
R. K. Piper
E. H. Carbaugh
T. J. Froelich

May 1996

Prepared for the U.S. Department of Energy under Contract DE-AC06-76RLO 1830

Pacific Northwest National Laboratory

Operated for the U.S. Department of Energy by Battelle 


\section{DISCLAIMER}

This report was prepared as an account of work sponsored by an agency of the United States Government. Neither the United States Government nor any agency thereof, nor Battelle Memorial Institute, nor any of their employees, makes any warranty, express or implied, or assumes any legal liability or responsibility for the accuracy; completeness, or usefulness of any information, apparatus, product, or process disclosed, or represents that its use would not infringe privately owned rights. Reference herein to any specific commercial product process, or service by trade name, trademark, manufacturer, or otherwise does not necessarily constitute or imply its endorsement, recommendation, or favoring by the United States Government or any agency thereof; or Battelle Memorial Institute. The views and opinions of authors expressed herein do not necessarily state or reflect those of the United States Government or any agency thereof.

\section{PACIFIC NORTHWEST NATIONAL LABORATORY operated by \\ BATTELLE \\ 1. ? : for the \\ UNITED STATES DEPARTMENT OF ENERGY \\ under Contract,DE-AC06-76RLO 1830}

Printed in the United States of Americs

Available to DOE and DOE contractors from the

Office of Scientific and Technical Information, P.O. Box 62, Oak Ridge, TN 37831; prices available from (615) $576-8401$.

Avan

Avalable to the public from the National Technical Information Service,

U.S. Department of Commerce, 5285 Port Royal Rd., Springfield, VA 22161

i 


\section{Hanford Radiological Protection Support Services Annual Report for 1995}

\author{
M. Lyon \\ D. E. Bihl \\ E. H. Carbaugh
}

\author{
J. J. Fix \\ R. K. Piper \\ T. J. Froelich
}

May 1996

Prepared for the U.S. Department of Energy under Contract DE-AC06-76RLO 1830

\section{MASTER}

Pacific Northwest National Laboratory

Richland, Washington 99352 



\begin{abstract}
Various Hanford Site radiation protection services provided by the Pacific Northwest National Laboratory for the U.S. Department of Energy Richland Operations Office and Hanford contractors are described in this annual report for calendar year 1995. These activities include external dosimetry measurements and evaluations, internal dosimetry measurements and evaluations, in vivo measurements, radiological record keeping, radiation source calibration, and instrument calibration and evaluation. For each of these activities, the routine program and any program changes or enhancements are described, as well as associated tasks, investigations, and studies. Program-related publications, presentations, and other staff professional activities are also described.
\end{abstract}





\section{Summary}

This report describes certain radiological protection support services performed by the Pacific Northwest National Laboratory (PNNL) during calendar year 1995, in support of the U. S. Department of Energy (DOE) Richland Operations Office (RL) and the Hanford contractors. Projects providing these sitewide services included 1) external dosimetry, 2) internal dosimetry, 3) in vivo measurements, 4) radiological records, 5) calibration of radiation sources traceable to the National Institute of Standards and Technology (NIST), and 6) instrument calibration and evaluation. Described in this report are the project routine tasks, any significant changes to the routine tasks, and any supporting studies performed during calendar year 1995. Also described are tasks performed by the projects that are funded by DOE Headquarters. Related professional activities, such as publications, presentations, and memberships on standards or industry committees, are also described.

The Hanford External Dosimetry Project (HEDP) provides external radioactive monitoring capabilities for all Hanford workers and visitors. The HEDP implemented the new Hanford personnel and environmental dosimetry system on January 1, 1995. The new system consists of a commercially provided thermoluminescent (TL) dosimetry system manufactured by Bicron/Harshaw (generally referred to as Harshaw) and a track-etch (TE) dosimetry system, developed by PNNL. Four formal project assessments were conducted during the year including 1) an intercontractor process improvement review, 2) a DOE/RL performance-based review, 3) a PNNL "Achieving the Competitive Edge (ACE)" evaluation, and 4) a unit price review. During 1995, HEDP staff passed all external dosimeter performance reviews. Several changes, as coordinated during meetings with the Hanford Personnel Dosimeter Advisory Committee, were made in routine project practices during the year. Testing of the new Hanford extremity dosimetry system planned for implementation during 1996 was initiated.

The Hanford Internal Dosimetry Project provides excreta bioassay monitoring, as well as associated evaluation and documentation of internal radiological exposure and dose to Hanford workers and visitors. During 1995 the project provided oversight to 4474 excreta bioassay requests (a decrease of $50 \%$ from 1994) and 4483 successful excreta bioassay measurements (including some results requested in 1994). Changes to the routine project included 1) taking over the management function for the bioassay analytical contract, 2) completion of the project quality assurance plan and major revisions to the project manual and procedures manual, and 3) adoption of Version 1.4 of the CINDY code. Workspecific bioassay monitoring programs were evaluated and designed for special projects. A two-year study on uranium in urine from local natural sources was completed.

The Hanford Whole Body Counting Project provides the capability to detect radioactive materials deposited in individuals using in vivo techniques. During 1995 the project performed 10,962 in vivo measurements, a decrease of $21 \%$ from 1994. As a part of the preparation for DOE Laboratory Accreditation Program review, the project participated in pilot testing for low energy photons. Some non-routine tasks performed included 1) participation in the Oak Ridge National Laboratory intercomparison program, 2) implementing the new computer system, and 3) issuing a new revision to the 
Whole Body Counting Manual. Improvements to the project included 1) a number of cost reductions, 2) replacement of a $\mathrm{NaI}$ detector in the Preview Counter, 3) expansion of the head counting calibration to include additional isotopes, and 4) incorporation of a resolution check of all routine detectors into daily procedures.

The Hanford Radiological Records Project preserves and administers all Hanford records of personnel radiological exposure as well as records of historical radiation protection and radiological dosimetry practices and policies. In addition to producing reports for DOE Headquarters, RL, Hanford contractors, individuals, and other authorized agencies, the project provides data for epidemiology and research projects. The project added some new reports, added a project procedures manual, revised the project manual, and converted to a unit pricing scheme. A number of changes and some new programs were made to the Hanford Radiological Exposure (REX) system, some based on new regulatory requirements and others to enhance the operational efficiency of the system. A large number of dosimetry changes were made electronically in REX to save the field dosimetry units from having to complete large numbers of paper forms. The laser optical disk system received a number of upgrades to enhance the operation of the system.

The Radiation Standards and Calibration Project maintains radiological standards necessary for appropriate characterization and calibration for the instrument calibration and external dosimetry projects. In support of this task, special instrument and dosimeter response-characterizing equipment and supplemental radiation reference fields are maintained, as necessary. This activity provides the means to characterize response to various radiation fields encountered at Hanford and ensures the calibration fields are in accordance with recommended standards and guides. Some modifications included instal- lation of upgraded and more accurate laser distance measuring equipment into several wells and installation of some new sources. Supporting studies conducted included determination of well calibration uncertainties and calibration of a ${ }^{241} \mathrm{AmBe}$ neutron reference field.

The Radcon Instrumentation Services Project (formerly the Instrument Calibration and Evaluation Program) provides complete and reliable radiation protection instrument services for site contractors to ensure personnel safety in the Hanford workplace. Specific tasks performed under this project during 1995 included calibration, maintenance, and repair of portable instrumentation; procurement and testing of new radiological control instruments; administration and technical support of the Hanford Instrument Evaluation Committee; and maintenance of a pool of portable survey instruments available for use by site contractors. In support of site contractor radiological control organizations, the project completed an evaluation of new and existing instruments in support of 10 CFR Part 835 (DOE 1993) compliance and, at the request of DOE-RL, initiated unit prices for services offered to site contractors. 


\section{Acknowledgments}

The authors would like to thank the staff members whose professional skills and technical expertise ensure the success of the Hanford External Dosimetry Project, Internal Dosimetry Project, Whole Body Counting Project, Radiological Records Project, Radiation Standards and Calibrations Project, and Radcon Instrumentation Services Project. 



\section{Abbreviations and Acronyms}

ACE Achieving the Competitive Edge

ACES Access Control Entry System

ANSI American National Standards Institute

ASSP Analytical Support Services Program

BCSR Boeing Computer Services-Richland

CAR computer-assisted retrieval

CEDE committed effective dose equivalent

$\mathrm{CP}$ cutie-pie (survey instrument)

CY calendar year

DEC Digital Equipment Corporation

DME distance measuring equipment

DOE U.S. Department of Energy

DOELAP DOE Laboratory Accreditation Program

EDF Emergency Decontamination Facility

EM Environmental Management

ERC Environmental Restoration Contractor

FY fiscal year

GM Geiger-Mueller (detector)

HCND Hanford combination neutron dosimeter

HED Hanford environmental dosimeter

HEDP Hanford External Dosimetry Project

HEHF Hanford Environmental Health Foundation

HHS Hanford Health Scheduling

HIEC Hanford Instrument Evaluation Committee

HPDAC Hanford Personnel Dosimetry Advisory Committee

HPGe high-purity germanium

HRRP Hanford Radiological Records Project

HSD Hanford standard dosimeter

HSRCM Hanford Site Radiological Control Manual

ICFKH ICF Kaiser Engineers Hanford Company

IDP Hanford Internal Dosimetry Project 
ISO International Standards Organization

IT IT Corporation

IVRRF In Vivo Radioassay and Research Facility

LAN local area network

LANL Los Alamos National Laboratory

LaserREX laser optical disk subsystem to REX

MDAs minimal detectable activities

MQA measurement quality assurance

NaI sodium iodide

NBS National Bureau of Standards

NIST National Institute of Standards and Technology

NRC U.S. Nuclear Regulatory Commission

ORNL Oak Ridge National Laboratory

PFP Plutonium Finishing Plant

PNAD Personal Nuclear Accident Dosimeters

PNNL Pacific Northwest National Laboratory

PTB Physikalisch-Technische Bundesanstalt

PTW Physikalisch-Technische Werkstäten

QA quality assurance

QC quality control

QUS quick uranium soluble

RCM Radiological Control Manual

RESL Radiological and Environmental Systems Laboratory

REX Radiological Exposure (system)

RIS Radcon Instrumentation Services (project)

RL U.S. Department of Energy Richland Field Office

ROIs regions of interest

RS\&C Radiation Standards and Calibrations (project)

SOW Statement of Work

TE track-etch (dosimetry system)

TEPC tissue equivalent proportional counter

TL thermoluminescent (dosimetry) 
TLD thermoluminexcent dosimeter

TRU transuranium

USTR U.S. Transuranium Registry

WBC whole-body count

WBCP Hanford Whole Body Counting Project

WHC Westinghouse Hanford Company

WIPP Waste Isolation Pilot Plant 



\section{Contents}

Abstract $\ldots \ldots \ldots \ldots \ldots \ldots \ldots \ldots \ldots \ldots \ldots \ldots \ldots \ldots \ldots \ldots \ldots \ldots$

Summary $\ldots \ldots \ldots \ldots \ldots \ldots \ldots \ldots \ldots \ldots \ldots \ldots \ldots \ldots \ldots \ldots$

Acknowledgments $\ldots \ldots \ldots \ldots \ldots \ldots \ldots \ldots \ldots \ldots \ldots \ldots \ldots \ldots$ vii

Abbreviations and Acronyms $\ldots \ldots \ldots \ldots \ldots \ldots \ldots \ldots \ldots \ldots \ldots \ldots$

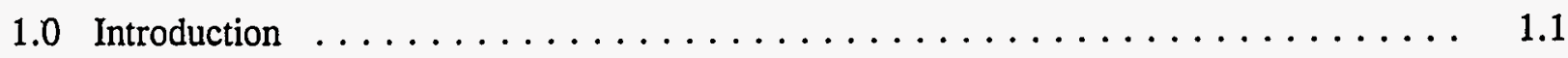

2.0 Hanford External Dosimetry Project $\ldots \ldots \ldots \ldots \ldots \ldots \ldots \ldots \ldots \ldots \ldots \ldots$

2.1 Program Performance-Based Reviews $\ldots \ldots \ldots \ldots \ldots \ldots \ldots \ldots \ldots \ldots$

2.1.1 Intercontractor Process Improvement Review . . . . . . . . . . 2.1

2.1.2 DOE/RL Performance-Based Assessment . . . . . . . . . 2.2

2.1.3 PNNL ACE Review $\ldots \ldots \ldots \ldots \ldots \ldots \ldots \ldots \ldots \ldots \ldots \ldots$

2.1.4 Unit Pricing Review $\ldots \ldots \ldots \ldots \ldots \ldots \ldots \ldots \ldots \ldots \ldots \ldots$

2.2 External Performance Testing Evaluations $\ldots \ldots \ldots \ldots \ldots \ldots \ldots \ldots$

2.2.1 WHC Blind Audit Dosimeters . . . . . . . . . . . 2.3

2.2.2 PNNL Blind Audit Environmental Dosimeters $\ldots \ldots \ldots \ldots \ldots \ldots$

2.3 New Hanford Dosimetry System $\ldots \ldots \ldots \ldots \ldots \ldots \ldots \ldots \ldots$

2.3.1 Hanford Personnel Thermoluminescent Dosimeters . . . . . . . . . 2.4

2.3.2 Hanford Personnel Track-Etch Dosimeter . . . . . . . . . . 2.6

2.3.3 Hanford Environmental Thermoluminescent Dosimeter . . . . . . . . 2.6

2.4 Dose Results During $1995 \ldots \ldots \ldots \ldots \ldots \ldots \ldots \ldots \ldots \ldots \ldots$

2.5 Changes in Routine HEDP Practices During $1995 \ldots \ldots \ldots \ldots \ldots \ldots$

2.5.1 Multiple Dosimeter Practice $\ldots \ldots \ldots \ldots \ldots \ldots \ldots \ldots \ldots \ldots$

2.5.2 Track-Etch Dosimetry $\ldots \ldots \ldots \ldots \ldots \ldots \ldots \ldots \ldots \ldots \ldots \ldots \ldots$

xiii 
2.5.3 Positive Neutron Dose $\ldots \ldots \ldots \ldots \ldots \ldots \ldots \ldots \ldots \ldots \ldots$

2.5.4 Extremity Dosimeter Dose $\ldots \ldots \ldots \ldots \ldots \ldots \ldots \ldots \ldots \ldots \ldots$

2.5.5 Damaged Mylar . . . . . . . . . . . . . . . 2.12

2.5.6 Personal Nuclear Accident Dosimeters (PNADs) . . . . . . . . . . . 2.12

2.5.7 DOELAP Processing Backup Agreement . . . . . . . . . . 2.12

2.6 New Extremity Dosimetry System $\ldots \ldots \ldots \ldots \ldots \ldots \ldots . \ldots \ldots$

2.7 Documentation $\ldots \ldots \ldots \ldots \ldots \ldots \ldots \ldots \ldots \ldots \ldots \ldots \ldots \ldots \ldots \ldots$

2.8 Project-Related Professional Activities $\ldots \ldots \ldots \ldots \ldots \ldots \ldots \ldots \ldots \ldots$

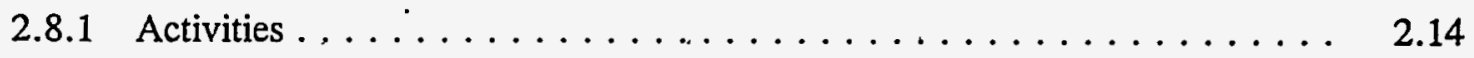

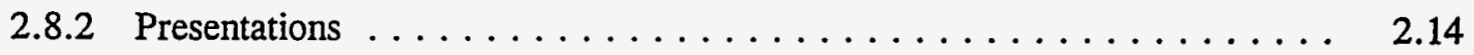

2.8 .3 Publications $\ldots \ldots \ldots \ldots \ldots \ldots \ldots \ldots \ldots \ldots \ldots \ldots \ldots \ldots \ldots \ldots$

2.8.4 Professional Memberships $\ldots \ldots \ldots \ldots \ldots \ldots \ldots \ldots \ldots \ldots \ldots \ldots$

3.0 Hanford Internal Dosimetry Project $\ldots \ldots \ldots \ldots \ldots \ldots \ldots \ldots \ldots \ldots \ldots$

3.1 Routine Tasks . . . . . . . . . . . .

3.1.1 Bioassay Capabilities $\ldots \ldots \ldots \ldots \ldots \ldots \ldots \ldots \ldots \ldots \ldots \ldots . \ldots \ldots$

3.1.2 Excreta Bioassay Contract Activities . . . . . . . . . . 3.6

3.1.3 Excreta Quality Control Oversight Program . . . . . . . . . . . 3.7

3.1.4 Policy and Documentation Changes $\ldots \ldots \ldots \ldots \ldots \ldots \ldots$

3.1.5 Adoption of CINDY Code (Version 1.4) $\ldots \ldots \ldots \ldots \ldots \ldots$

3.1.6 Annual Whole Body Counting Protocol for Mixed Fission Product and Spent Fuel Mixtures . . . . . . . . . . . . . 3.8 .

3.1.7 Specịal Bioassay Requirements Evaluations $\ldots \ldots \ldots \ldots \ldots \ldots \ldots$

3.1.8 Project Efficiency Improvements and Cost Reduction Activities . . . . . . 3.11

3.2 Monitoring and Assessment Activities $\ldots \ldots \ldots \ldots \ldots \ldots \ldots \ldots \ldots$ 
3.2.1 Excreta Bioassay Monitoring Activities . . . . . . . . . . . 3.11

3.2.2 Potential Intake Evaluations $\ldots \ldots \ldots \ldots \ldots \ldots \ldots \ldots \ldots \ldots$

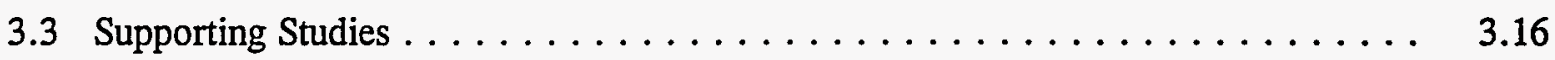

3.3.1 Uranium Background Study $\ldots \ldots \ldots \ldots \ldots \ldots \ldots \ldots \ldots$

3.4 Project-Related Professional Activities . . . . . . . . . . . . . 3.19

3.4 .1 Presentations . . . . . . . . . . . . . . . . . 3.19

3.4.2 Professional Memberships $\ldots \ldots \ldots \ldots \ldots \ldots \ldots \ldots \ldots \ldots \ldots$

4.0 Hanford Whole Body Counting Project $\ldots \ldots \ldots \ldots \ldots \ldots \ldots \ldots \ldots \ldots \ldots$

4.1 Routine Tasks . . . . . . . . . . . . . . . . . . . 4.1

4.1.1 Routine In Vivo Radiobioassay $\ldots \ldots \ldots \ldots \ldots \ldots \ldots \ldots \ldots \ldots$

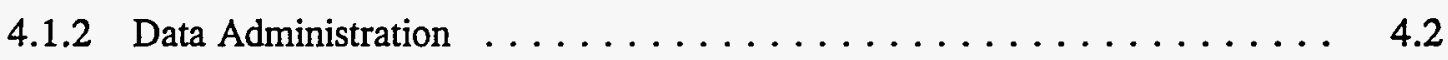

4.1 .3 Technical Services $\ldots \ldots \ldots \ldots \ldots \ldots \ldots \ldots \ldots \ldots \ldots$

4.1.4 Equipment Maintenance $\ldots \ldots \ldots \ldots \ldots \ldots \ldots \ldots \ldots \ldots$

4.1 .5 Quality Assurance Support $\ldots \ldots \ldots \ldots \ldots \ldots \ldots \ldots \ldots$

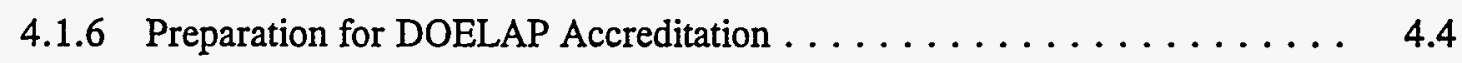

4.1 .7 Project Management $\ldots \ldots \ldots \ldots \ldots \ldots \ldots \ldots \ldots \ldots \ldots$

4.2 Summary of Measurements $\ldots \ldots \ldots \ldots \ldots \ldots \ldots \ldots \ldots \ldots \ldots$

4.2 .1 Summary of 1995 IVRRF Measurements $\ldots \ldots \ldots \ldots \ldots \ldots . \ldots$

4.2 .2 Remote Counter $\ldots \ldots \ldots \ldots \ldots \ldots \ldots \ldots \ldots \ldots \ldots \ldots$

4.3 Non-Routine Tasks $\ldots \ldots \ldots \ldots \ldots \ldots \ldots \ldots \ldots \ldots$

4.3.1 ORNL Intercomparison Program $\ldots \ldots \ldots \ldots \ldots \ldots \ldots \ldots$

4.3.2 NEXEC Software and Hardware System $\ldots \ldots \ldots \ldots \ldots \ldots$

4.3.3 Hanford Whole Body Counting Manual $\ldots \ldots \ldots \ldots \ldots \ldots \ldots$ 
4.4 Improvements to the Whole Body Counting Project $\ldots \ldots \ldots \ldots \ldots \ldots$

4.4.1 Process Improvement - AC̣E Breakthrough $\ldots \ldots \ldots \ldots \ldots \ldots \ldots . \ldots$

4.4.2 New NaI Detector in Preview Counter $\ldots \ldots \ldots \ldots \ldots \ldots . \ldots . . \ldots$

4.4.3 Planned Replacement of Aging Detectors . . . . . . . . . . . . 4.10

4.4.4 Expanded Head Counting Calibration $\ldots \ldots \ldots \ldots \ldots \ldots \ldots \ldots$ 4.10

4.4.5 New Daily Resolution Checks . . . . . . . . . . . . . . . 4.11

4.4.6 Investigation of Using Preamplifier Pole Zero to Reduce Background . . . 4.11

4.4.7 Monitoring of Palmer Cell Structural Crack . . . . . . . . . . 4.11

4.5 Supporting Programs and Studies at the IVRRF $\ldots \ldots \ldots \ldots \ldots \ldots \ldots \ldots$

4.5 .1 DOE Phantom Library $\ldots \ldots \ldots \ldots \ldots \ldots \ldots \ldots \ldots \ldots \ldots . \ldots \ldots$

4.5.2 U.S. Transuranium Registry Support $\ldots \ldots \ldots \ldots \ldots \ldots \ldots \ldots \ldots . . \ldots$

4.6 Project-Related Professional Activities . . . . . . . . . . . . . 4.12

4.6 .1 Presentations $\ldots \ldots \ldots \ldots \ldots \ldots \ldots \ldots \ldots \ldots \ldots \ldots \ldots \ldots \ldots \ldots .12$

4.6.2. Professional Memberships $\ldots \ldots \ldots \ldots \ldots \ldots \ldots \ldots \ldots \ldots . \ldots \ldots$

5.0 Hanford Radiological Records Project $\ldots \ldots \ldots \ldots \ldots \ldots \ldots \ldots \ldots \ldots \ldots$

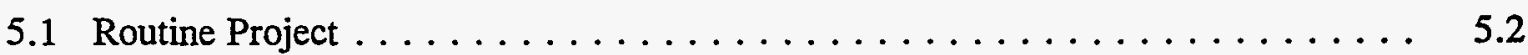

5.2 Supporting Projects $\ldots \ldots \ldots \ldots \ldots \ldots \ldots \ldots \ldots \ldots \ldots \ldots$

5.3 Project-Related Professional Activities $\ldots \ldots \ldots \ldots \ldots \ldots \ldots \ldots \ldots$

5.3.1 Professional Memberships $\ldots \ldots \ldots \ldots \ldots \ldots \ldots \ldots \ldots \ldots$

6.0 Radiation Standards and Calibrations Project $\ldots \ldots \ldots \ldots \ldots \ldots \ldots$

6.1 Routine Tasks $\ldots \ldots \ldots \ldots \ldots \ldots \ldots \ldots \ldots \ldots \ldots \ldots \ldots \ldots \ldots$

6.1 .1 Standards and Capabilities $\ldots \ldots \ldots \ldots \ldots \ldots \ldots \ldots \ldots \ldots$

6.1 .2 Traceability to National Standards $\ldots \ldots \ldots \ldots \ldots . \ldots \ldots$ 
6.1.3 Calibrations and Constancy Checks $\ldots \ldots \ldots \ldots \ldots \ldots \ldots \ldots$

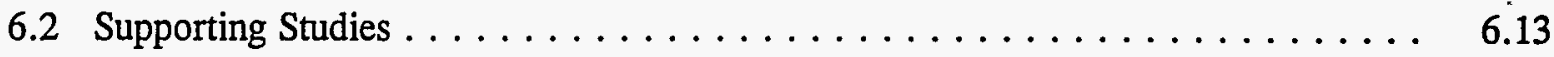

6.2.1 Determination of Well Calibration Uncertainties $\ldots \ldots \ldots \ldots \ldots . \ldots . . \ldots$

6.2.2 Calibration of $\mathrm{a}^{241} \mathrm{AmBe}$ Neutron Reference Field . . . . . . . . . . 6.14

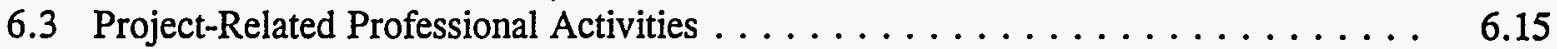

7.0 Radcon Instrumentation Services Project $\ldots \ldots \ldots \ldots \ldots \ldots \ldots \ldots \ldots \ldots \ldots$

7.1 Routine Tasks . . . . . . . . . 7.1

7.2 Project Improvements in Calibration and Maintenance Operations . . . . . . . 7.2

7.2.1 Instrument Evaluation and Testing $\ldots \ldots \ldots \ldots \ldots \ldots \ldots . \ldots \ldots$

7.3 Supporting Investigation and Studies $\ldots \ldots \ldots \ldots \ldots \ldots \ldots \ldots$

7.3.1 Testing to Qualify Site Instruments for Use in the Hanford Environment $\ldots \quad 7.4$

7.3.2 Stack Monitoring Systems Technical Assistance $\ldots \ldots \ldots \ldots \ldots . \ldots . . \ldots$

7.4 Project Related Professional Activities $\ldots \ldots \ldots \ldots \ldots \ldots \ldots \ldots \ldots$

7.4 .1 Presentations $\ldots \ldots \ldots \ldots \ldots \ldots \ldots \ldots \ldots \ldots \ldots \ldots$

7.4.2 Professional Memberships $\ldots \ldots \ldots \ldots \ldots \ldots \ldots \ldots \ldots$

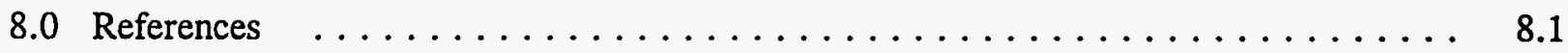




\section{Figures}

1.1 Management Structure and Major Communication Interfaces for Hanford

Radiological Support Services . . . . . . . . . . . . . . . . 1.2

2.1 Hanford Combination Neutron Dosimeter $\ldots \ldots \ldots \ldots \ldots \ldots \ldots$

2.2 Hanford Track-Etch Dosimetry Counting System $\ldots \ldots \ldots \ldots \ldots$

2.3 Hanford Environmental Dosimeter $\ldots \ldots \ldots \ldots \ldots \ldots \ldots \ldots \ldots \ldots \ldots \ldots$

2.4 Trend in Reported Hanford Personnel Dosimeter Results . . . . . . . . . . . . . . 2.9

3.1 Standard and Nonstandard Excreta Requests by Month $\ldots \ldots \ldots \ldots \ldots . \ldots \ldots$

3.2 Routine Urine Measurements Made from 1989 Through 1995 . . . . . . . . . . . . 3.13

4.1 In Vivo Measurements Made at the IVRRF From 1990 Through $1995 \ldots \ldots$

4.2 PNNL Performance in ORNL Intercomparisons of In Vivo Measurements . . . . . . . 4.9

$6.1 \mathrm{~GB}^{\mathrm{G}} 60^{60} \mathrm{Co}$ Irradiation $\ldots \ldots \ldots \ldots \ldots \ldots \ldots \ldots \ldots \ldots \ldots \ldots$

6.2 Example Spectrum of X-Ray Configurations $\ldots \ldots \ldots \ldots \ldots \ldots$

6.3 Typical Traceability Pathway for PNNL Photon Reference Fields $\ldots \ldots \ldots . . \ldots$

6.4 Typical Traceability Pathway for PNNL Neutron Reference Fields . . . . . . . . . . 6.9

6.5 Typical Traceability Pathway for PNNL Beta Reference Fields $\ldots \ldots \ldots \ldots . \ldots$ 


\section{Tables}

2.1 Audit Dosimeters Processed During $1995 \ldots \ldots \ldots \ldots \ldots \ldots \ldots \ldots \ldots \ldots$

3.1 Specified Miminum Detectable Activities and Screening Levels for Routine

Excreta Analyses During 1995 . . . . . . . . . . . . . . . . . . .

3.2 Minimum Detectable Activities and Screening Levels for Routine in Vivo

Measurements During $1995 \ldots \ldots \ldots \ldots \ldots \ldots \ldots \ldots$

3.3 Specified Minimum Detectable Activities for Emergency and Expedited Excreta

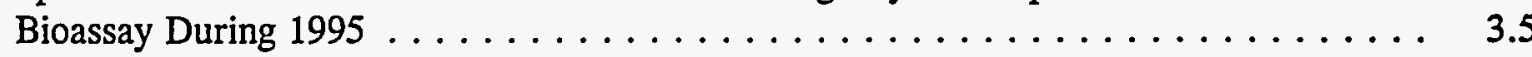

3.4 Project Change Records for $1995 \ldots \ldots \ldots \ldots \ldots \ldots \ldots \ldots$

3.5 Worker Excreta Measurements Reported in $1995 \ldots \ldots \ldots \ldots \ldots \ldots \ldots$

3.6 Summary of Potential Intake Incidents During $1995 \ldots \ldots \ldots \ldots \ldots \ldots$

3.7 Summary of Confirmed Intake Cases Identified Through the Routine Bioassay

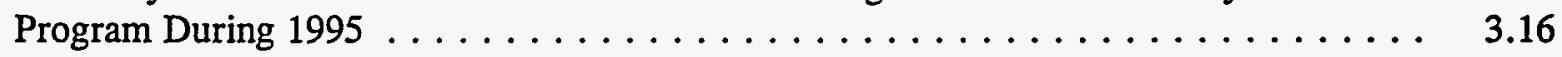

3.8 Comparison of Potential Intakes By Reason Code, $1990-1995$. . . . . . . . . . . . 3.17

3.9 Range of Internal Doses Assigned to the Hanford Work Force in $1995 \ldots \ldots \ldots$

4.1 In Vivo Measurements Performed During 1995 and Recorded in REX Database . . . . 4.6

5.1 Records Activity for Calendar Year $1995 \ldots \ldots \ldots \ldots \ldots \ldots$

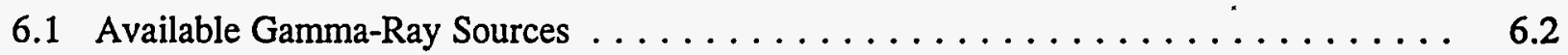

6.2 Complete.Listing of Available X-Ray Configuration Techniques and Their Characteristics ............................. 6.5

6.3 Results of 1995 NIST Measurement Quality Assurance Intercomparison _ . . . . . . 6.9

7.1 Calendar Year 1995 Instrument Calibrations by Unit-Price Category $\ldots \ldots \ldots \ldots .2$ 



\subsection{Introduction}

This annual report documents the calendar year (CY) 1995 activities of specific radiation protection services performed by the Pacific Northwest National Laboratory (PNNL) ${ }^{(a)}$ for the U.S. Department of Energy (DOE) Richland Field Office (RL) and the Hanford Site contractors. These sitewide services are provided by projects in 1) internal dosimetry, 2) whole body counting, 3) external dosimetry, 4) instrument calibration and evaluation, 5) calibration of radiation sources traceable to the National Institute of Science and Technology (NIST), and 6) radiological records. All of these services fall within the purview of the Health Protection Department of the PNNL Health Division.

Although some of the projects described in this report are involved in activities funded by other sources, only those activities funded by RL, DOE Headquarters, or the Hanford contractors are addressed here. Services provided for non-RL activities are performed only to the extent that they do not adversely affect services to DOE and its contractors. These non-RL services provide funds that support the overall program and reduce costs to RL. They also reduce costs to the Hanford contractors, which comprise Bechtel Hanford, Inc. (BHI), Boeing Computer Services - Richland (BCSR), the Hanford Environmental ح Health Foundation (HEHF), ICF Kaiser Engineers (ICFKH), PNNL, and Westinghouse Hanford Company (WHC).

Each of the six Hanford projects is described in a separate section of this report. Project descriptions include

- the routine program, including any significant changes or improvements

- investigations, studies, and tasks performed in support of the routine program

- other project-related activities, such as publications, presentations, and professional memberships.

The PNNL and RL management structure and communication interfaces for each PNNL-operated project, as of the end of calendar year 1995, are shown in the organizational chart in Figure 1.1. The RL Quality, Safety, and Health Programs are responsible for PNNL services in this area.

DOE added the word "National" to the Pacific Northwest Laboratory name during 1995. The Laboratory is now known as Pacific Northwest National Laboratory, which is abbreviated PNNL.

(a) Pacific Northwest National Laboratory is operated by Battelle Memorial Institute for the U.S. Department of Energy under Contract DE-AC06-76RLO 1830. 


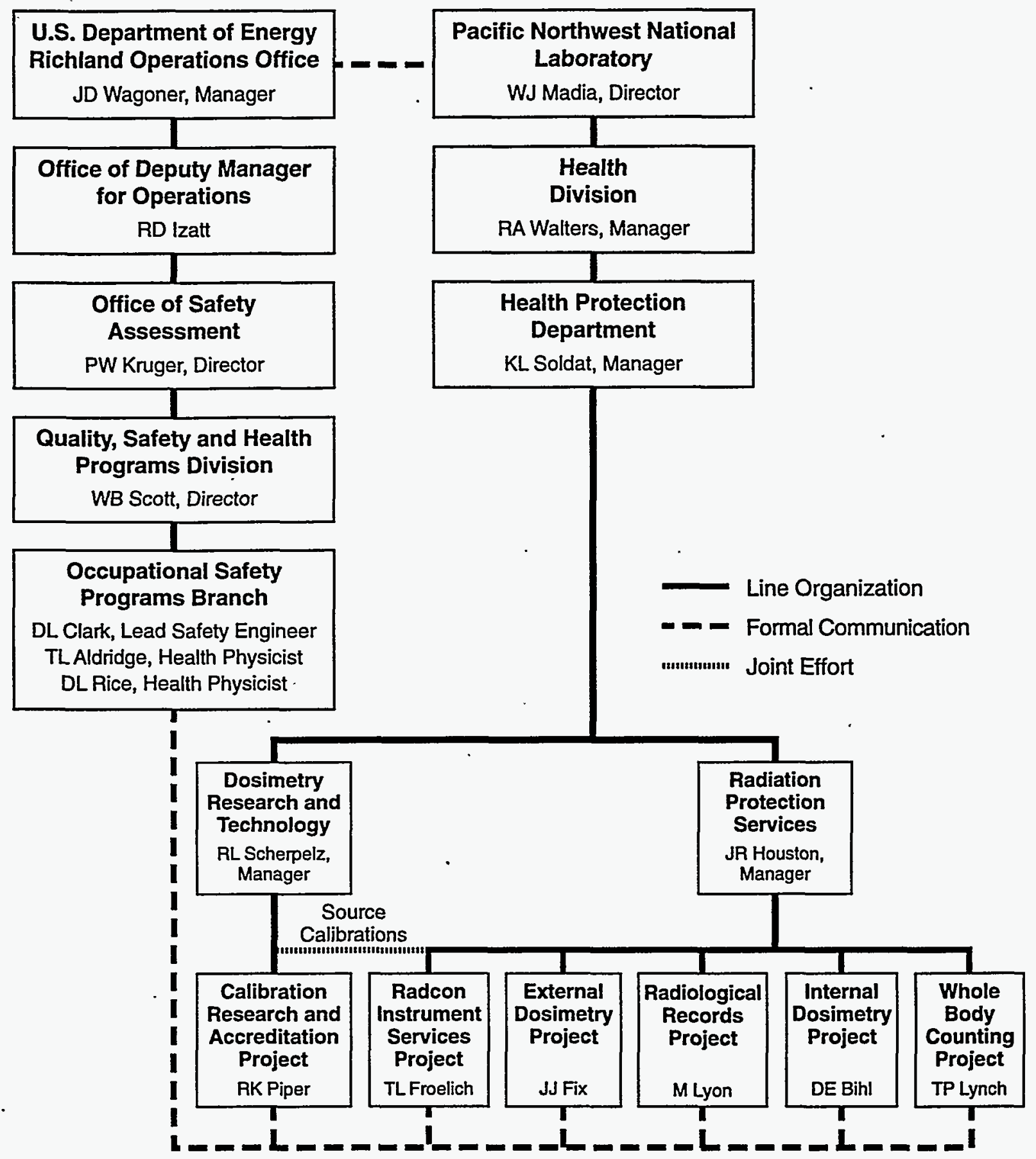

Figure 1.1. Management Structure and Major Communication Interfaces for Hanford Radiological Support Services 


\subsection{Hanford External Dosimetry Project}

The Hanford External Dosimetry Project (HEDP) is a multifaceted effort involving all Hanford contractors. Dose-of-record information from external radiation for Hanford personnel is provided by this project in compliance with DOE requirements as set forth in 10 CFR Part 835, "Occupation Radiation Protection" (DOE 1993). HEDP dosimeter results provide the means used by contractor personnel to project, control, and measure radiation doses received by personnel. Project staff also provide site-wide nuclear accident and environmental dosimetry capabilities in compliance with applicable DOE requirements.

During 1995, official dose-of-record information was conducted using the new Hanford dosimetry system implemented January 1, 1995. The new system consists of a commercially procured thermoluminescent (TL) dosimetry system (manufactured by Bicron/Harshaw) ${ }^{(\mathrm{a})}$ and a PNNL-developed track etch (TE) dosimetry system. The new dosimetry system consists of a Hanford standard dosimeter (HSD), a Hanford combination neutron dosimeter (HCND), and a Hanford environmental dosimeter (HED). All personnel assigned a personnel dosimeter receive the HSD, except for personnel potentially exposed to neutron radiation where an HCND is assigned. The HSD does have a neutron response capability which detects exposure to neutron radiation even though no official dose is determined. During 1995, the Hanford two-chip ring dosimeter continued to be used for the official extremity dose of record. However, pilot testing of a new Bicron/Harshaw "chipstrate" extremity dosimeter was begun. This system is scheduled for site-wide implementation during 1996.

\subsection{Program Performance-Based Reviews}

HEDP practices, procedures, and costs were reviewed during 1995 with the goal of developing the highest value for DOE/RL and Hanford contractor external dosimetry activities. Essentially all areas of project support were evaluated. Four distinct reviews are described in the following sections.

\subsubsection{Intercontractor Process Improvement Review}

A Hanford intercontractor review was conducted during the Spring of 1995 to evaluate alternatives to reduce overall dosimetry and radiological record costs at Hanford. All organizations significantly involved in personnel and environmental dosimetry participated. Numerous alternatives were identified and rated according to the feasibility of implementation and the potential cost saving. From this effort, four specific goals were assigned to the HEDP as follows:

1. The most highly rated goal among the participants was for HEDP staff to report all available dose-ofrecord results as soon as practicable to the Hanford Radiological Exposure (REX) system.

Thereafter, the respective Hanford contractor radiation protection organizations would use this

(a) Bicron, Saint-Gobain/Norton Industrial Ceramic Corporation, Solon, Ohio. 
information as soon as possible for use in tracking and controlling worker dose. In particular, WHC has pursued developing computer capabilities to upload this dose information to their Access Control Entry System (ACES). HEDP staff implemented the necessary capabilities during 1995 to report available personnel and extremity dose results daily to the REX database operated by the Hanford Radiological Records Project.

2. The second goal involved HEDP staff assigning personnel dosimeters directly to Hanford workers as opposed to the current practice of HEDP staff assigning dosimeters to the respective Hanford contractor field dosimetry organizations who then assign the dosimeters to their respective employees. After evaluation, it was determined that achieving this goal would not benefit the respective contractor organization's effort to maintain overall accountability of dosimeters and dose results.

3. The third goal involved having only HEDP staff conduct electronic wanding of the dosimeters and eliminate existing wanding conducted by Hanford contractor dosimetry organizations. At Hanford, dosimeter accountability is achieved by using a unique barcode label on each dosimeter. Electronic wanding of this label is used to track individual dosimeter movement from the HEDP 318 Building processing laboratory to the respective contractor dosimetry organizations, dosimeter assignment to the worker, and subsequent return of the dosimeter to the HEDP 318 Building processing laboratory. All dosimeter wanding is integrated into a single sitewide dosimeter accountability system. Following evaluation, it was determined achieving this goal would not benefit overall efforts to maintain dosimeter accountability.

4. The fourth goal involved an evaluation of staggering the environmental dosimeter quarterly exchanges. The benefit of this goal is the potential to reduce HEDP staffing requirements associated with preparing both the personnel and environmental dosimeters scheduled for quarterly exchanges at the same time. This goal is still under evaluation awaiting determination by PNNL and WHC environmental surveillance programs regarding their willingness to change to a new site-wide schedule.

\subsubsection{DOE/RL Performance-Based Assessment}

Two DOE/RL representatives conducted a performance-based assessment of HEDP activities during May-June 1995. Their focus was an evaluation of the status of project activities compared to applicable requirements and the associated cost. In particular, the incremental cost of satisfying DOE Laboratory Accreditation Program (DOELAP) requirements was evaluated. Copies of all project documentation and financial reports for the past few years were examined. The review concluded there was essentially no reasonable method by which the incremental costs of various project requirements (i.e., compliance, quality assurance, accreditation, etc.) could be separated from routine dosimeter processing costs. In essence the existing dosimetry processing practices were adopted to satisfy all applicable project requirements. 


\subsubsection{PNNL ACE Review}

PNNL conducted an in-depth internal evaluation, termed "Achieving the Competitive Edge (ACE)," of the HEDP, and other dosimetry projects, during August-September 1995 with the goal of achieving a higher overall project value (i.e., optimizing cost and performance). This activity involved PNNL. technical staff independent from the project as well as project staff, financial support staff, and ACE coordinating staff. This review involved an assessment of HEDP regulatory drivers, staffing, costing, etc. Through the ACE process, HEDP was able to identify an overall cost savings of $40 \%: 30 \%$ immediately during fiscal year (FY) 1996 and an additional 10\% thereafter. These savings were adopted in formal HEDP budget plans.

\subsubsection{Unit Pricing Review}

HEDP implemented unit pricing for dosimeter processing tasks for FY 1996. The basis for these unit prices was developed in consultation with DOE/RL and Hanford contractor dosimetry organizations. The respective unit prices consider the technical complexity, cost, frequency, and timeliness of each type of dosimeter processing. Different unit prices were prepared for each type of personnel and environmental dosimeter processing; whether the exchange was monthly, quarterly, or annual; and whether the processing had to be done immediately, within 24 hours, or routinely. Objectives of unit pricing are to provide accountability for the cost of HEDP processing services and to provide Hanford contractor dosimetry organizations with the capability to control their respective overall processing costs.

\subsection{External Performance Testing Evaluations}

Two external reviews of the accuracy of HEDP reported doses were conducted during 1995 as discussed in the following sections.

\subsubsection{WHC Blind Audit Dosimeters}

WHC routinely submits several audit dosimeters to be processed along with their personnel dosimeters. The HEDP successfully passed each monthly blind audit dosimeter evaluation conducted by WHC during 1995. With the exception of the neutron dose category during the second quarter, the HEDP also passed each of the quarterly evaluations conducted by WHC using the DOELAP methodology and criteria. An investigation was conducted of the cause for the single failure. Corrective action involved a modification to the neutron algorithm for the Hanford combination neutron dosimeter. This was done to eliminate a consistent high bias (15-20\%) which had been present, as observed on audit dosimeters exposed to bare ${ }^{252} \mathrm{Cf}$, since the inception of the new dosimetry system on January 1,1995 . The bias was the cause for failing the second quarter WHC DOELAP evaluation. Documentation of the change was included in HEDP files. The results of these audits are provided by WHC to the Hanford Radiation Protection Historical Files operated by the Hanford Radiological Records Project. 


\subsubsection{PNNL Blind Audit Environmental Dosimeters}

PNNL Environmental Surveillance Program staff routinely submit audit environmental dosimeters to be processed along with their quarterly exchanged environmental dosimeters. The given exposure ranges between 15 and 25 mrem of ${ }^{137} \mathrm{Cs}$ gamma radiation. A result is noted as abnormal if the given exposure is outside of pre-established tolerance levels. Approximately $20 \%$ of the reported results are typically noted as abnormal because of the tight tolerance levels established. Results of these audits are routinely included in the annual Hanford environmental surveillance reports (Dirkes et al. 1994) and in HEDP project files.

\subsection{New Hanford Dosimetry System}

Effective January 1, 1995, a new Hanford site personnel and environmental dosimeter system was implemented. This new system consists of a commercially procured TL dosimetry system (manufactured by Bicron/Harshaw $\left.{ }^{(a)}\right)$ and a PNNL-developed TE dosimetry system. Three new dosimeters were implemented: 1) an HSD, 2) an HCND, and 3) an HED. All personnel assigned a personnel dosimeter receive the HSD, except for those personnel potentially exposed to neutron radiation where a HCND is assigned. The HSD does have a neutron response capability which detects exposure to neutron radiation. For extremity dosimetry, the Hanford two-chip ring dosimeter was used during 1995 with plans to implement a new extremity dosimeter during 1996. The HED is used for all environmental dosimetry applications.

\subsubsection{Hanford Personnel Thermoluminescent Dosimeters}

The Hanford Standard and Combination Neutron Dosimeters contain four element dosimeter cards which are processed on Harshaw/Bicron model 8800 reader systems. Each of these dosimeter cards contain radiation sensitive phosphors which vary slightly in type and thickness. These cards are enclosed in a dosimeter holder which, over the location of each radiation sensitive phosphor, contain specific filter materials which also vary in composition. The combination of the filter thickness and composition (i.e., copper, tin, plastic, etc.), and the phosphor (i.e., $\mathrm{CaF}_{2}: \mathrm{Dy},{ }^{6} \mathrm{LiF}$, or ${ }^{7} \mathrm{LiF}$ ) result in dosimeter specific response characteristics which are used to calculate radiation dose. Figure $2.1 \mathrm{~b}$ is an illustration of the HCND showing the dosimeter cards and holders. There are four radiation sensitive phosphors in each card. The two cards shown are placed within the two dosimeter holders. The two dosimeters holders are issued as a pair being placed in a plastic Hanford holder as shown in Figure 2.1a. The HCND actually contains three dosimetry components consisting of 1 ) a TL dosimeter (smaller dosimeter shown on the right side of Figure 2.1) responsive to beta and photon radiation used to calculate shallow, eye, and deep dose; 2) a TL neutron dosimeter (larger dosimeter shown in Figure 2.1) responsive to photon and neutron radiation used to calculate neutron dose; and 3) a TE neutron dosimeter (two foils of CR-39 plastic shown above the dosimeter card on the left side of Figure $2.1 \mathrm{~b}$ ) responsive only to neutron radiation. The two TE dosimeter foils are also placed in the larger dosimeter holder.

(a) Bicron, Saint-Gobain/Norton Industrial Ceramics Corporation, Solon, Ohio. 


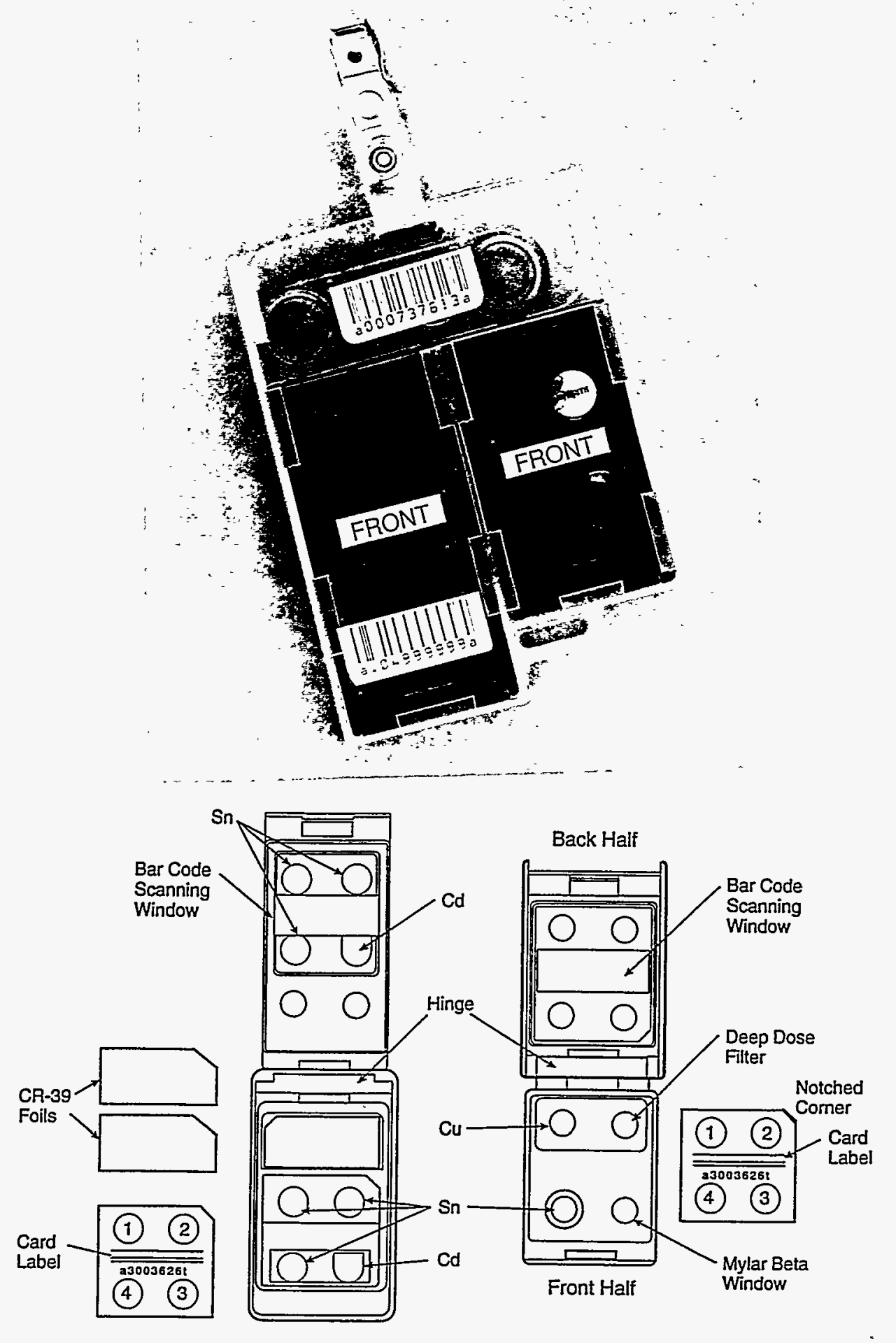

Figure 2.1. Hanford Combination Neutron Dosimeter a) Actual photo of dosimeter and b) Schematic of dosimeter with description of dosimeter elements. 
The HSD is nearly identical to the smaller dosimeter shown on the right side of Figure 2.1. The only difference is the type of phosphor used in one position of the card. In the HCND, which is intended to be used in neutron fields, only ${ }^{7} \mathrm{LiF}$ phosphors were used which have no significant response to neutron radiation. This is done to preserve the shallow-, eye-, and deep-dose calculation capabilities of this dosimeter for lower energy photons. In the HSD, where no exposure to neutron radiation is planned, a single ${ }^{6} \mathrm{LiF}$ phosphor is used. This phosphor is very sensitive to neutron radiation. The ${ }^{7} \mathrm{LiF}$ and ${ }^{6} \mathrm{LiF}$ phosphors, which are the same size, have identical response to beta and photon radiation. In this manner, the HSD will detect any significant inadvertent exposure to neutron radiation. Typically, if neutrons are detected by the HSD, an investigation is made to determine the cause, and if the individual should be issued an HCND.

\subsubsection{Hanford Personnel Track-Etch Dosimeter}

The two TE dosimeter foils provide a method, independent from the TL dosimeter, to measure neutron dose. The combination of these two systems provides significantly improved capabilities to measure and interpret neutron dose in many exposure environments. During 1995, response characteristics of the automated TL dosimetry system were used to identify TE dosimetry foils to be processed. Processing TE dosimeter foils is time consuming and relatively slow. Each foil must be electrochemically etched for several hours prior to reading the number of neutron-caused tracks using a microscope. Figure 2.2 illustrates the Hanford TE counting system showing a technician working with the computer controlled microscope system and a screen image of tracks on one of the foils shown on the monitor in the background. Based on field measurements of neutron dose and spectra during 1995, the decision was made to discontinue routine use of the TE dosimetry system effective January 1, 1996. This decision was based on the significant dose under-response of the TE dosimeter to actual measured neutron dose in Hanford work environments. The TE dosimeter foils have a lower energy threshold of about $100 \mathrm{keV}$. In current Hanford work environments, where little handling of the plutonium is done, significant neutron dose occurs for neutrons less than about $100 \mathrm{keV}$ which is not measured with the TE dosimetry foils. Current plans are to maintain the DOELAP accredited TE dosimetry system to support anticipated future efforts to move the plutonium inventory at Hanford to a DOE long-term repository. The TE dosimeter, in combination with the TL neutron dosimeter, is anticipated to provide good dosimetry capabilities during any direct handling of the plutonium.

\subsubsection{Hanford Environmental Thermoluminescent Dosimeter}

The HED consists of one card and one holder as illustrated in Figure 2.3. The card contains four TL phosphors consisting of two ${ }^{7} \mathrm{LiF}$ and two $\mathrm{CaF}_{2}: \mathrm{Dy}$. The two $\mathrm{CaF}_{2}: \mathrm{Dy}$ phosphors are placed behind the metallic filters (consisting of $0.05 \mathrm{~mm}$ lead and $0.25 \mathrm{~mm}$ tantalum) shown in Figure 2.3. For field deployment, each environmental dosimeter is wrapped in light opaque foil and enclosed in a sealed plastic bag. These cards are also processed on the 8800 automated reader system. Typically, Hanford contractors deploy about 200 environmental dosimeters throughout the Hanford environs. These dosimeters are typically exchanged quarterly. 


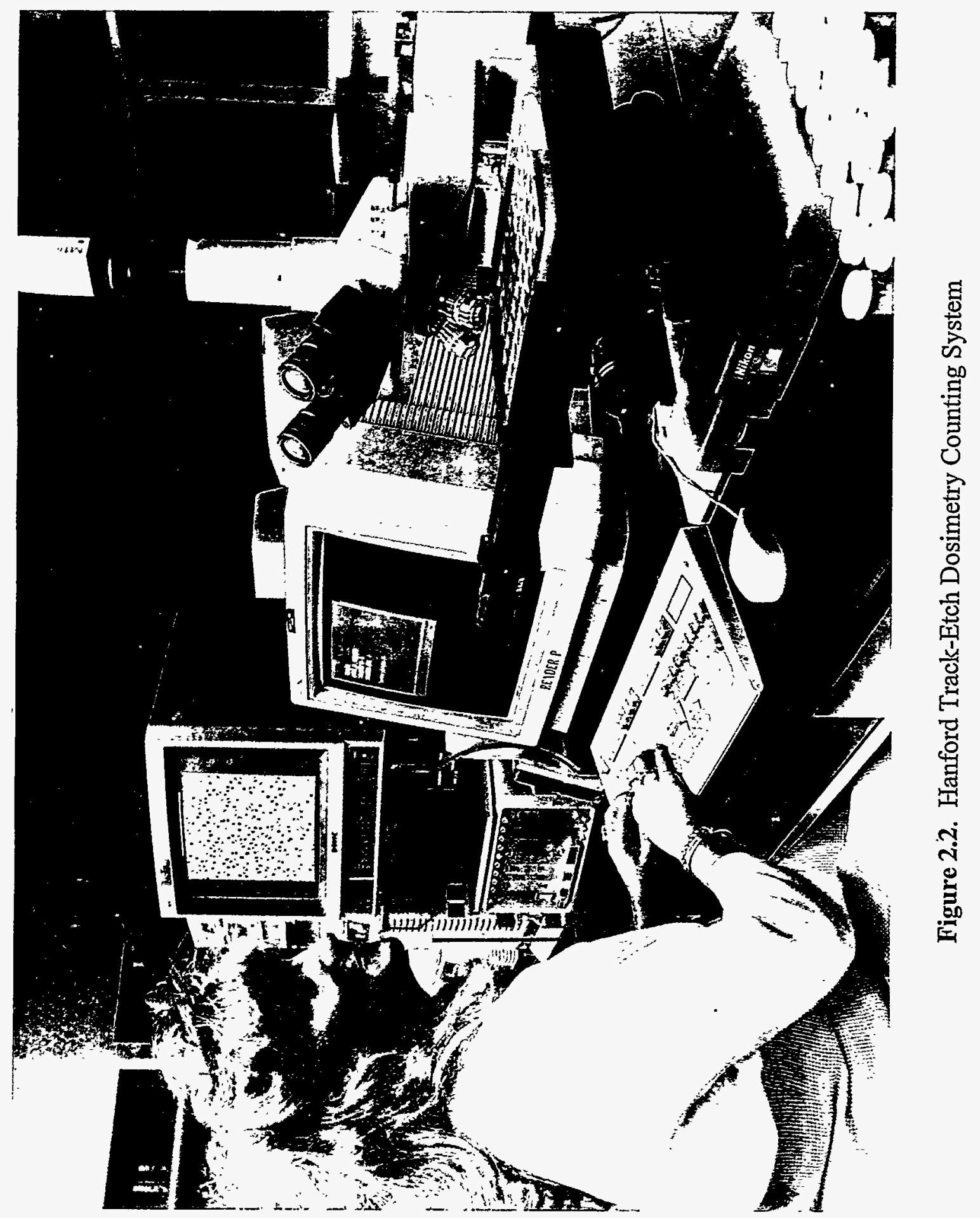




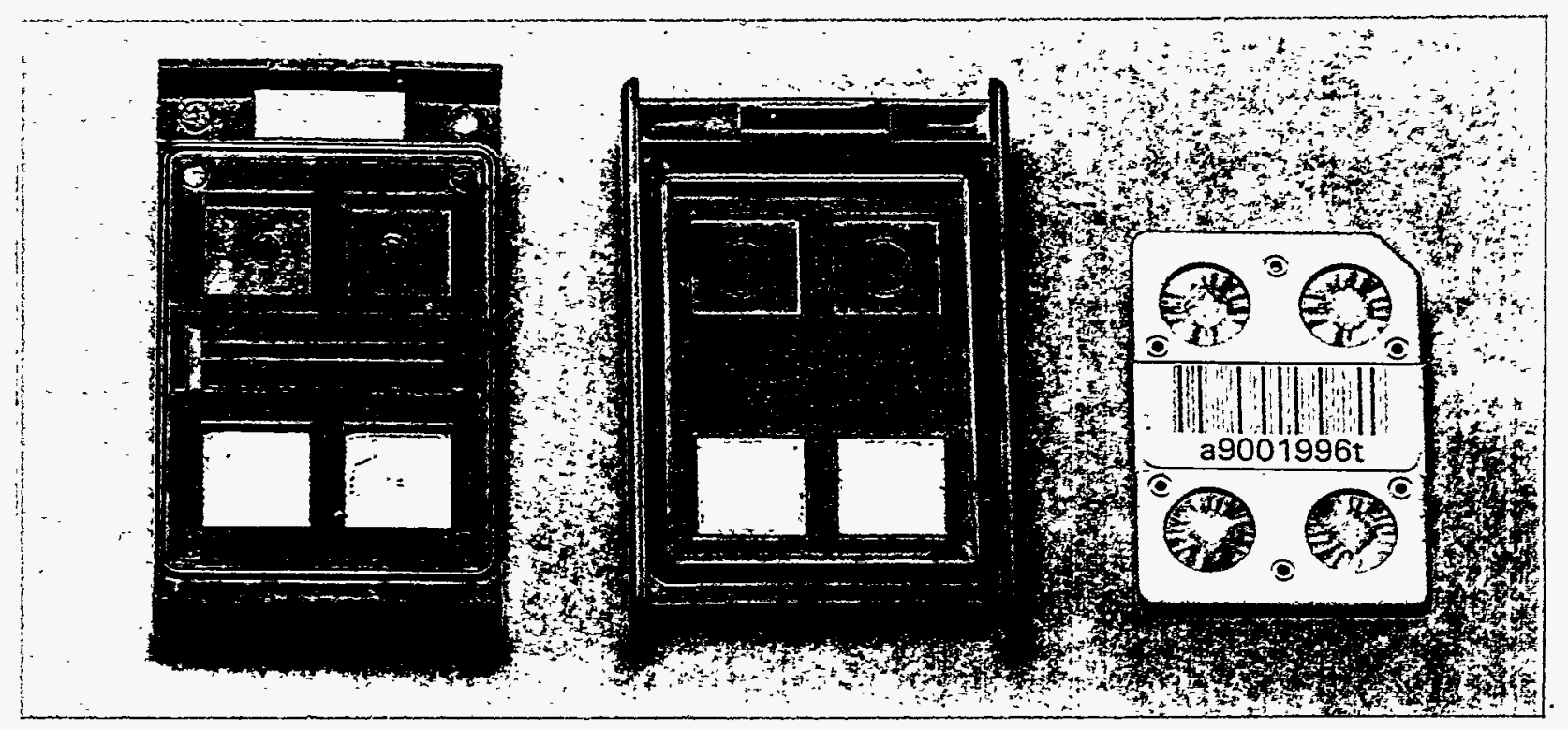

Figure 2.3. Hanford Environmental Dosimeter

\subsection{Dose Results During 1995}

During 1995, HEDP reported 71,049 official dose results. This is a decrease of approximately $16 \%$ from the previous 1994 annual total of 84,798 . The annual number of reported official dose results is illustrated in Figure 2.4 for 1990-1995 for each type of dosimeter. Comparison of the dosimeter assignments between 1994 and 1995 is complicated by the change in dosimetry systems. For the old system, several thousand single-chip basic dosimeters were assigned whereas the new dosimetry system has only multi-chip dosimeters. Ring dosimeter processing during 1995 continued to increase slightly compared to previous years.

Actual dosimeter processing exceeded the 71,049 official dose results reported due to the following reasons:

- processing a neutron dosimeter actually involves processing two separate TL dosimeters, and may also involve processing the TE dosimeter

- unused temporary personnel dosimeters (i.e., unassigned) are processed in the event it is subsequently determined the dosimeter was actually worn 


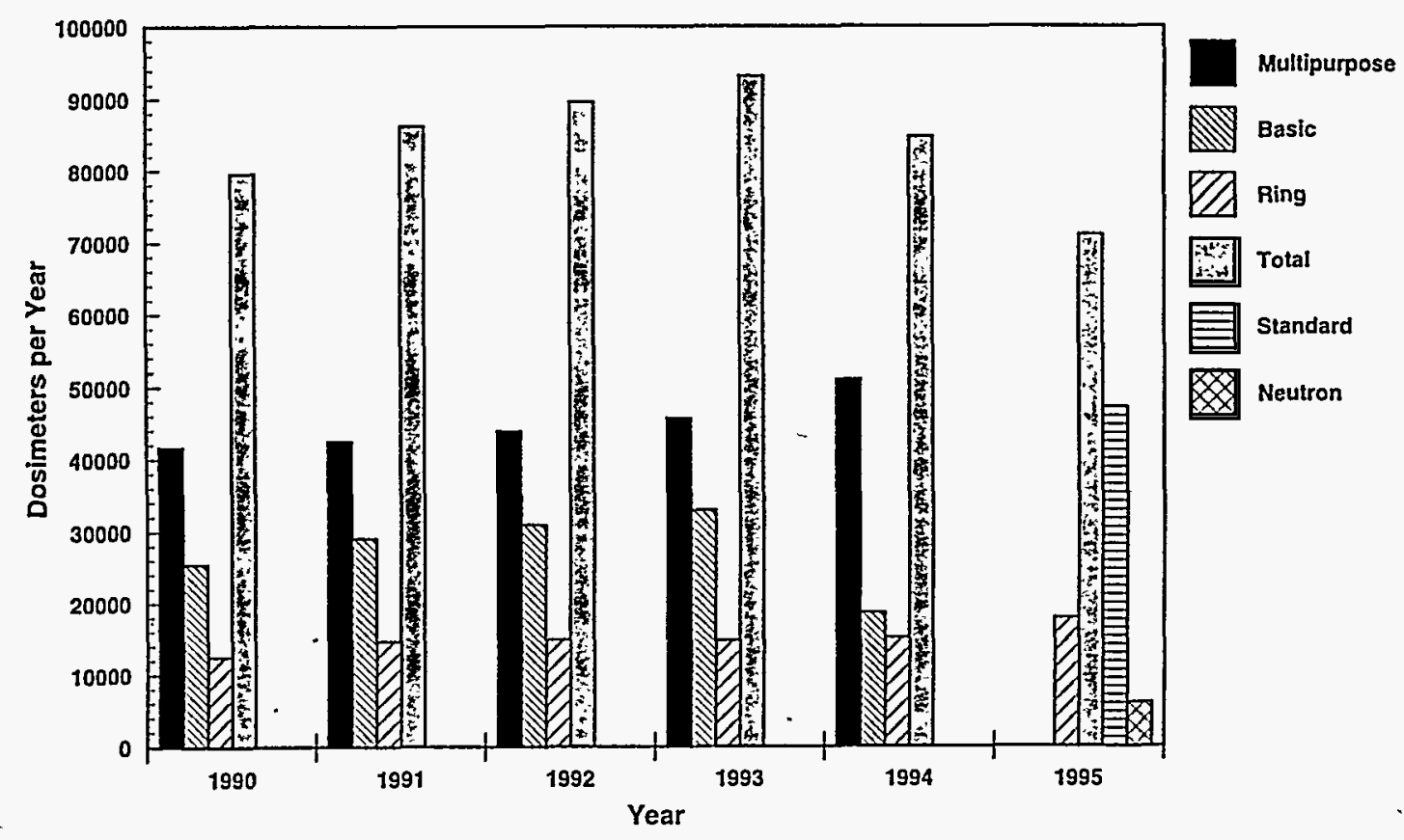

Figure 2.4. Trend in Reported Hanford Personnel Dosimeter Results

- a minimum of two quality-control (e.g., blank and dosed) dosimeters are processed along with a maximum of every 50 personnel dosimeters

- all personnel and environmental dosimeters are processed prior to issue to ensure all residual signals have been removed

- all new dosimeter cards are acceptance tested which includes five separate tests involving dosimeter processing.

Each year numerous internal audit dosimeters are processed to ensure the integrity of dosimeter processing. During 1995, a total of 480 internal audit dosimeters were processed. A breakdown of the internal audit dosimeters is shown in Table 2.1 .

Control charts are used to evaluate the results for each of the audit dosimeter categories. Charts are prepared for every dosimeter and radiation type for each of the thirteen dosimeter processings (i.e., every month plus annual) conducted each year. A quality control report is prepared for each processing. Copies are distributed to all Hanford contractor radiation protection organizations, as well as the Hanford Radiation Protection Historical File. Copies of the control charts are also provided to the historical file. 
Table 2.1. Audit Dosimeters Processed During 1995

\begin{tabular}{||l|c|c|c|c||}
\hline & \multicolumn{4}{|c|}{ Dose Category } \\
\hline \multicolumn{1}{|c|}{ Dosimeter } & Shallow & Deep & Fast Neutron & Blank \\
\hline \hline Standard & 120 & 120 & NA $^{(a)}$ & 60 \\
\hline Combination Neutron & NA & NA & 120 & 60 \\
\hline Rings & NA & 120 & NA & Controls \\
\hline \hline
\end{tabular}

\subsection{Changes in Routine HEDP Practices During 1995}

Modifications to HEDP practices are discussed during meetings of the Hanford Personnel Dosimetry Advisory Committee (HPDAC). Changes in project practices made during 1995 are described in the following:

\subsubsection{Multiple Dosimeter Practice}

During the March 1995 Hanford Personnel Dosimetry Advisory Committee (HPDAC) $)^{(a)}$ meeting, requested dose conversion factors and multiple dosimeter dose assignment practices were included in Chapter 6.0 of PNNL-MA-842, "Hanford External Dosimetry Technical Basis Manual." Dose conversion factors were provided to identify those values used for Hanford dose evaluations. Substantial discussion continued throughout the year regarding an acceptable Hanford multiple dosimeter practice. This situation is complex because of the number and variety of work conditions at Hanford involving nonuniform fields. Competing philosophies are to 1) place the primary dosimeter at the position of the whole body with the highest dose or 2) use multiple dosimeters to evaluate the dose at selected positions of the whole body compared to the dose measured by the primary dosimeter located at the front of the torso. Other complications involved short-term versus longer-term multiple dosimeter assignment, whether the primary dosimeter should be used while the multiple dosimeters are worn, and whether different practices should be used for nonuniform neutron radiation exposure.

(a) Bihl, D.E. "Minutes of Hanford Personnel Dosimetry Advisory Committee Meeting on March 22, 1995." (A copy is available in the Hanford Radiation Protection Historical Files, Pacific Northwest National Laboratory, Richland, Washington.) 


\subsection{2' Track-Etch Dosimetry}

A special meeting of the HPDAC was held on May $8,1995^{(a)}$ to discuss the possibility of terminating the routine track-etch dosimetry component of the Hanford combination neutron dosimeter at the end of CY 1995. This item was discussed throughout the year at several HPDAC meetings. At the November $17,1995^{(b)}$ meeting the position was adopted to proceed with termination of routine assignment of TE dosimeter foils but to maintain DOELAP accredited TE dosimeter capabilities. This decision was adopted because of the measured under response of the TE dosimeter for existing Plutonium Finishing Plant (PFP) fields and the potential for future large-scale handling of plutonium at PFP.

\subsubsection{Positive Neutron Dose}

The issue of positive neutron doses on HSD was discussed at the May 17, 1995, meeting ${ }^{(\mathrm{c})}$ of the HPDAC. This issue has often arisen since implementation of the new dosimetry system. As originally designed, a positive neutron response indication on an HSD would alert the respective contractor radiation protection organization to assign an HCND. The notification threshold for a positive neutron response was increased beginning with the April 1995 dosimeter processing based on the expected dosimeter response in PFP degraded neutron spectra. The HPDAC concurred with the HEDP recommendation to change the level at which positive neutron dose is reported from $10 \mathrm{mrem}$ to 20 mrem "interpreted" dose based on a bare ${ }^{252} \mathrm{Cf}$ neutron spectrum. Based on field measurements, this calibration factor will significantly overestimate the actual neutron dose for PFP work environments. There is the associated increased probability to miss actual low-level neutron dose for work environments involving high-energy neutron radiation. However, there are no known high-energy neutron work environments where this has been observed.

\subsubsection{Extremity Dosimeter Dose}

During the July 19, 1995, meeting ${ }^{(d)}$ of the HPDAC, Hanford contractors agreed to implement the use of a facility specific calibration factor for extremity dosimeters similar to the practice used for neutron radiation with personnel dosimeters. This was done to compensate for the known under response of the Hanford ring dosimeter to high-intensity beta radiation fields in some work environments. HEDP

(a) Fix, J. J. "Minutes of Hanford Personnel Dosimetry Advisory Committee Meeting on May 8, 1995." (A copy is available in the Hanford Radiation Protection Historical Files, Pacific Northwest National Laboratory, Richland, Washington.)

(b) Fix, J. J. "Minutes of Hanford Personnel Dosimetry Advisory Committee Meeting on November 15, 1995." (A copy is available in the Hanford Radiation Protection Historical Files, Pacific Northwest National Laboratory, Richland, Washington.)

(c) Fix, J. J. "Minutes of Hanford Personnel Dosimetry Advisory Committee Meeting on May 17, 1995:" (A copy is available in the Hanford Radiation Protection Historical Files, Pacific Northwest National Laboratory, Richland, Washington.)

(d) Fix, J. J. "Minutes of Hanford Personnel Dosimetry Advisory Committee Meeting on July 19, 1995." (A copy is available in the Hanford Radiation Protection Historical Files, Pacific Northwest National Laboratory, Richland, Washington.) 
continues to use ${ }^{137} \mathrm{Cs}$ exposures as the primary calibration. During 1995 , facility-specific calibration factors of $2.0,3.0$, and 4.0 were determined for specific work environments. Default calibration factors of 3.0 and 4.0 were adopted by Hanford contractor dosimetry organizations based on an evaluation of radiation fields within their respective facilities.

\subsubsection{Damaged Mylar}

The thin Mylar-covered window on HSDs has shown a significant incidence of damage. Often the damage is apparently caused by the clip being used to affix the dosimeter. An ad hoc committee was formed to evaluate options to minimize damage. Based on recommendations from this committee, the HPDAC, at its meeting on November $15,1995,{ }^{(a)}$ requested HEDP staff to proceed with installing black tape on one end of the dosimeter holder to preclude using this end of the dosimeter to affix the existing clip. This was as a short-term solution. HEDP staff has pursued a longer-term solution in recommending use of a different clip for affixing the HSDs without damage to the Mylar window.

\subsubsection{Personal Nuclear Accident Dosimeters (PNADs)}

An ad hoc committee recommended that each of the existing PNADs be modified by inserting a TLD-700 chip. The modified PNAD would meet all 10 CFR Part 835 performance criteria and would eliminate the need to wear personnel dosimeters. The HPDAC adopted the recommendation of the ad hoc committee during its meeting of December 20, 1995. The HEDP was directed to implement the modification during 1996 as time permits. This is expected to reduce the need for personnel dosimeters for several hundred WHC and PNNL staff.

\subsubsection{DOELAP Processing Backup Agreement}

An agreement among Los Alamos National Laboratory (LANL), Sandia National Laboratory, the Waste Isolation Pilot Plant (WIPP), and PNNL personnel dosimetry organizations for backup dosimeter processing support was finalized. The availability of backup processing capability is one of the issues assessed under the DOELAP onsite technical review. This agreement replaces the HEDP practice of maintaining parallel processing capabilities in different laboratory facilities within the 318 Building.

\subsection{New Extremity Dosimetry System}

Extensive testing of the new Hanford TL Extremity Dosimetry system was begun during 1995. The new TL dosimetry system consists of the Harshaw chipstrate extremity dosimeter placed in a Hanford holder which is still under development. The dosimeter would be processed in one of two Harshaw 6600 hot-gas reader systems. The operating system for the Harshaw 6600 reader system is

(a) Fix, J. J. "Minutes of Hanford Personnel Dosimetry Advisory Committee Meeting on November 15, 1995." (A copy is available in the Hanford Radiation Protection Historical Files, Pacific Northwest National Laboratory, Richland, Washington.) 
essentially identical to the operating system used for the Harshaw 8800 reader systems used to process personnel and environmental dosimeters. Numerous studies have been conducted on the performance of this equipment including reader stability, dose response, light sensitivity, readout protocol, etc.

Pilot testing the new Hanford TL Extremity Dosimetry system was begun during 1995. Chipstrate "thin element" extremity dosimeters were assigned, along with the existing ring dosimeter, to staff at selected PNNL and WHC laboratories. The testing is being done to evaluate the durability, comfort, and accuracy of the new dosimeter. Laboratory studies are also underway to evaluate chipstrate response to ${ }^{137} \mathrm{Cs},{ }^{241} \mathrm{Am},{ }^{90} \mathrm{Sr} /{ }^{90} \mathrm{Y}$, and ${ }^{204} \mathrm{Tl}$ radiation sources as well as $\mathrm{M} 30, \mathrm{~S} 60, \mathrm{M} 150$, and H150 filtered $\mathrm{x}$-ray techniques. This is necessary to demonstrate satisfactory performance under the recently finalized ANSI N13.32, "American National Standard - Performance Testing of Extremity Dosimeter" (ANSI 1995).

\subsection{Documentation}

Several manuals are used to administer the HEDP. A summary of all project manuals follows:

1. PNNL-MA-568. Hanford External Dosimetry Project Manual. Pacific Northwest National Laboratory, Richland, Washington (internal manual).

2. PNNL-MA-583. Location of Criticality Alarms and Nuclear Accident Dosimeters at Hanford. Pacific Northwest National Laboratory, Richland, Washington (internal manual).

3. PNNL-MA-841. Hanford External Dosimetry Project Procedures Manual. Pacific Northwest National Laboratory, Richland, Washington (internal manual).

4. PNNL-MA-842. Hanford External Dosimetry Project Technical Basis Manual. Pacific Northwest National Laboratory, Richland, Washington (internal manual).

5. PNNL-MA-843. Track-Etch Detector Analysis (TEDA) Users Manual. Pacific Northwest National Laboratory, Richland, Washington (internal manual).

The HEDP Quality Assurance Plan, LSC-022, ${ }^{(a)}$ is used to identify quality assurance requirements of the project.

\subsection{Project-Related Professional Activities}

Staff activities, presentations, publications, and professional memberships during 1995 are listed in this section.

(a) Internal Manual, LSC-022, "Quality Assurance Plan for Hanford External Dosimetry Project," Pacific Northwest National Laboratory, Richland, Washington. 


\subsubsection{Activities}

Jack J. Fix conducted a DOE Laboratory Accreditation Program onsite technical assessment of the Brookhaven National Laboratory dosimetry program during August 14-15, 1995.

Jack J. Fix participated in a review of a National Institute for Occupational Safety and Health (NIOSH) and Centers for Disease Control and Prevention (CDC) draft research proposal entitled, "MultiSite Case-Control Study of Leukemia and Ionizing Radiation," on November 28, 1995, in Cincinnati, Ohio.

Bruce A. Rathbone served as a member of the technical steering committee for the Harshaw/Bicron TLD User's symposium held March 13-17, 1995, in Las Vegas, Nevada. This symposium included attendees from throughout the world.

Bruce A. Rathbone conducted a DOELAP onsite technical assessment of the West Valley Demonstration Project dosimetry program during August 22-25, 1995.

\subsubsection{Presentations}

Endres, A. W. 1995. Field Calibration of the Hanford Personnel Neutron Dosimeter. Presented at the Harshaw/Bicron TLD User Symposium, March 13-17, 1995, Las Vegas, Nevada.

Fix, J. J. 1995. Retrospective Evaluation of Hanford Personnel Neutron Dose. Presented at the annual Health Physics Society Meeting, July 23-28, 1995, Boston, Massachusetts.

Rathbone, B. A. 1995. Sensitivity and Residual in LiF:Mg,Cu,P as a Function of Maximum Readout Temperature. Presented at the Harshaw/Bicron TLD User's Symposium, March 13-17, 1995, Las Vegas, Nevada.

\subsubsection{Publications}

Gilbert, E. S. and J. J. Fix. 1995. "Accounting for Bias in Dose Estimates in Analyses of Data From Nuclear Worker Mortality Studies." Health Physics 68(5):650-660.

Cardis, E., E. S. Gilbert, L. Carpenter, G. Howe, I. Kato, B. K. Armstrong, V. Beral, G. Cowper, A. Douglas, J. J. Fix, S. A. Fry, J. Kaldor, C. Lave, L. Salmon, P. G. Smith, G. L. Voelz, and L. D. Wiggs. 1995. "Effects of Low Doses and Low Dose Rates of External Ionizing Radiation: Cancer Mortality Among Nuclear Industry Workers in Three Countries." Radiation Research 142:117-132. 
Cardis, E., E. S. Gilbert, L. Carpenter, G. Howe, I. Kato, J. Fix, L. Salmon, G. Cowper, B. K. Armstrong, V. Beral, A. Douglas, S. A. Fry, J. Kaldor, C. Lave, P. G. Smith, G. Voelz, and L. Wiggs. 1995. Combined Analyses of Cancer Mortality Among Nuclear Industry Workers in Canada, the United Kingdom, and the United States of America. IARC Technical Report No. 25, International Agency for Research on Cancer, Lyon, France.

PNNL-MA-856(a)

\subsubsection{Professional Memberships}

Fix, J. J. Member of DOE Comprehensive Epidemiologic Data Resource (CEDR) status group.

Fix, J. J. Member of DOE Laboratory Accreditation Program (DOELAP) Oversight Board.

Fix, J. J. Voting member of Health Physics Society Standards Committee.

Fix, J. J. Consultant to ANSI N13.29, "American National Standard for Dosimetry - Environmental Dosimetry Performance Criteria for Testing."

Rathbone, B. A. and J. J. Fix. DOE Laboratory Accreditation Program (DOELAP) Technical Assessors in personnel dosimetry.

(a) Internal Manual, PNNL-MA-856, "Hanford Site Criticality Incident Response Plan," Pacific Northwest National Laboratory, Richland, Washington. 



\subsection{Hanford Internal Dosimetry Project}

The Hanford Internal Dosimetry Project (IDP) was initiated in 1946 to provide for the assessment and documentation of occupational doses from intakes of radionuclides at the Hanford Site. The program is administered in support of Hanford radiation protection programs, as required by 10 CFR Part 835, "Occupational Radiation Protection" (DOE 1993) and the Hanford Site Radiological Control Manual, HSRCM-1 (RL 1994). Additional guidance is provided by the implementation guide (DOE 1994a, 1994b). The project provides the following internal dosimetry services:

- administration of a routine bioassay monitoring program

- investigation and assessment of potential internal exposures

- monitoring performance of the contract excreta bioassay laboratory

- selection and application of models, procedures, and practices for evaluating internal exposures

- technical support to RL and to Hanford Site contractors

- 24-hour, single-point-of-contact technical support for radiological incidents at Hanford.

\subsection{Routine Tasks}

Intakes of radionuclides are generally prevented by containment or other protective measures; therefore, intakes are generally assumed to result from an acute intake. Dose assessment is based on this assumption, except for work with tritium. Tritium intake is generally assumed to occur chronically . throughout the period of exposure, and urine samples are generally obtained at the beginning and ending of discrete work periods. Historically, chronic intake conditions were also assumed for uranium work, but, in 1995, almost no work occurred with or around uranium and acute intake conditions were assumed for any potential uranium intakes.

Other operational aspects of the IDP are described in the following documents:

- the technical aspects of internal dose calculations are established in the Technical Basis for Internal Dosimetry at Hanford, Rev. 1 (Sula et al. 1991)

- the protocols and practices for operation of the project and coordination with the Hanford Site contractors are established in the Hanford Internal Dosimetry Project Manual(a)

(a) Internal Manual, PNL-MA-552, Pacific Northwest National Laboratory, Richland, Washington. 
- detailed procedures are contained in the Hanford Internal Dosimetry Procedures Manual, ${ }^{(a)}$ which was completely revised and reissued in 1995

- the Quality Assurance Plan for the Operation of the Hanford Internal Dosimetry Project( ${ }^{(b)}$

- the technical agreements with the excreta lab are established by a Statement of Work (SOW).

The practices and technical aspects of operating the Hanford Whole Body Counting Project are established in the Whole Body Counting Manual (c) (see Chapter 4.0). Individual assessments of internal dose are documented in each individual's file in the Hanford Radiological Records Project (HRRP) files. Bioassay measurement results and internal doses are maintained in the REX database, which is operated by the HRRP (see Chapter 5.0).

Some facility operations that potentially impacted the IDP during 1995 are

- New work was conducted at PNNL involving radionuclides not previously encountered at Hanford, at least not encountered as separated and concentrated entities. The work involved generating signficant activities of short-lived alpha-emitting radionuclides with potential in the medical industry for cancer treatment. Two small pilot tests were conducted in 1995: one involved separation of ${ }^{223} \mathrm{Ra}$ from ${ }^{227} \mathrm{Ac}$ and ${ }^{227} \mathrm{Th}$ and the other involved separation of ${ }^{225} \mathrm{Ra}$ from ${ }^{229} \mathrm{Th}$ (see section 3.1.7).

- Phase I deactivation for the PUREX N-cell was completed in January 1995. This consisted of removal of small pieces of contaminated equipment from seven gloveboxes. Phase II, completed later in the year, consisted of cutting up and removing large pieces of equipment. Sludge stabilization was conducted at the PFP. Completed in June 1995, this work consisted of converting moist, plutonium-contaminated sludge into plutonium oxide powder by heating to nearly 1000 degrees Celsius. (This makes the material more stable from an operations point of view but more difficult to detect from a bioassay point of view.)

- Characterization of the waste in the Tank Farms was a major operation in 1995. Samples of the tank waste were collected and shipped to 222-S Laboratory, 200 West Area, for analysis. This work was. ongoing at the end of the year (see Section 3.1.6).

\subsubsection{Bioassay Capabilities}

Bioassay monitoring is performed regularly for workers who might inhale, ingest, or absorb radionuclides into their bodies in the course of their jobs. Measurement types and frequencies are based on the radionuclides of concern and their anticipated physical and chemical form. Minimum detectable

(a) Internal Manual, PNL-MA-565, Rev. 1, Pacific Northwest National Laboratory, Richland, Washington.

(b) Internal Manual, LSC-026, Rev. 0, Pacific Northwest National Laboratory, Richland, Washington.

(c) Internal Manual, PNL-MA-574, Rev. 1, Pacific Northwest National Laboratory, Richland, Washington. 
activities (MDAs) and follow-up levels for routine excreta and in vivo bioassay measurements are shown in Tables 3.1 and 3.2. MDAs for emergency and expedited excreta measurements are provided in Table 3.3.

Table 3.1. Specified Miminum Detectable Activities and Screening Levels for Routine Excreta Analyses During 1995

\begin{tabular}{|c|c|c|}
\hline Analysis $^{(a)}$ & $\begin{array}{l}\text { Contractual } \\
\mathrm{MDA}^{(b, c)}\end{array}$ & $\begin{array}{l}\text { Screening Level and } \\
\text { Sampling Frequency }(c, 0)\end{array}$ \\
\hline${ }^{238} \mathrm{Pu},{ }^{239} \mathrm{Pu}$ & $0.02 \mathrm{dpm}$ & $0.01 \mathrm{dpm}(\mathrm{A})$ \\
\hline${ }^{90} \mathrm{Sr}$ & $10 \mathrm{dpm}$ & $\begin{array}{l}26 \mathrm{dpm}(\mathrm{A}) \\
11 \mathrm{dpm}(\mathrm{BE})\end{array}$ \\
\hline${ }^{234} U^{(c)},{ }^{238} U$ & $0.02 \mathrm{dpm}$ & $0.15 \mathrm{dpm}(\mathrm{A}, \mathrm{Q})^{(\mathfrak{n})}$ \\
\hline${ }^{235} \mathrm{U}$ & $0.02 \mathrm{dpm}$ & $\begin{array}{l}0.01(\mathrm{~A}) \\
0.02 \mathrm{dpm}(\mathrm{Q}) \\
\end{array}$ \\
\hline${ }^{241} \mathrm{Am},{ }^{242} \mathrm{Cm}$ & $0.02 \mathrm{dpm}$ & $0.01 \mathrm{dpm}(\mathrm{A})$ \\
\hline${ }^{228} \mathrm{Th},{ }^{230} \mathrm{Th},{ }^{232} \mathrm{Th}$ & $0.10 \mathrm{dpm}$ & $\begin{array}{l}0.05 \mathrm{dpm} \\
\text { (not established) }\end{array}$ \\
\hline${ }^{225} \mathrm{Ac},{ }^{227} \mathrm{Th}$ & $0.10 \mathrm{dpm}$ & $\begin{array}{l}0.05 \mathrm{dpm} \\
\text { (not established) }\end{array}$ \\
\hline Elemental U & $0.06 \mu \mathrm{g}$ & $0.2 \mu \mathrm{g}(\mathrm{Q})^{(\mathrm{n})}$ \\
\hline Elemental U (QUS) & $0.50 \mu \mathrm{g}$ & $\begin{array}{l}11 \mu \mathrm{g}(\mathrm{BW}) \\
4 \mu \mathrm{g}(\mathrm{M})\end{array}$ \\
\hline Tritium & $20 \mathrm{dpm} / \mathrm{mL}$ & $80 \mathrm{dpm} / \mathrm{mL}^{(\mathrm{g})}$ \\
\hline
\end{tabular}

(a) Analysis of urine samples, unless otherwise indicated.

(b) Specified MDA based on Type I and Type II errors of 5\%, as described in the SOW (a copy is available in the Hanford Radiation Protection Historical Files).

(c) Amount per total sample volume, unless otherwise indicated.

(d) Investigation of a potential internal exposure is performed when this value is exceeded (routine bioassay monitoring frequency: A-annual, BEbiennial, BW-biweekly, M-monthly, Q-quarterly).

(e) The lab cannot discriminate between ${ }^{233} \mathrm{U}$ and ${ }^{234} \mathrm{U}$ and reports the results as ${ }^{234} \mathrm{U}$ (beginning in 1994).

(f) Upper level of expected environmentally derived uranium in urine for the Hanford region.

(g) Special screening levels are established for short-term tritium work where beginning and ending work samples are obtained instead of monthly routine sampling. 
Table 3.2. Minimum Detectable Activities and Screening Levels for Routine in Vivo Measurements During 1995

\begin{tabular}{|c|c|c|}
\hline Measurement/Radionuclide ${ }^{(\mathrm{a})}$ & $\begin{array}{c}\mathrm{MDA}^{(\mathrm{b})} \\
\mathrm{nCi}\end{array}$ & $\begin{array}{c}\text { Screening Level } \\
(\mathrm{c})\end{array}$ \\
\hline \hline Whole-Body Count $^{(\mathrm{d})}$ & & 4 \\
\hline${ }^{60} \mathrm{Co}$ & 4 & Any detected \\
\hline${ }^{154} \mathrm{Eu}$ & 8 & Any detected \\
\hline${ }^{137} \mathrm{Cs}$ & 4 & $\cdot$ \\
\hline Lung Count & & Any detected \\
\hline${ }^{235} \mathrm{U}$ & 0.2 & Any detected \\
\hline${ }^{238} \mathrm{U}$ (by $\left.{ }^{234} \mathrm{Th}\right)$ & 3 & Any detected \\
\hline${ }^{241} \mathrm{Am}$ & 0.3 & \\
\hline \hline
\end{tabular}

(a) For selected radionuclides. (The detection of radionuclides not listed resulted in follow-up.)

(b) For each in vivo count, the decision levels (approximately half of the MDAs) were reported under "detection limit" to REX, but, in terms of overall detectability for all measurement, these a MDAs were still applicable. Different detectors, number of detectors in an array, and count times were used for lung counting at various times during the year, each combination resulting in different MDAs. The lung counting MDAs shown are the highest of the combinations.

(c) Level for which an investigation of internal exposure was considered. Any detected activity above background (i.e., above the decision level) was reported to the IDP.

(d) MDAs apply to the preview counter only; lower MDAs were obtained using the germanium array which was used when activity was first detected using the preview counter. 
Table 3.3. Specified Minimum Detectable Activities for Emergency and Expedited Excreta Bioassay During 1995

\begin{tabular}{|c|c|c|}
\hline \multirow[b]{2}{*}{ Analysis ${ }^{(a)}$} & \multicolumn{2}{|c|}{ MDA (per sample) } \\
\hline & Urine & Feces \\
\hline \multicolumn{3}{|l|}{ Emergency Analyses ${ }^{(b)}$} \\
\hline Isotopic Plutonium by Alpha Spectrometry & $0.5 \mathrm{dpm}$ & $9 \mathrm{dpm}$ \\
\hline Isotopic Uranium by Alpha Spectrometry & $1.0 \mathrm{dpm}$ & $12 \mathrm{dpm}$ \\
\hline${ }^{241}$ Am by Alpha Spectrometry & $1.0 \mathrm{dpm}$ & $20 \mathrm{dpm}$ \\
\hline${ }^{241}$ Am by LEPD ${ }^{(c)}$ & $20 \mathrm{dpm}$ & $20 \mathrm{dpm}$ \\
\hline Total Radiostrontium & $80 \mathrm{dpm}$ & $450 \mathrm{dpm}$ \\
\hline Elemental Uranium & $7 \mu \mathrm{g}$ & $8 \mu \mathrm{g}$ \\
\hline Tritium & $100 \mathrm{dpm} / \mathrm{mL}$ & 一 \\
\hline \multicolumn{3}{|l|}{ Expedited Analyses $^{(d)}$} \\
\hline Isotopic Plutonium by Alpha Spectrometry & $0.08 \mathrm{dpm}$ & $3 \mathrm{dpm}$ \\
\hline Isotopic Uranium by Alpha Spectrometry & $0.12 \mathrm{dpm}$ & $4 \mathrm{dpm}$ \\
\hline${ }^{241}$ Am by Alpha Spectrometry & $0.08 \mathrm{dpm}$ & $6 \mathrm{dpm}$ \\
\hline${ }^{241}$ Am by LEPD & $5 \mathrm{dpm}$ & $5 \mathrm{dpm}$ \\
\hline Total Radiostrontium & $50 \mathrm{dpm}$ & $150 \mathrm{dpm}$ \\
\hline Elemental Uranium & $0.5 \mu \mathrm{g}$ & $5 \mu \mathrm{g}$ \\
\hline Tritium & $100 \mathrm{dpm} / \mathrm{mL}$ & 一 \\
\hline \multicolumn{3}{|c|}{$\begin{array}{l}\text { (a) For the more critical analyses only. The list does not contain all the } \\
\text { analyses covered in the contract. } \\
\text { (b) Verbal reporting time was generally within } 8 \text { hours after receipt of the } \\
\text { sample; reporting times were even shorter for some analyses. } \\
\text { (c) Low Energy Photon Detector; direct counting of x-rays without } \\
\text { radiochemical separation. } \\
\text { (d) Verbal reporting time was by } 9: 00 \text { a.m. on the second business day after } \\
\text { receipt of the sample. }\end{array}$} \\
\hline
\end{tabular}


The excreta values in Tables 3.1 and 3.3 remained unchanged since 1992. New routine excreta analyses ( ${ }^{225} \mathrm{Ac}$ and ${ }^{227} \mathrm{Th}$ ) were added to the list to accommodate the PNNL medical radionuclides work. Also, ${ }^{229} \mathrm{Th}$ was proposed for addition to the list of reported radionucides under the isotopic thorium, alpha spectroscopy method because of the PNNL medical radionucides project (see Section 3.1.7); however, at the end of the year, the contract laboratory had not completed testing of changes to their procedure.

Both MDAs and screening levels for several radionuclides detected in vivo were changed from previous years. These changes were implemented via revisions to the Whole Body Counting Manual (May) and the Hanford Internal Dosimetry Project Manual (June). In general the MDAs were reduced due to detector improvements. Screening levels were reduced because the screening level criterion was changed from 10 mrem annual effective dose equivalent to $10 \mathrm{mrem}$ committed effective dose equivalent (CEDE) and because of new knowledge about actinides contained in mixtures of ${ }^{137} \mathrm{Cs}$ and ${ }^{90} \mathrm{Sr}$.

IDP also worked with PNNL's Atomic and Molecular Chemistry group to develop and implement a new urinalysis capability for ${ }^{236} \mathrm{U}$. This analysis uses inductively coupled plasma mass spectrometry to measure extremely small mass of ${ }^{236} \mathrm{U}$. Because ${ }^{236} \mathrm{U}$ is present in trace amounts in Hanford uranium associated with the weapons fuel cycle, the presence or absence of ${ }^{236} U$ can indicate whether an intake of uranium is from Hanford work or from natural sources. This analysis will be used as a follow-up measurement on the residual of a routine urine sample that contains uranium above the environmental screening level.

\subsubsection{Excreta Bioassay Contract Activities}

The Analytical Support Services Program (ASSP) was disbanded on March 1, 1995. Contract management functions for the bioassay analytical contract with IT Corporation (IT) were transferred from ASSP to the IDP. Prior to this transfer, IDP'successfully lobbied to reverse a decision to transfer management of the contract to WHC. A separate prior contract with IT for limited analyses was closed after records related to the contract were transferred to PNNL.

In August 1995, the HPDAC ad hoc committee on bioassay kit delivery options ${ }^{(a)}$ decided to continue the present system of home delivery, but the contract technical administrator was requested to investigate possible hidden costs associated with home delivery. He found that no more than 10 hours per week are spent on delivery problems by Hanford staff, and elimination of home kit delivery would probably increase, not decrease, the work in this area. Furthermore, the contractor bioassay cost model identified $\$ 43,000$ in expenses directly related to home delivery. This is the maximum that eliminating this function from the contract could save, but in reality some kit tracking functions would be transferred to Hanford personnel. The HPDAC decided to continue home delivery for at least another year.

(a) Bihl, D.E. "Minutes of the Hanford Personnel Dosimetry Advisory Committee Meeting on August 16, 1995." (A copy is available in the Hanford Radiation Protection Historical Files.) 
In December 1995 the IDP was notified that DOE-RL Waste Programs Division was coordinating an effort to establish a sitewide sample management office for Hanford. This effort was in response to a letter from Thomas Grumbly, Assistant Secretary for Environmental Management (EM), setting policy on EM sample management. The policy specifically specified EM programs and environmental samples, but all analytical work for Hanford was being reviewed. One aspect of the preliminary plan, inclusion of bioassay analytical radiochemistry in a broad scope analytical contract for all Hanford work, could potentially remove control of the performance specifications of the contract from the IDP. At year end, IDP was just beginning to consider the ramifications of this development and to talk to contractor dosimetry groups about a common position.

An Inspection of Services was performed in June 1995 to review contract compliance as it related to 1) implementation of analytical procedures and review of data packages generated for isotopic plutonium and uranium analyses by alpha spectrometry; 2) implementation of bioassay kit scheduling, preparation, and delivery; 3) compliance to quality assurance (QA) requirements of the contract; and 4) review of data packages for completeness. The inspection resulted in two findings and two observations primarily pertaining to procedures. In January of 1996, all findings and observations were closed.

\subsubsection{Excreta Quality Control Oversight Program}

The Excreta Quality Control (QC) Oversight Report for the period July 1, 1994, through June 30, 1995, was issued in November. Analyses for tritium, ${ }^{90} \mathrm{Sr},{ }^{238} \mathrm{Pu},{ }^{239} \mathrm{Pu},{ }^{241} \mathrm{Am},{ }^{234} \mathrm{U},{ }^{235} \mathrm{U},{ }^{238} \mathrm{U},{ }^{228} \mathrm{Th},{ }^{232} \mathrm{Th}$, and elemental uranium were tested. The QC samples submitted by IDP during the report period represented about $4 \%$ of the total samples submitted. This is about the same as during the 1994 report period.

All urine analyses met or exceeded statistical specifications in the SOW. However, the strontium procedure results contained an unsatisfactory number of statistical outliers, and the isotopic plutonium and isotopic americium procedures contained too many false negatives (results for samples spiked at the contractual detection level that were reported as less than one-half the contractual detection level). Performance statistics for isotopic thorium and elemental uranium fecal analyses were unacceptable. Because of budget limitations, follow-up by the IDP for the fecal procedures was not available so IT quality control results will have to suffice as performance indicators.

An enhancement to REX was completed for the QC tracking program. A new table, containing records of spiked samples, freed the internal dosimetry technician from the time-consuming task of manually entering QC results into a separate database. The new program has the added feature of selectable dates for the output file. The old PARADOX program produced a file of all available results for a given nuclide. That file then had to be manually edited to get data for the period of interest. 


\subsubsection{Policy and Documentation Changes}

Until April 1995, small-scope changes to the practices or technical aspects of the IDP were documented by Project Change Records. The Project Change Record identified the change, its effective date, and the reasons for and impacts of the change. A copy of the record was placed in the Hanford Radiological Protection Historical Files. Project Change Records issued by the IDP in 1995 are shown in Table 3.4. A.batch of Project Change Records were issued in April to implement changes that resulted from a review of the project for compliance with 10 CFR Part 835 . These changes were later incorporated into the Hanford Internal Dosimetry Project Manual, ${ }^{(a)}$ and the Hanford Internal Dosimetry Procedures Manual. (b) The process of issuing Project Change Records was discontinued after this batch, consistent with implementation of new methods for changing manuals introduced by the project QA plan.

Considerable accomplishments in writing and revising project documentation occurred in 1995 . The Quality Assurance Plan for the Operation of the Hanford Internal Dosimetry Project ${ }^{(\mathrm{c})}$ was completed on March 31, 1995. Revision 2 of the Hanford Internal Dosimetry Project Manual was completed in June 1995, incorporating several years of Project Change Records and other changes resulting from the QA plan. A two-year effort to completely reformat and rewrite every procedure in the Hanford Internal Dosimetry Procedures Manual was completed in July 1995. Procedure writing, reviewing, and approving and training of staff were conducted according to protocols in the new QA plan. The On-Call Exposure Evaluator Manual ${ }^{(\mathrm{d})}$ was completed in November 1995. The latter action consisted of converting a notebook that had been maintained for years into a controlled document. So as to not lose the rapid access to the pertinent information necessary to assist responders during incidents, the manual was formatted in a somewhat innovative style.

\subsubsection{Adoption of CINDY Code (Version 1.4)}

Version 1.4 of the CINDY Computer Code (Strenge et al. 1990a, 1990b) for internal dose calculations was accepted in September 1995 for routine use by the IDP following acceptance testing and verification. The testing plan and its documentation are maintained in the project record files.

\subsubsection{Annual Whole Body Counting Protocol for Mixed Fission Product and Spent Fuel Mixtures}

The HPDAC established a policy of continuing annual whole body counting exams as the primary bioassay protocol for mixed fission product and spent fuel mixtures, even though this frequency may not meet the 100-mrem bioassay program design goal specified in the DOE Implementation Guide for

(a) Internal Manual, PNL-MA-552, Rev. 1, Pacific Northwest National Laboratory, Richland, Washington.

(b) Internal Manual, PNL-MA-565, Rev. 0, Pacific Northwest National Laboratory, Richland, Washington.

(c) Internal Manual, No. LSC-026, Rev. 0, Pacific Northwest National Laboratory, Richland, Washington.

(d) Internal Manual, PNL-MA-857, Pacific Northwest National Laboratory, Richland, Washington. 
Table 3.4. Project Change Records for 1995

\begin{tabular}{||l|l|l|l||}
\hline \hline PCR No. & $\begin{array}{c}\text { Effective } \\
\text { Date }\end{array}$ & \multicolumn{1}{|c|}{ Title } & \multicolumn{1}{|c|}{ Affected Areas of Project } \\
\hline \hline $95-001$ & $04-12-95$ & Estimating and Reporting Intake & $\begin{array}{l}\text { Added requirement to calculate intake and } \\
\text { provided technical bases for doing so for } \\
\text { different radionuclides. Removed require- } \\
\text { ment for annual doses in INTERTRAC. }\end{array}$ \\
\hline $95-002$ & $04-12-95$ & Organ Dose Recording Level & $\begin{array}{l}\text { Replaced annual dose equivalent with } \\
\text { CEDE. }\end{array}$ \\
\hline $95-003$ & $04-12-95$ & $\begin{array}{l}\text { When Bioassay Data are Inade- } \\
\text { quate for Dose Assessment }\end{array}$ & $\begin{array}{l}\text { Clarified under what conditions air sample } \\
\text { data would be used for dose assessment } \\
\text { instead of bioassay data. }\end{array}$ \\
\hline $95-004$ & $04-12-95$ & CEDE-Based Screening Levels & $\begin{array}{l}\text { Changed the criterion for screening levels to } \\
\text { 10-mrem CEDE. }\end{array}$ \\
\hline $95-005$ & $04-12-95$ & $\begin{array}{l}\text { Audits of the Internal Dosimetry } \\
\text { Project }\end{array}$ & $\begin{array}{l}\text { Clarified what types of audits are intended to } \\
\text { fulfill the requirements of 10 CFR 835.102. }\end{array}$ \\
\hline $95-006$ & $04-12-95$ & $\begin{array}{l}\text { Bioassay Associated with } \\
\text { Declared Pregnancy }\end{array}$ & $\begin{array}{l}\text { Provided guidance on bioassay programs } \\
\text { needed for demonstrating compliance with } \\
\text { limits for declared pregnant workers. }\end{array}$ \\
\hline $95-009$ & $04-12-95$ & $\begin{array}{l}\text { Bioassay Limitations for Minors } \\
\text { and Visitors }\end{array}$ & $\begin{array}{l}\text { Recommended that radiation work permits } \\
\text { prohibit minors and visitors from being } \\
\text { exposed to plutonium, thorium, and } \\
\text { insoluble uranium in a manner that could } \\
\text { result in an intake. }\end{array}$ \\
\hline $95-007$ & $04-12-95$ & $\begin{array}{l}\text { Interpretation of "Confirmed } \\
\text { Intake" }\end{array}$ & $\begin{array}{l}\text { Madight revisions to the criteria for a } \\
\text { confirmed intake. }\end{array}$ \\
\hline $95-008$ & $04-12-95$ & Uncertainties in Evaluations & $\begin{array}{l}\text { Provided statement concerning factors in } \\
\text { ofse assessment that can result in a change } \\
\text { of 50\% or more to the dose calculation. }\end{array}$ \\
\hline
\end{tabular}


Internal Dosimetry Programs (DOE 1994a). Based on new data characterizing radionuclide compositions of contamination at many places on the Hanford Site, Internal Dosimetry staff had presented to the HPDAC minimum detectable dose values for various bioassay types and frequencies for the mixtures. $A$ wide range of radionuclide mixtures which might be encountered in current waste management activities had come to light, and in many cases semi-annual or quarterly measurements were needed to meet the 100 mrem criterion. ${ }^{(a)}$

The DOE Implementation Guide allows consideration of cost effectiveness and worker convenience as factors to be considered in establishing bioassay frequency, as well as the desired goal of 100 -mrem CEDE. The use of special bioassay monitoring initiated in response to workplace indicators was deemed a preferred way to detect and document intakes. Criteria used by all the contractors to inititiate special bioassay were judged to be extremely sensitive and reactive; consequently, worker protection was not compromised by leaving periodic monitoring at an annual frequency. A minimum detectable dose of $100-$ mrem CEDE was still considered a design goal, but was not considered mandatory.

\subsubsection{Special Bioassay Requirements Evaluations}

Bioassay programs were developed for three work activities in the 325 Building. Infrequent work associated with characterizing small quantities of depleted uranium powder in a fume hood was identified as adequately covered by an initial baseline uranium urinalysis bioassay followed by end-of-assignment urinalyses. Annual whole body counting was deemed to be adequate routine bioassay for $\mathrm{X}$-ray crystallography sample preparation of spent fuel or tank waste consisting predominantly of ${ }^{137} \mathrm{Cs}$ and ${ }^{90} \mathrm{Sr}$ with very slight ${ }^{239} \mathrm{Pu}$ content ( $<1 \%$ of total activity). General guidance for bioassay program design for work with spent fuel mixtures was provided to PNNL Radiological Control to address a broad range of possibilities. The guidance included annual whole body counting for unprocessed spent fuel, with the possibility of biennial ${ }^{90} \mathrm{Sr}$ and annual plutonium urinalysis and chest counting for processed spent fuel. Uranium urinalysis was considered warranted only if uranium was sufficiently separated to be considered a single source.

Work-specific bioassay monitoring programs were also designed for the PNNL medical radionuclides work involving separation of ${ }^{227} \mathrm{Th}$ and ${ }^{223} \mathrm{Ra}$ from ${ }^{227} \mathrm{Ac}$ in one phase of the work and separation of ${ }^{225} \mathrm{Ra}$ and ${ }^{225} \mathrm{Ac}$ from ${ }^{229} \mathrm{Th}$ in the other phase. In all cases ending-work excreta bioassay were considered necessary but were not very sensitive (in terms of minimum detectable dose). However, because these were small-scale pilot tests, air sampling was established as the primary means to detect intakes and to calculate internal dose. If the projects grow, development of more sensitive and rapid bioassay methods will be needed.

(a) J.J. Fix. "Minutes of the Hanford Personnel Dosimetry Advisory Committee Meeting Held on July 19, 1995." (A copy is available in the Hanford Radiation Records Historical Files.) 


\subsubsection{Project Efficiency Improvements and Cost Reduction Activities}

Several activities were conducted in 1995 to improve the efficiency and reduce costs of the bioassay monitoring program at Hanford overall and, specifically, the IDP. Beginning in February, a series of facilitated meetings were held with contractor representatives, the Whole Body Counting Project manager, and the IDP manager to explore ways to improve the overall processes of the bioassay monitoring program at Hanford. Recommendations of the meetings focused on improving criteria for putting workers on bioassay programs and for eliminating unnecessary requests for bioassay. Follow-up efforts by the contractors resulted in a major decline in the requests for excreta bioassay and some decline in the number of in vivo measurements over the remainder of the year.

In July 1995, the IDP was included in an ACE breakthrough analysis of dosimetry services. The ACE Breakthrough Team conducted an intense, 6-week analysis of the IDP, Whole Body Counting Project, External Dosimetry Project, and Radiological Records Project, searching for ways to significantly reduce work and cost in the projects for implementation in FYs 1996 and 1997. The team goal was to reduce costs by $40 \%$ relative to the FY 1994 actual expenditures. All of the projects met or nearly met the goal. IDP was able to reduce costs because of the significant decrease in excreta bioassay requests, some specific efficiency improvements, and by reducing the scope of the excreta bioassay QC oversight program. The latter meant fewer samples, a return to single-blind samples, and elimination of laboratory intercomparison samples.

\subsection{Monitoring and Assessment Activities.}

The IDP excreta bioassay monitoring and internal dose assessment activities during 1995 are summarized in this section. The Whole Body Counting Project and its associated statistics are discussed in Chapter 4.0.

\subsubsection{Excreta Bioassay Monitoring Activities}

Sample requests can be categorized as standard or nonstandard. Standard requests are those generated by REX from a predetermined, routine schedule (e.g., a worker may be scheduled for an annual sample collected every April). These requests are downloaded from REX and electronically transferred to the analysis laboratory just before the start of each month. All other requests are considered nonstandard requests. Contractors and IDP staff enter the nonstandard requests into REX manually. IDP staff check the nonstandard request file in REX for input errors and perform the electronic transfer of the requests to the laboratory. Figure 3.1 shows the monthly distribution of standard and nonstandard requests for 1995. A total of 4474 samples were requested in 1995, down 50\% from the 1994 requests. This major decrease reflects the activities of the contractors, after the February 1995 process improvement meetings, to eliminate unnecessary requests. As usual, the majority of the samples (68\%) were standard requests, compared to $62 \%$ in 1994 and $57 \%$ in 1993. 


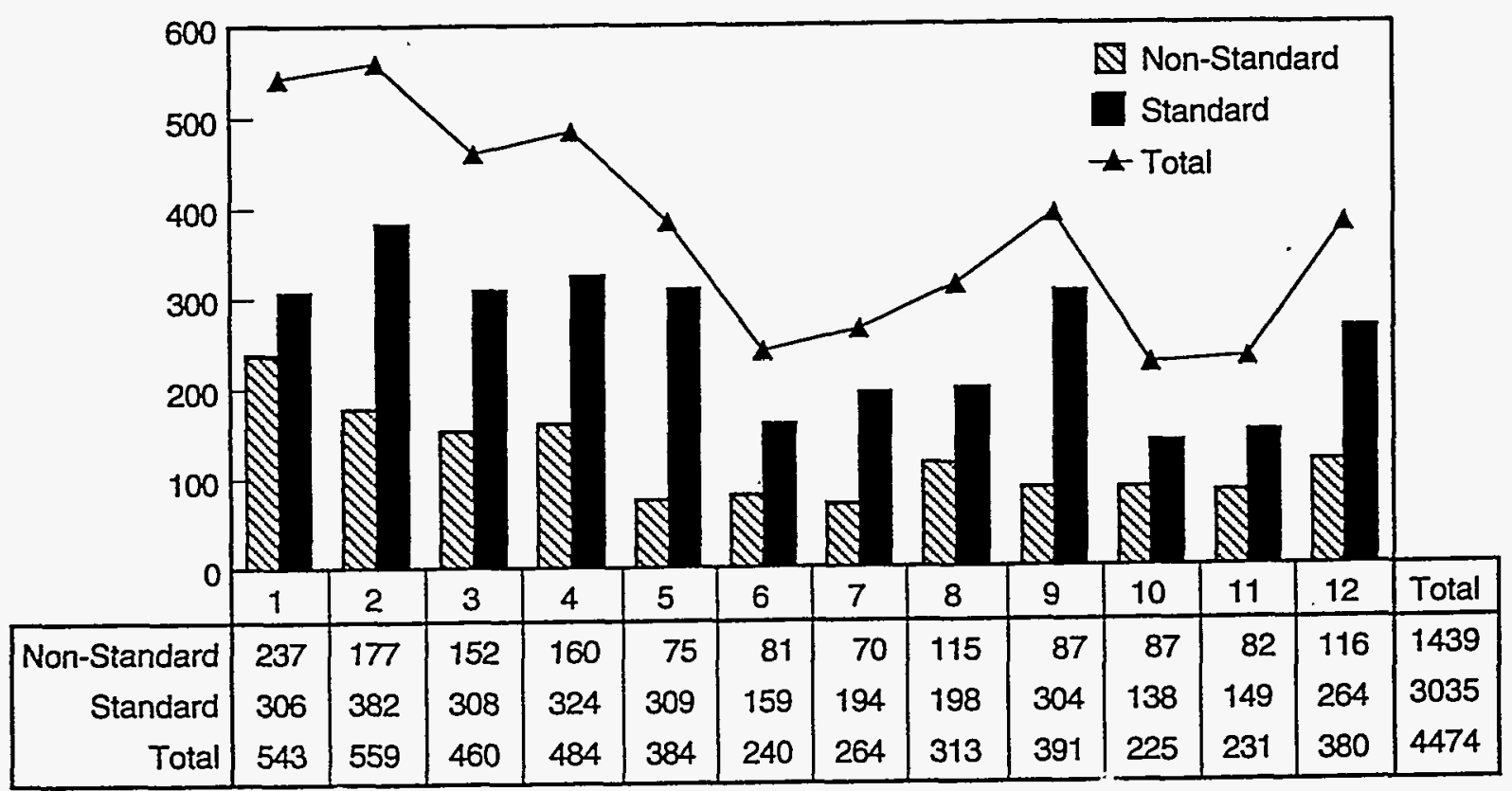

1995

Figure 3.1. Standard and Nonstandard Excreta Requests by Month

During FY 1995, 4483 excreta bioassay measurements were successfully performed in support of Hanford activities, excluding cancellations, no-samples, samples without valid results, and QC samples. Of these, $97 \%$ were classified as routine (including measurements on visitors) and $3 \%$ were due to special circumstances, such as response to unplanned potential intakes or follow-up analyses to high routine measurements. Interestingly, for the first time since these statistics have been obtained, the number of excreta measurements exceeded the number of requests. This is unusual because the number of requests includes the various no-sample categories. But the measurements obtained in 1995 include results from samples requested in November and December of 1994 , which were months with a large number of requests relative to November and December 1995. So the time lag between requests and results received and the downward trend in requests throughout 1995 accounted for the unusual statistic.

Figure 3.2 provides the trend in routine urinalyses since 1989. The figure shows that the number of routine measurements in 1995 was similar to numbers in 1989 and 1990 . There were far fewer strontium analyses in 1995 compared to 1989 or 1990, however. This was due to a directed effort by the contractors to rely on ${ }^{137} \mathrm{Cs}$ in whole body counts as an indicator of intake of fission product mixtures. 


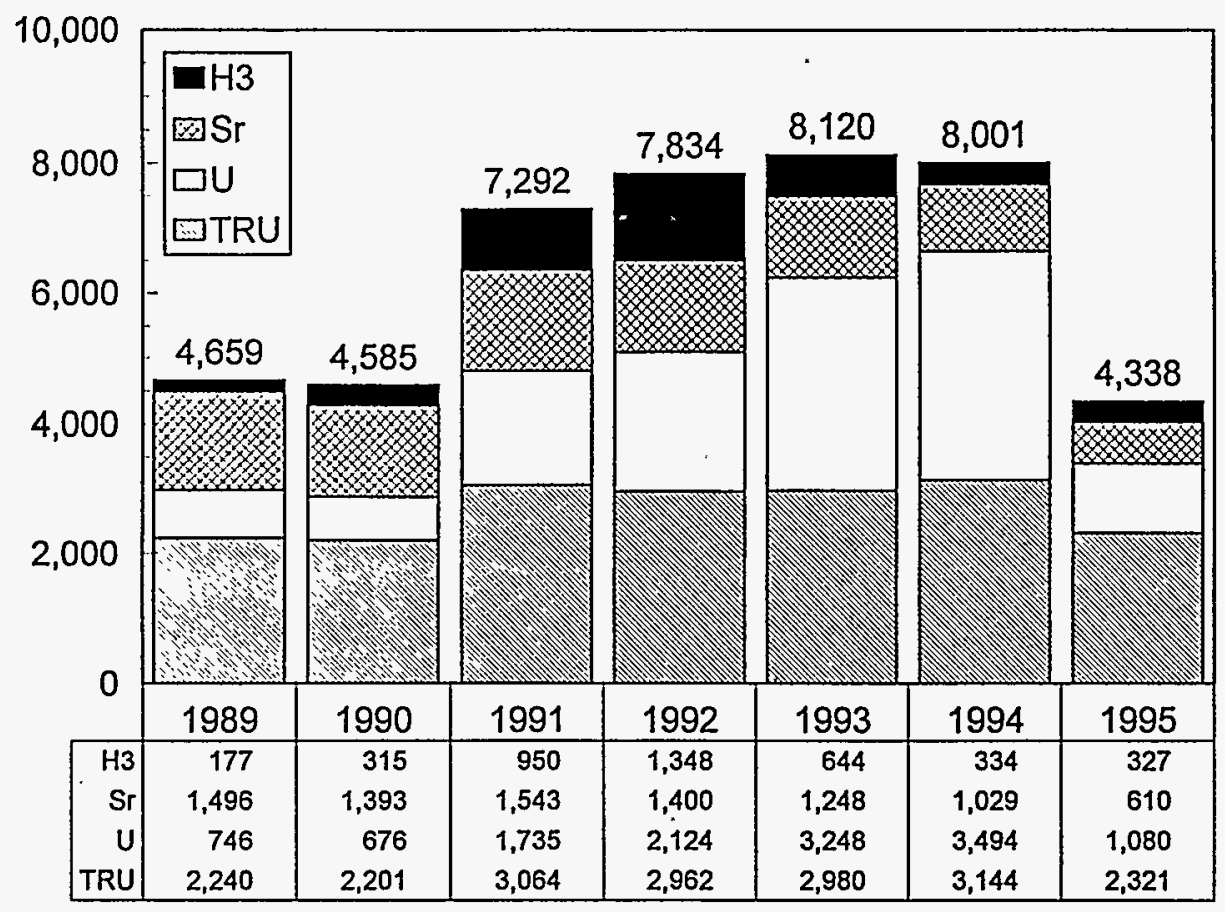

Figure 3.2. Routine Urine Measurements Made from 1989 Through 1995

Details on the type of excreta measurements categorized by contractor are provided in Table 3.5. Overall the number of excreta measurements decreased by $46 \%$ from 1994 . Uranium analyses showed the largest change, decreasing by $70 \%$ relative to 1994 analyses. This reflects the closing of most uranium-contaminated facilities in 1994.

Not all excreta bioassay requests produce valid measurement results; these are referred to as nosamples. When this happens the sample has to be requested again. In 1995, 860 excreta sample requests were designated as no-samples, down from 1269 no-samples in 1994. In terms of percentage of total requests, the 1995 rate (19\%) was greater than the 1994 rate (14\%) and less than the 1993 rate (23\%). Turnover in scheduling staff may have contributed to the slight increase. Unsuccessful sample collections (their associated no-sample code and percentage of the total no-samples) were attributed to the following causes: kit not delivered (ND, 1\%), no sample received (NS, 19\%), lost container (LC, $52 \%$ ), insufficient sample volume (IS, 19\%), and lost in lab (LL, 9\%).

\subsubsection{Potential Intake Evaluations}

Investigations of possible radionuclide intakes are performed following an indication from a routinely scheduled bioassay measurement (high routine) or for a potential exposure incident identified in the workplace (incident). Potential exposure incidents are identified by workplace indicators such as air sampling, contamination surveys, nasal smears, or smears from potentially contaminated wounds. Evaluations are also performed for newly hired workers that incurred intakes prior to their Hanford 
Table 3.5. Worker Excreta Measurements Reported in 1995

\begin{tabular}{|c|c|c|c|c|c|c|c|}
\hline Type/Reason & OEE & ICFKH & PNL & WHC & ERC & Other & Total \\
\hline $\begin{array}{l}{ }^{3} \mathrm{H} \text {-urine } \\
\quad \text { Routine Schedule(a) } \\
\text { Special Request }{ }^{(\mathrm{b})}\end{array}$ & $\begin{array}{l}0 \\
0\end{array}$ & $\begin{array}{l}7 \\
0\end{array}$ & $\begin{array}{r}284 \\
0\end{array}$ & $\begin{array}{r}32 \\
1\end{array}$ & $\begin{array}{l}4 \\
0\end{array}$ & $\begin{array}{l}9 \\
0\end{array}$ & $\begin{array}{r}336 \\
1\end{array}$ \\
\hline $\begin{array}{l}{ }^{90} \mathrm{Sr} \text {-urine } \\
\text { Routine Schedule } \\
\text { Special Request }\end{array}$ & $\begin{array}{l}7 \\
0\end{array}$ & $\begin{array}{r}155 \\
4\end{array}$ & $\begin{array}{r}169 \\
-0\end{array}$ & $\begin{array}{r}256 \\
1\end{array}$ & $\begin{array}{r}23 \\
0\end{array}$ & $\begin{array}{l}0 \\
0\end{array}$ & $\begin{array}{r}610 \\
5\end{array}$ \\
\hline $\begin{array}{c}\text { Uranium-urine } \\
\text { Routine Schedule } \\
\text { Special Schedule }\end{array}$ & $\begin{array}{r}19 \\
0\end{array}$ & $\begin{array}{r}551 \\
1\end{array}$ & $\begin{array}{r}178 \\
5\end{array}$ & $\begin{array}{r}291 \\
5\end{array}$ & $\begin{array}{r}41 \\
0\end{array}$ & $\begin{array}{l}0 \\
0\end{array}$ & $\begin{array}{c}1080 \\
11\end{array}$ \\
\hline $\begin{array}{l}\text { Plutonium-urine } \\
\text { Routine Schedule } \\
\text { Special Schedule }\end{array}$ & $\begin{array}{r}28 \\
2\end{array}$ & $\begin{array}{r}465 \\
17\end{array}$ & $\begin{array}{r}292 \\
3\end{array}$ & $\begin{array}{r}1378 \\
34\end{array}$ & $\begin{array}{r}28 \\
0\end{array}$ & $\begin{array}{l}6 \\
0\end{array}$ & $\begin{array}{c}2197 \\
56\end{array}$ \\
\hline $\begin{array}{l}\text { Other TRU-urine } \\
\text { Routine Schedule } \\
\text { Special Schedule }\end{array}$ & $\begin{array}{l}0 \\
0\end{array}$ & $\begin{array}{r}38 \\
8\end{array}$ & $\begin{array}{l}49 \\
18\end{array}$ & $\begin{array}{r}28 \\
5\end{array}$ & $\begin{array}{l}0 \\
0\end{array}$ & $\begin{array}{l}0 \\
0\end{array}$ & $\begin{array}{r}115 \\
31\end{array}$ \\
\hline $\begin{array}{l}\text { TRU-fecal } \\
\text { Routine Schedule } \\
\text { Special Schedule }\end{array}$ & $\begin{array}{l}0 \\
0\end{array}$ & $\begin{array}{l}0 \\
3\end{array}$ & $\begin{array}{l}0 \\
9\end{array}$ & $\begin{array}{r}0 \\
29\end{array}$ & $\begin{array}{l}0 \\
0\end{array}$ & $\begin{array}{l}0 \\
0\end{array}$ & $\begin{array}{r}0 \\
41\end{array}$ \\
\hline Analyses Totals & 56 & 1249 & 1007 & 2060 & 96 & $1 \tilde{5}$ & 4483 \\
\hline $\begin{array}{l}\text { Recounts or Reanalyses } \\
\text { Plutonium-urine } \\
{ }^{90} \mathrm{Sr} \text {-urine } \\
{ }^{3} \mathrm{H} \text {-urine } \\
\text { Uranium-urine }\end{array}$ & $\begin{array}{l}0 \\
0 \\
0 \\
0\end{array}$ & $\begin{array}{r}12 \\
0 \\
0 \\
0\end{array}$ & $\begin{array}{l}0 \\
0 \\
0 \\
4\end{array}$ & $\begin{array}{r}10 \\
0 \\
0 \\
0\end{array}$ & $\begin{array}{l}0 \\
0 \\
0 \\
0\end{array}$ & $\begin{array}{l}0 \\
0 \\
0 \\
0\end{array}$ & $\begin{array}{r}22 \\
0 \\
0 \\
4\end{array}$ \\
\hline
\end{tabular}

(a) Routine measurements include those with reason codes of routine (PR), baseline (BL), contractor request (CR), ending work (EA), and termination (TM).

(b) Special measurements are those with reason code of special (SP), recount (R1 or $\mathrm{R} 2$ ), and reanalysis (RA and $\mathrm{RB}$ ). 
employment to assure that the intake information is converted to dose in a manner consistent with DOE regulations (pre-Hanford). Reevaluations of internal dose are also conducted periodically for workers with significant long-term body burdens (reevaluations).

During FY 1995, 23 incidents with the potential for intake, involving 51 workers, were identified through workplace monitoring. Of the 51 workers involved in the incidents, intakes were confirmed for only 11 workers, one dose assessment was performed based on air sample data without bioassay confirmation, and one case was still open. The highest calculated dose among the 11 workers was 210 mrem CEDE. The radionuclides and groups involved included ${ }^{137} \mathrm{Cs}$ and/or ${ }^{90} \mathrm{Sr}$ (13 incidents with 26 workers), TRU ( 6 incidents with 23 workers), $U$ ( 1 incident with 1 worker), and mixed activation products - principally ${ }^{60} \mathrm{Co}$ - ( 1 incident with 1 worker). Table 3.6 shows the incident breakdown by contractor, area, and facility.

Table 3.6. Summary of Potential Intake Incidents During 1995

\begin{tabular}{|c|c|c|c|c|c|c|}
\hline \multicolumn{2}{|r|}{ Facility } & \multirow[b]{2}{*}{ Custodian } & \multirow{2}{*}{$\begin{array}{l}\text { Number of } \\
\text { Incidents }\end{array}$} & \multirow{2}{*}{$\begin{array}{c}\text { Number of } \\
\text { Workers }\end{array}$} & \multirow{2}{*}{$\begin{array}{c}\text { Worker } \\
\text { Contractor }\end{array}$} & \multirow{2}{*}{$\begin{array}{l}\text { Principal } \\
\text { Nuclide }\end{array}$} \\
\hline Area & ID & & & & & \\
\hline $100 \mathrm{~K}$ & $100 \mathrm{KE}$ & WHC & 2 & 3 & $\begin{array}{l}\text { WHC, } \\
\text { ICFKH }\end{array}$ & ${ }^{137} \mathrm{Cs}$ \\
\hline $100 \mathrm{~N}$ & $105 \mathrm{~N}$ & $E R C^{(a)}$ & 1 & 1 & ERC & ${ }^{60} \mathrm{Co}$ \\
\hline 100 & $116 \mathrm{BC}$ crib & ERC & 1 & 1 & ERC & Pu mix \\
\hline \multirow[t]{3}{*}{$200 \mathrm{E}$} & $202-A$ & WHC & 2 & 2 & WHC & ${ }^{137} \mathrm{Cs}, \mathrm{U}$ \\
\hline & $241-A Z$ & WHC & 1 & 1 & ICFKH & ${ }^{137} \mathrm{Cs}$ \\
\hline & $241-C$ & WHC & 1 & 1 & ICFKH & ${ }^{137} \mathrm{Cs}$ \\
\hline \multirow[t]{9}{*}{$200 \mathrm{~W}$} & 202-S & ERC & 1 & 1 & ERC & ${ }^{137} \mathrm{Cs}$ \\
\hline & 222-S & WHC & 1 & 8 & WHC & ${ }^{137} \mathrm{Cs}$ \\
\hline & $233-S$ & ERC & 1 & 1 & ERC & Pu mix \\
\hline & SX108 & WHC & 1 & 2 & WHC & ${ }^{137} \mathrm{Cs}$ \\
\hline & $241-S$ & WHC & 1 & 2 & WHC & ${ }^{90} \mathrm{Sr}$ \\
\hline & $242-\mathrm{T}$ & WHC & 1 & 2 & WHC & ${ }^{137} \mathrm{Cs}$ \\
\hline & $232-Z$ & WHC & 1 & 7 & WHC & Pu mix \\
\hline & $2736 Z$ & WHC & 2 & 7 & WHC & Pu mix \\
\hline & Burial Trench 14 & WHC & 1 & 2 & WHC & ${ }^{137} \mathrm{Cs}$ \\
\hline \multirow[t]{4}{*}{300} & 331 & PNNL & 1 & 3 & PNNL & Pu mix, TRU \\
\hline & 324 & PNNL & 3 & 3 & PNNL & ${ }^{137} \mathrm{Cs}$ \\
\hline & 325 & PNNL & 1 & 4 & $\begin{array}{l}\text { PNNL, } \\
\text { ICFKH }\end{array}$ & Pu mix \\
\hline & & Total & 23 & 51 & & \\
\hline
\end{tabular}


In addition to incidents, potential intakes can be discovered through the routine bioassay program, although in recent years very few actual (i.e., confirmed) intakes were discovered this way. In 1995, there were 59 evaluations started because of routine bioassay results that exceeded the criteria for investigation. However, an intake was assigned for only one worker. This was a uranium intake which might have occurred at 202A sometime between November 1994 and February 1995. Because the dose was low and because soluble uranium leaves the body quickly, the employer chose not to obtain special bioassay. Hence, the possible intake was neither confirmed nor ruled out. The estimated internal dose from this intake was much less than 100 mrem CEDE. Table 3.7 shows internal dose evaluations for 1995 resulting from high routine bioassay results. Table 3.8 provides the trends in all types of potential intake evaluations since 1990.

There were no workers who had been identified as having potential chronic exposures to uranium or tritium in 1995.

Continuing from 1994, significant progress was made at working through a long list of overdue reevaluations.

The range of internal doses assigned to the Hanford work force in 1995 is summarized in Table 3.9.

\subsection{Supporting Studies}

Completion of a special study conducted by the IDP is described in the following subsection.

Table 3.7. Summary of Confirmed Intake Cases Identified Through the Routine Bioassay Program During 1995

\begin{tabular}{|c|c|c|c|c|c|c|}
\hline \multicolumn{2}{|c|}{ Facility } & \multirow[b]{2}{*}{ Custodian } & \multirow{2}{*}{$\begin{array}{c}\text { Number of } \\
\text { Workers }\end{array}$} & \multirow[b]{2}{*}{ Contractor } & \multirow{2}{*}{$\begin{array}{c}\text { Principal } \\
\text { Nuclide }\end{array}$} & \multirow[b]{2}{*}{ Reason } \\
\hline Area & Building & & & & & \\
\hline $200 \mathrm{E}$ & $202 \mathrm{~A}$ & WHC & 1 & WHC & $\mathrm{U}$ & High Routine \\
\hline \multicolumn{7}{|c|}{ (Assigned but not confirmed.) } \\
\hline & & Total & 1 & & & \\
\hline
\end{tabular}


Table 3.8. Comparison of Potential Intakes By Reason Code, 1990-1995

\begin{tabular}{|c|c|c|c|c|c|c|}
\hline & 1990 & 1991 & 1992 & 1993 & 1994 & 1995 \\
\hline $\begin{array}{l}\text { Incident, Total } \\
\text { Confirmed } \\
\text { Unconfirmed } \\
\text { Open }\end{array}$ & 30 & 90 & 30 & $\begin{array}{l}51 \\
17 \\
34\end{array}$ & $\begin{array}{r}33 \\
7 \\
26\end{array}$ & $\begin{array}{r}51 \\
12 \\
38 \\
1\end{array}$ \\
\hline $\begin{array}{l}\text { High Routine, Total } \\
\text { Confirmed } \\
\text { Unconfirmed } \\
\text { Open }\end{array}$ & 93 & 69 & 141 & $\begin{array}{r}65 \\
0 \\
62 \\
3\end{array}$ & $\begin{array}{r}91 \\
14 \\
72 \\
5\end{array}$ & $\begin{array}{r}59 \\
1 \\
58\end{array}$ \\
\hline $\begin{array}{l}\text { Contractor Request, Total } \\
\text { Confirmed } \\
\text { Unconfirmed }\end{array}$ & 5 & 0 & 0 & $\begin{array}{l}1 \\
1 \\
0\end{array}$ & $\begin{array}{l}3 \\
0 \\
3\end{array}$ & 0 \\
\hline $\begin{array}{l}\text { Chronic Exposure, Total } \\
\text { Confirmed } \\
\text { Unconfirmed }\end{array}$ & 95 & 30 & 4 & $\begin{array}{l}6 \\
0 \\
6\end{array}$ & $\begin{array}{l}0 \\
0 \\
0\end{array}$ & $\begin{array}{l}0 \\
0 \\
0\end{array}$ \\
\hline $\begin{array}{l}\text { Pre-Hanford, Total } \\
\text { Confirmed } \\
\text { Unconfirmed } \\
\text { Open }\end{array}$ & & & 20 & $\begin{array}{l}3 \\
3 \\
0\end{array}$ & $\begin{array}{r}35 \\
30 \\
4 \\
1\end{array}$ & $\begin{array}{l}9 \\
9\end{array}$ \\
\hline $\begin{array}{l}\text { Totals } \\
\text { Confirmed } \\
\text { Unconfirmed } \\
\text { Open }\end{array}$ & 223 & 189 & 195 & $\begin{array}{r}126 \\
21 \\
102 \\
3\end{array}$ & $\begin{array}{r}162 \\
51 \\
105 \\
6\end{array}$ & $\begin{array}{r}119 \\
22 \\
96 \\
1\end{array}$ \\
\hline $\begin{array}{l}\text { Revaluation, Total Initiated } \\
\text { Completed } \\
\text { Open }\end{array}$ & 5 & 1 & 4 & $\begin{array}{l}3 \\
0 \\
3\end{array}$ & $\begin{array}{r}12 \\
8 \\
4\end{array}$ & $\begin{array}{r}11 \\
17 \\
1\end{array}$ \\
\hline
\end{tabular}


Table 3.9. Range of Internal Doses Assigned to the Hanford Work Force in 1995

\begin{tabular}{|c|c|c|c|c|c|c|}
\hline \multirow[b]{2}{*}{ Dose (mrem) $)^{(a)}$} & \multicolumn{6}{|c|}{ Numbers of Workers } \\
\hline & DOE & ICFKH & PNNL & WHC & ERC & Total \\
\hline$<100$ & 0 & $4(2)$ & $4(1)$ & $9(3)$ & $2(1)$ & $19(7)$ \\
\hline $100-<500$ & 0 & 0 & $1(1)$ & 2 & 0 & $3(1)$ \\
\hline $500-<2000$ & $1(1)$ & 0 & 0 & 0 & 0 & $1(1)$ \\
\hline $2000-<5000$ & 0 & 0 & 0 & 0 & 0 & 0 \\
\hline$>5000$ & 0 & 0 & 0 & 0 & 0 & 0 \\
\hline $\begin{array}{l}\text { (a) CEDE. Bas } \\
\text { occurred in } \\
\text { (b) Number in p } \\
\text { exposures. }\end{array}$ & $\begin{array}{l}\text { Is } 10 \\
\text { yea } \\
\text { nthe }\end{array}$ & $\begin{array}{l}\text { evalua } \\
\text { efers } t\end{array}$ & , alth & the $i$ & $\begin{array}{l}\text { ke co } \\
\text { offs }\end{array}$ & have \\
\hline
\end{tabular}

\subsubsection{Uranium Background Study}

The two-year study of excretion of uranium in urine from natural sources around the Hanford Site was concluded in June 1995. A letter report ${ }^{(a)}$ was issued to DOE-RL and Hanford contractor dosimetry representatives. The study reached the following conclusions:

- The historical environmental screening level of $0.2 \mu \mathrm{g} / \mathrm{d}$ is appropriate for most individuals, although $2-5 \%$ of the workers may excrete considerably more than this due to nonoccupational sources.

- The use of the ${ }^{238} \mathrm{U}$ to ${ }^{234} \mathrm{U}$ activity ratio as a indicator of the Hanford Site being the source of excreted uranium is not feasible.

- There was no correlation between the amount of uranium in urine and the amount in home drinking water, except for possibly a weak correlation when the uranium in water was very high.

- A correlation between excretion and geographic location within the Yakima River Valley and the Tri-Cities, Washington, was not discovered.

- A seasonal effect on the concentration of uranium in urine was not discovered.

(a) Long, M.P., E.H. Carbaugh, R.L. Buschbom. "Final Report - Natural Uranium Background Study." June 26, 1995. (A copy is available in the Hanford Radiological Records Historical Files.) 


\subsection{Project-Related Professional Activities}

IDP staff presentations and professional memberships during 1995 are listed in this section.

\subsubsection{Presentations}

Carbaugh, E. H. 1995. Reevaluations of Internal Dose - $A$ Good Idea? Presented at the 40th Annual Meeting of the Health Physics Society, July 23-27, 1995, Boston, Massachusetts. Also presented at the Columbia Chapter Health Physics Society meeting, September 19, 1995, Richland, Washington.

Carbaugh, E. H. 1995. Practical Applications of Internal Dosimetry Calculations. A professional enrichment course presented at the 40th Annual Meeting of the Health Physics Society, July 23-27, 1995, Boston, Massachusetts.

MacLellan, J. A. 1995. Discrimination Between Occupational and Environmental Sources of Internal Uranium Exposure. Poster presented at the 40th Annual Meeting of the Health Physics Society, July 2327, 1995, Boston, Massachusetts. Also presented at the Columbia Chapter Health Physics Society Meeting, September 19, 1995, Richland, Washington.

Wyse, E. J., O. T. Farmer, J. P. Bramson, J. A. MacLellan, and D. W. Koppenaal. 1995. Radioanalytical Applications of ICP/MS Using Enhanced Sensitivity Techniques. Poster presented at the 40th Annual Meeting of the Health Physics Society, July 23-27, 1995, Boston, Massachusetts.

\subsubsection{Professional Memberships}

Bihl, D. E. Chair ANSI Standards Committee N13.39, Internal Dosimetry Programs.

Carbaugh, E. H. Member ANSI Standards Committee N13.25, Internal Dosimetry Standards for Plutonium.

MacLellan, J. A. Member ANSI Standards Committee N13.30, Performance Criteria Against Which Rabiobioassay Laboratories Will Be Tested. 


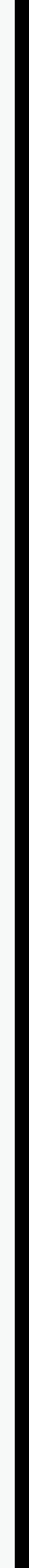




\subsection{Hanford Whole Body Counting Project}

The Hanford Whole Body Counting Project (WBCP) has been an integral part of worker radiation protection for the Hanford Site since 1959. As part of the Hanford Radiological Protection Services Program operated by PNNL, the project provides for the detection of radionuclides in Hanford workers by direct (in vivo) measurement, and the associated management, operation, and maintenance of the onsite in vivo facilities and equipment. The project operates and maintains equipment in the 747-A building, the 747-A Trailer, a mobile whole body counting trailer, and the Emergency Decontamination Facility (EDF) located next to Kadlec Hospital in Richland, Washington. Collectively, the facilities are known as the In Vivo Radioassay and Research Facility (IVRRF). Project requirements for the WBCP are outlined in the Whole Body Counting Manual. ${ }^{(\mathrm{a})}$

The activities of the project, which include routine measurements of Hanford workers, special request studies, and measurement instrumentation development work are described in this chapter. The primary function of the WBCP is to provide accurate, highly sensitive, well-documented, and timely measurements of workers potentially exposed to radionuclides encountered from occupational sources at Hanford. Measurement data are provided to the IDP for use in quantifying potential intakes and estimating internal doses. All measurement results and calibration data are transmitted as permanent records to the HRRP, and are stored on the REX system database. Information copies of the measurement records are kept on file at the IVRRF.

The routinely used measurement facilities at the IVRRF include the Preview Counter (used for rapid screening, whole-body measurements); the Iron Room, Stainless Steel Room, and Lead Room (each containing germanium counting systems); and the Palmer Room (containing the scanning germanium whole body counter). There is also some counting equipment in the EDF. Operating hours are currently from 8:00 a.m. to noon and 1:00 p.m. to 3:00 p.m. on weekdays. By special request, additional hours can be scheduled to cover off-shift or after-work counts. The facilities and equipment are also available on an on-call basis for incident response during off-hours.

\subsection{Routine Tasks}

Routine activities of the WBCP for 1995 included technical services for direct radiobioassay, equipment maintenance, data processing, quality assurance support, and project management.

\subsubsection{Routine In Vivo Radiobioassay}

Many different types of direct bioassay measurements are performed for the work force at the Hanford Site. Both routine (periodic) measurements and special request or incident analyses are

(a) Internal Manual, PNL-MA-574, Pacific Northwest National Laboratory, Richland, Washington. 
supported (summary statistics can be found in Section 4.2). The frequency of measurements for personnel is established by the contractor using guidance from the IDP. Contractors schedule routine IVRRF measurements through the Hanford Health Scheduling (HHS) system, a computerized scheduling system administered by HEHF that reports a daily roster of personnel scheduled to be counted.

The type of measurement is determined by the exposure scenario or the physiological location of a potential intake. Generally, an employee with potential exposure to intakes of radionuclides which emit high-energy gamma rays (e.g., fission products such as ${ }^{137} \mathrm{Cs}$ or activation products such as ${ }^{60} \mathrm{Co}$ ) receive an annual whole-body count (WBC) performed on the Preview Counter. The Preview Counter consists of a short (200-second) count in a standing position using five sodium iodide (NaI) detectors.

Verification of any positive result is performed with the scanning coaxial germanium system in order to identify and quantify the specific radionuclides present.

If the work involves transuranium radionuclides or insoluble uranium isotopes, lung counts are performed. In past years these counts were in addition to routine whole-body exams; however, in 1995 a cost-savings was implemented by eliminating the whole-body exam as a part of the routine monitoring for workers with potential for exposure only to uranium and transuranium radionuclides. Radioactivity that is detected by lung counting is verified by a second count. Several other types of counts may also be . done to provide more accurate quantification and localization of the intake.

All of the routine counting systems are interfaced to Acquisition Interface Modules which are connected by a local area network (LAN) to two Digital Equipment Corporation (DEC) Model 3100 workstations. The workstations control the counting functions and retrieve the completed data. Computer codes developed at PNNL are used to evaluate each spectra result collected with the in vivo measurement. Additional commercial software residing on the DEC Model 3100 workstations (Genie ${ }^{\mathrm{TM}}$ System Spectroscopy Applications, obtained from Canberra Industries and written for VAX/VMS) can be used to analyze spectra. The VAX workstations are in turn interfaced by the LAN to an IBM RISC 6000 minicomputer that operates as a database for all IVRRF measurement results. The database also sends the results to the REX system database.

\subsubsection{Data Administration}

Data administration for the IVRRF provides for the maintenance of the computer hardware and software related to the analysis and storage of in vivo measurement results. Verification of PNNLdeveloped software that is run on the computer platforms used at the IVRRF is also performed. New software written to augment and replace existing algorithms is verified, validated, and documented prior to routine use. Repair or replacement of computer hardware or components is also performed. Database management is performed at IVRRF to store, archive, backup, and analyze all measurements. The database currently runs Oracle ${ }^{\mathrm{Tu}}$ software and backups are performed both daily and weekly.

An unacceptably high rate of errors was discovered in July 1995 for in vivo results sent to the REX database between March 30 and June 30, 1995. The overall error rate was about 2\%, which, though 
small, was much higher than normal. Corrective actions included reviewing the problem areas; on-thejob training to new, more-detailed operating procedures; and enhanced supervisory oversight for the short-term. Subsequent transmittals returned to the normal error rate of $<0.1 \%$. .

\subsubsection{Technical Services}

Routine technical services are provided to support the operation of the IVRRF. These services support the project objectives of the performance, analysis, and documentation of over 10,000 annual routine measurements. Additionally, 2000 calibration and daily QC measurements are performed on an annual basis. Technical services include the calibration, operation, procurement, and routine maintenance of the counting systems; the record-keeping and receptionist duties of the operating station; and the training, qualification, and testing of technical personnel. Radioactive calibration sources undergo semiannual witnessed inventories.

At the close of 1995, the counting systems at IVRRF included 2 low-energy lung monitoring systems (Iron, and Stainless Steel Rooms), 2 WBC systems (Palmer Room and Preview Counter); wound, thyroid, and organ monitoring detectors (Lead Room); 2 counting systems (Stand Up and Shadow Shield Lung Monitor) in the remote WBC trailer located in the 200 East area; and, at the EDF, a wound counting system and a backup shadow shield whole body counting system.

\subsubsection{Equipment Maintenance}

Specific preventive maintenance is performed by PNNL Craft Services personnel on the many counting systems used at the IVRRF. Maintenance is also required for counting systems that require repair or replacement of electronic components. The procurement of expense-funded equipment necessary to keep the counting instrumentation and associated computer systems operating reliably is also performed. Due to the high number of routine measurements performed at the IVRRF, new electronic equipment is often necessary to replace older, worn equipment. Components that require periodic replacement include power supplies, preamplifiers, line amplifiers, analog-to-digital converters, signal routers, and LAN interface modules. Replacement of detectors is a less frequent event, caused by either detector failure or gradual degradation in performance.

The air supply fan for the Lead and Iron Rooms was replaced in 1995 and acoustically insulated to reduce the background noise level in these cells. Unfortunately the reduction was less than anticipated and noise remains a minor nuisance.

A fifth coaxial germanium detector (with an efficiency of $120 \%$ relative to a 3-inch by 3 -inch $\mathrm{NaI}$ detector) was added to the Palmer Room system in November 1995. However, shortly thereafter, a different coaxial germanium detector was declared inoperable due to excessive noise and poor resolution. The system was recalibrated with four detectors. 
The Lead Room lung counting system was taken out of service in June 1995 after failing efficiency checks due to degraded resolution. Two detectors remained operational for miscellaneous counting. With the reduced work load, this cell functions acceptably by doing only head and wound counts.

\subsubsection{Quality Assurance Support}

Quality Assurance (QA) and QC measures impact every part of the routine counting program. The WBCP has a formal QA program based on specifications of the Quality Assurance Manual ${ }^{(a)}$ and other current guidance. Reviews of project quality are performed by outside QA engineers and supplemented by industry QA inspections from independent subject experts from other DOE radiobioassay facilities. Additional reviews of project quality are performed in accordance with 10 CFR Part 835 (DOE 1993), which requires a planned functional audit of the project every 3 years. The Hanford contractors also perform joint audits of the WBCP.

The WBCP has historically been designated as a QA Impact Level III project. However, it became clear based on the issuance of DOE Order 5700.6C (DOE 1991) and the pending issuance of ANSI N13.30 (ANSI 1993) that the WBCP would not achieve DOELAP accreditation without upgrades in the QA area. In response to this, a new WBCP QA Plan (LSC-021 Rev 2) was completed and issued in March 1995, using the guidance contained in the Quality Assurance Guidance Document for Hanford Dosimetry Projects. ${ }^{(b)}$ As part of the QA upgrades, procedures were removed from the Whole Body Counting Manual ${ }^{(\mathrm{c})}$ and incorporated into a new Procedures Manual (PNL-MA-554). ${ }^{(\mathrm{d})}$.

\subsubsection{Preparation for DOELAP Accreditation}

One of the major areas of emphasis in the routine monitoring program is preparation for the DOELAP accreditation, as specified in the draft standard, ANSI N13.30, "Performance Criteria for Radiobioassay" (ANSI 1993). DOE plans to implement the accreditation program in an official capacity in FY 1997, after which failure to pass the performance testing criteria would restrict the radiobioassay laboratory from performing measurements for DOE or DOE contractor personnel. The ANSI standard sets forth the requirements for accreditation of bioassay laboratories, based on performance criteria and program quality measures: Planning for this accreditation required upgrading several areas of the routine program operations, including QA, procedures, and documentation, as discussed in Section 4.1.5.

The WBCP participated in the DOELAP pilot testing conducted through the Radiological and Environmental Sciences Laboratory (RESL) at the Idaho Falls operations office. The WBCP was notified it met the criteria for bias and precision testing in the ${ }^{137} \mathrm{Cs}$ and ${ }^{134} \mathrm{Cs}$ round of DOELAP pilot testing held in 1994. In 1995, measurements of low energy photons (e.g., $\mathrm{Pu}, \mathrm{U}, \mathrm{Am}$ ) were made on lung

(a) Internal Manual, PNL-MA-70, Rev. 2, Pacific Northwest National Laboratory, Richland, Washington.

(b) Internal Manual, HDP-001, Pacific Northwest National Laboratory, Richland, Washington.

(c) Internal Manual, PNL-MA-574, Pacific Northwest National Laboratory, Richland, Washington.

(d) Internal Manual, PNL-MA-554, Pacific Northwest National Laboratory, Richland, Washington. 
phantoms for the final DOELAP pilot test. Five sets of lungs were counted five times each, with Hanford calibration lung sets counted between each DOELAP lung set as a calibration check. Data analysis and reporting will be completed in 1996.

\subsubsection{Project Management}

Routine project management activities include supervision of staff, financial control activities, annual development and updating of planning documents (WBCP Long-Range Plan, Fiscal Year Work Plan), and contributions to the Hanford Radiological Protection Support Services Annual Report.

A special 1995 project management activity was the preparation of a justification for keeping IVRRF services as part of the mandatory site-wide services. The justification included a description of the current project, its scope, staffing, funding, advantages, disadvantages, out-sourcing considerations, a comparison of the WBCP and commercial whole body counting services, and split service considerations. The justification was included as part of a total Radiological Protection Services Program submittal to RL. ${ }^{(a)}$

\subsection{Summary of Measurements}

Measurements taken at the IVRRF and remote counter locations during 1995 are summarized below.

\subsubsection{Summary of 1995 IVRRF Measurements}

The total number and type of measurements made on personnel during 1995 are given in Table 4.1. In 1995, a total of 10,962 measurements were made for RL and the Hanford contractors representing a $21 \%$ decrease from the number performed in 1994 . This decrease primarily represents contractoridentified reductions in the total personnel requiring chest and WBCs. Figure 4.1 depicts the in vivo measurements made at the IVRRF during the past six years.

\subsubsection{Remote Counter}

The remote whole body counter facility was taken out of service in August 1995 and placed in a standby condition. Because of the continued decrease in use of the facility, it was determined that it was no longer a cost-effective alternative, and its use was discontinued. The facility is housed in a trailer located in the 200-East area, and has served primarily as a convenience for routine measurements, eliminating the time required for workers to travel to Richland for examination at the 747-A building. The trailer will be moved to the 747-A building sometime in 1996.

(a) Letter dated February 13, 1995, to Ms. D. L. Clark (DOE-RL) from J. R. Houston (PNNL), "Justifications for Maintaining the Site-Wide Radiological Support Services as Mandatory Site Services." 
Table 4.1. In Vivo Measurements Performed During 1995 and Recorded in REX Database

\begin{tabular}{|c|c|c|c|c|c|c|c|c|}
\hline \multirow{2}{*}{$\begin{array}{l}\text { Count Type and } \\
\text { Reason }\end{array}$} & \multirow[b]{2}{*}{ BCSR } & \multirow[b]{2}{*}{$\mathrm{ERC}$} & \multirow[b]{2}{*}{ DOE } & \multicolumn{3}{|c|}{ Contractor Code } & \multirow[b]{2}{*}{ Other ${ }^{(a)}$} & \multirow[b]{2}{*}{ Total } \\
\hline & & & & ICFKH & PNNL & WHC & & \\
\hline \multicolumn{9}{|l|}{ Whole Body Count } \\
\hline Routine Schedule & 64 & 781 & 215 & 1,647 & 1,678 & 4,289 & 25 & 8,699 \\
\hline Special Request & 0 & 2 & 0 & 9 & 7 & 16 & 0 & 34 \\
\hline Contractor Request & 0 & 17 & 131 & 21 & 37 & 81 & 0 & 287 \\
\hline Total & 64 & 800 & 346 & 1,677 & 1,722 & 4,386 & 25 & 9,020 \\
\hline \multicolumn{9}{|l|}{ Chest } \\
\hline Routine Schedule & 20 & 42 & 14 & 492 & 318 & 978 & 3 & 1,867 \\
\hline Special Request & 0 & 0 & 0 & 4 & 4 & 22 & 0 & 30 \\
\hline Contractor Request & 0 & 0 & 1 & 2 & 4 & 11 & 0 & 18 \\
\hline Total & 20 & 42 & 15 & 498 & 326 & 1,011 & 3 & 1,915 \\
\hline \multicolumn{9}{|l|}{ Other } \\
\hline Routine Schedule & 0 & 0 & 0 & 0 & 0 & 0 & 0 & 0 \\
\hline Special Request & 0 & 1 & 0 & 0 & 0 & 26 & 0 & 27 \\
\hline Contractor Request & 0 & 0 & 0 & 0 & 0 & 0 & 0 & 0 \\
\hline Total & 0 & 1 & 0 & 0 & 0 & 26 & 0 & 27 \\
\hline Grand Total & 84 & 843 & 361 & 2,175 & 2,048 & 5,423 & 28 & 10,962 \\
\hline \multicolumn{9}{|c|}{$\begin{array}{l}\text { (a) Other represents US Army Corps of Engineers, Hanford Environmental Health } \\
\text { Foundation, and US West. }\end{array}$} \\
\hline
\end{tabular}

The remote counter is a stand-up multi-detector $\mathrm{NaI}(\mathrm{Tl})$ counting system, connected to an IBM Model 25 in the trailer. This equipment is interfaced with the main facility at the 747-A Building via telephone modem. The system is operated remotely from the 747-A Building by IVRRF technicians. During remote measurements, continuous audio and visual communications are maintained with the subjects in the trailer. Visual images are transmitted to the 747-A Building via a photophone system, while a dedicated phone line between the trailer and the 747-A Building provides audio communications. The system sensitivity is comparable to the preview whole body counter in the 747-A Building. 


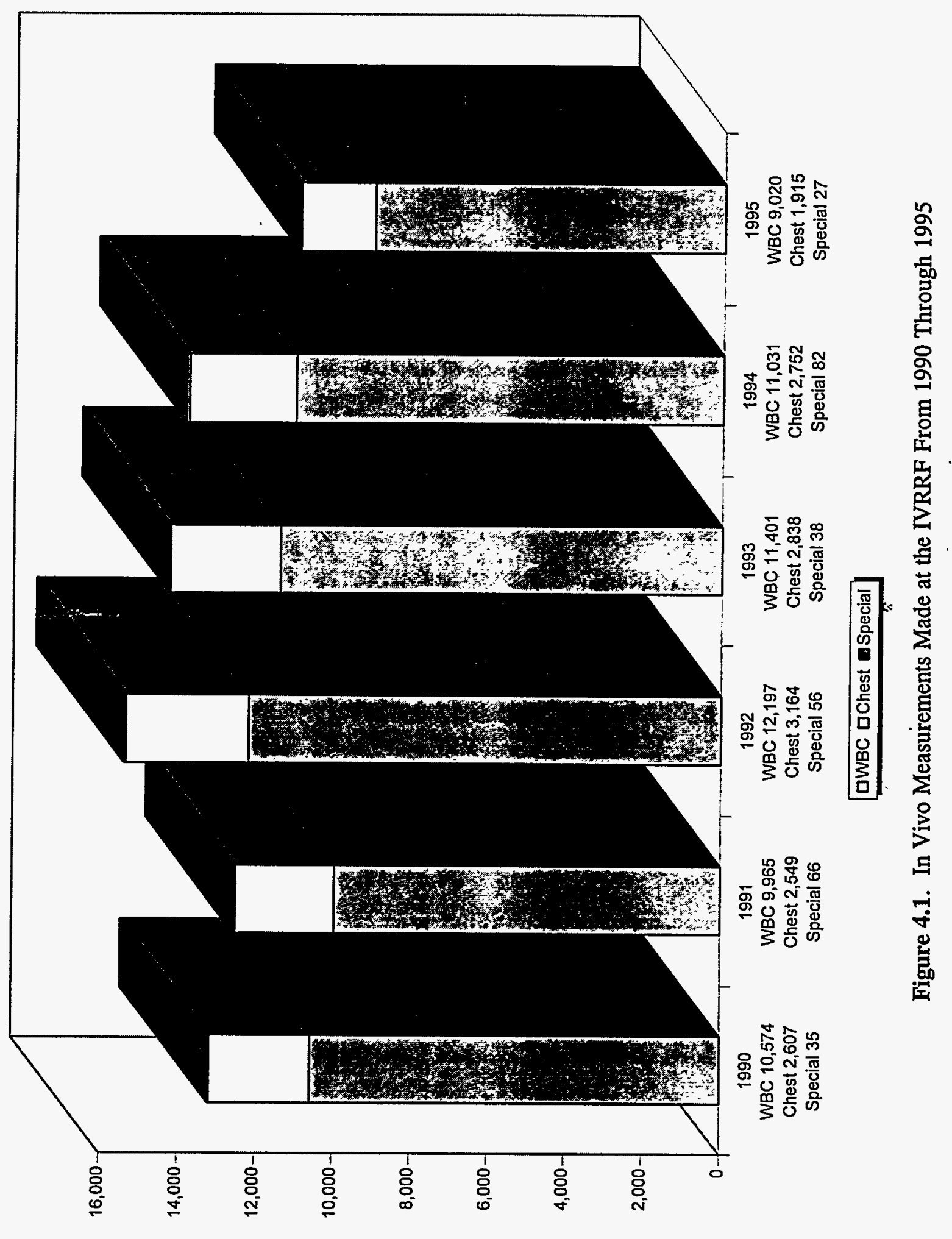




\subsection{Non-Routine Tasks}

Several supporting tasks were performed in 1995. These included an intercomparison program with another DOE laboratory, implementation of a new computer system, and development of a new project manual for the WBCP.

\subsubsection{ORNL Intercomparison Program}

The IVRRF participated again this year in a radiobioassay intercomparison program operated by Oak Ridge National Laboratory (ORNL). Preparation bottles containing unknown activities of radioactive material are sent quarterly to program participants for analysis. The bottles fit inside the cavities of a plexiglass block phantom. Measurements of the unknowns in the phantom, while not representative of human in vivo bioassay measurements, provide an indication of the measurement precision and bias and serve as a training aide for technicians. Three sets of unknowns were analyzed in 1995 using the coaxial germanium scanning system. Radionuclides included in the intercomparison were ${ }^{57} \mathrm{Co},{ }^{60} \mathrm{Co},{ }^{88} \mathrm{Y},{ }^{133} \mathrm{Ba}$, and ${ }^{137} \mathrm{Cs}$. A summary of the PNNL measurement bias from the intercomparison is shown in Figure 4.2. The data reflect a $3.5 \%$ average positive bias.

\subsubsection{NEXEC Software and Hardware System}

The new IVRRF computer system, named NEXEC (for New EXEC), was placed into routine operation in March 1995, replacing the old HP9000 which ran EXEC. Following an anticipated period of debugging, the system has demonstrated very satisfactory and stable operation. The system supports three platforms (i.e., PC running Windows-based Visual Basic, VAX WS 3100 running VMS, and the IBM RISC- 6000 running AIX), their interfaces, and the interface with the Oracle ${ }^{\mathrm{TM}}$ database management system that resides on the RISC-6000. Since the HP9000 was no longer the primary system for IVRRF operations and was used only as a back-up system, the maintenance contract on the HP9000 computer system was canceled as a cost-savings measure.

\subsubsection{Hanford Whole Body Counting Manual}

Revision 2 to the Hanford Whole Body Counting Manual ${ }^{(\mathrm{a})}$ was issued in May 1995. The revised manual contains policy and technical basis information but not procedures. The detailed operating procedures will be compiled in a separate procedures manual planned for completion in early 1996.

\subsection{Improvements to the Whole Body Counting Project}

Several improvements were completed at the IVRRF during 1995 that affected counting equipment, procedures, and facilities upgrades. These improvements are described in the following sections.

(a) Internal Manual, PNL-MA-574, Pacific Northwest National Laboratory, Richland, Washington. 


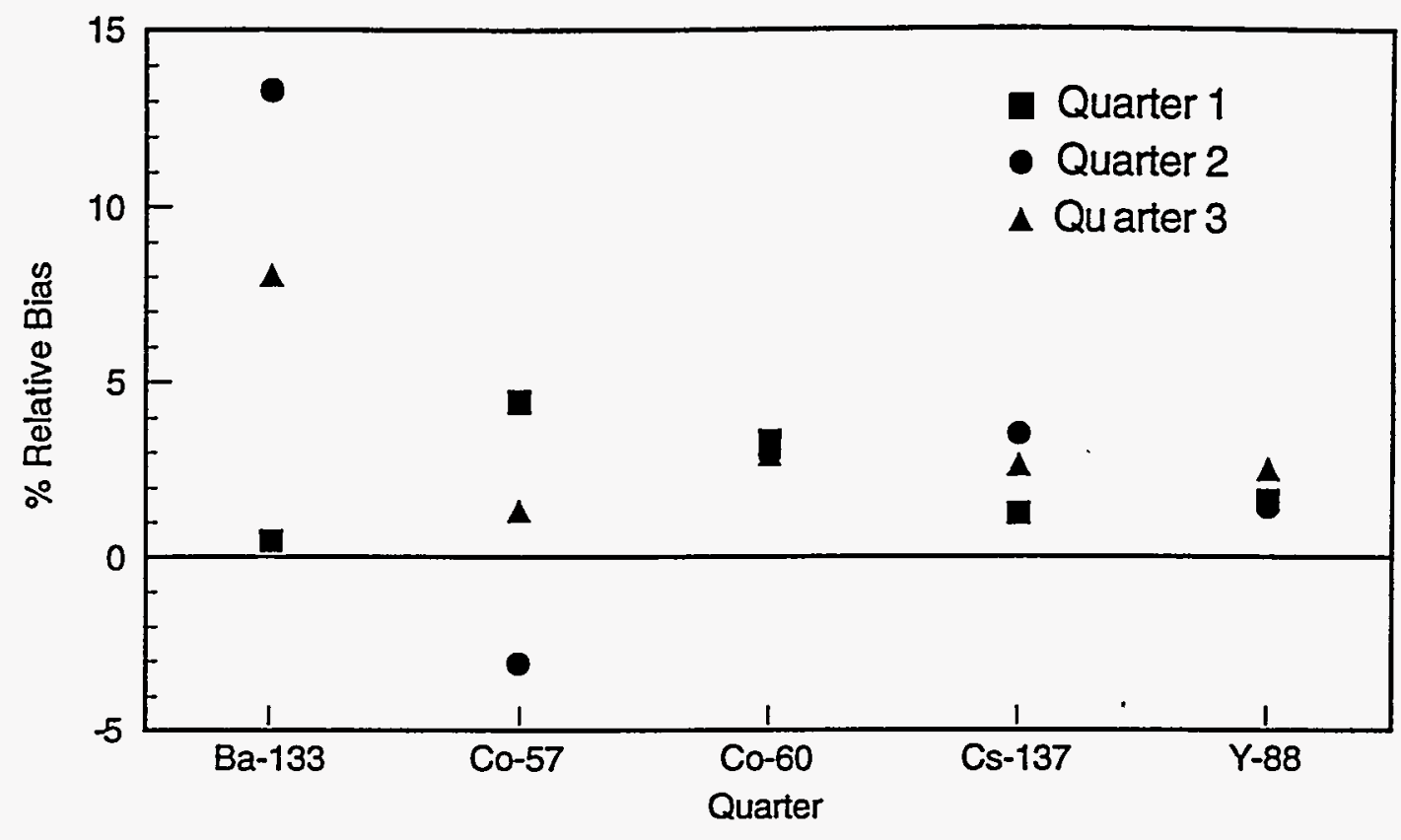

\begin{tabular}{|l|l|r|r|r|}
\hline Quarter & Isotope & \multicolumn{1}{|c|}{ Actual } & \multicolumn{1}{c|}{ Measured } & \multicolumn{1}{c|}{ Bias } \\
\hline Quarter 1 & Ba-133 & $168.3 \pm 8.4$ & $169.0 \pm 51.0$ & $0.4 \%$ \\
& Co-57 & $39.1 \pm 2.0$ & $40.8 \pm 12.2$ & $4.4 \%$ \\
& Co-60 & $33.8 \pm 1.7$ & $34.9 \pm 10.5$ & $3.3 \%$ \\
& Cs-137 & $95.5 \pm 4.8$ & $96.6 \pm 29.0$ & $1.2 \%$ \\
& Y-88 & $196.8 \pm 9.9$ & $200.0 \pm 60.0$ & $1.6 \%$ \\
\hline Quarter 2 & Ba-133 & $35.3 \pm 1.8$ & $40.0 \pm 12.0$ & $13.3 \%$ \\
& Co-57 & $151.7 \pm 7.6$ & $147.0 \pm 44.0$ & $-3.1 \%$ \\
& Co-60 & $179.8 \pm 9.0$ & $185.0 \pm 56.0$ & $2.9 \%$ \\
& Cs-137 & $83.4 \pm 4.2$ & $86.3 \pm 25.9$ & $3.5 \%$ \\
& Y-88 & $100.6 \pm 5.0$ & $102.0 \pm 31.0$ & $1.4 \%$ \\
\hline \multirow{2}{*}{ Quarter 3 } & Ba-133 & $80.0 \pm 4.0$ & $86.4 \pm 25.9$ & $8.0 \%$ \\
& Co-57 & $94.7 \pm 4.7$ & $95.9 \pm 28.8$ & $1.3 \%$ \\
& Co-60 & $113.7 \pm 5.7$ & $117.0 \pm 35.0$ & $2.9 \%$ \\
& Cs-137 & $138.4 \pm 7.0$ & $142.0 \pm 43.0$ & $2.6 \%$ \\
& Y-88 & $59.5 \pm 3.0$ & $60.9 \pm 18.3$ & $2.5 \%$ \\
\hline
\end{tabular}

Figure 4.2. PNNL Performance in ORNL Intercomparisons of In Vivo Measurements 


\subsubsection{Process Improvement - ACE Breakthrough}

In 1995 a major effort was made to identify and implement cost-effective process improvements in the WBCP. These improvements were done in conjunction with the IDP and were part of the ACE effort for the Hanford Radiological Protection Services Program. Meetings were held with contractor dosimetry representatives to identify ways to reduce costs and to address quality improvement issues. The meetings were facilitated by staff from the PNNL Quality Program Directorate having expertise in total quality management and process efficiency analysis. It was determined that the greatest potential for cost savings centered on reducing the demand for bioassays. A total of $\$ 482 \mathrm{~K}$ in cost reductions for FY 1996 were identified, some of which required modification to operating practices. The changes included placing the remote whole body counter in a standby mode, reducing the number of counts scheduled, eliminating the shower before routine lung counting, reducing instrument technician support, and reducing the operating hours. Two IVRRF technicians and a secretary who left under the voluntary reduction of force program were not replaced, providing additional savings.

\subsubsection{New NaI Detector in Preview Counter}

The $4 \times 11$ inch sodium iodide detector in the Preview Counter was replaced in 1995. The system was then recalibrated and the calculation algorithm for quantifying the counts was modified. The new detector provides improved resolution and helps eliminate interferences, thereby reducing recounts. The Preview Counter system uses four $4 \times 9$ inch detectors and one $4 \times 11$ inch detector for detection of high-energy fission and activation products. Two of the $4 \times 9$ inch detectors were replaced in 1994 .

\subsubsection{Planned Replacement of Aging Detectors}

Delivery of three semi-planar, high-purity germanium (HPGe) detectors required for upgrade of the second lung counter system was delayed by the vendor. This will slip the total upgrade effort into 1996. Because the older detectors continued to function reliably, this did not pose a significant problem. Two of the three detectors were received in November 1995 and underwent acceptance testing.

\subsubsection{Expanded Head Counting Calibration}

Head counting capability was expanded into quantifying ${ }^{226} \mathrm{Ra}$ and ${ }^{228} \mathrm{Ra}$. This was accomplished by creating a calibration equation for head counting over the energy range of $13 \mathrm{keV}$ to $350 \mathrm{keV}$ using two $20-\mathrm{cm}^{2}$ detectors over the forehead, based on measurements of a head phantom containing ${ }^{152} \mathrm{Eu}$ and ${ }^{241} \mathrm{Am}$. The ${ }^{241} \mathrm{Am}$ count rate per unit activity measured from the Eu/Am phantom and the U.S. Transuranium Registry (USTR) ${ }^{241} \mathrm{Am}$ phantom were within $15 \%$, which is considered adequate agreement. Data from head counts on workers with no recorded occupational exposure to ${ }^{226} \mathrm{Ra}$ or ${ }^{235} \mathrm{U}$ were analyzed to estimate the background in the ${ }^{226} \mathrm{Ra}$ region of interest. 


\subsubsection{New Daily Resolution Checks}

A method was developed to evaluate resolution of all routine detector systems by incorporating a resolution check into daily procedures, as required by ANSI N13.30 (ANSI 1993). The method uses Genie Spectroscopy Software (by Canberra) and can test each detector in an array separately, printing out the resulting full-width half-maximum resolution value.

\subsubsection{Investigation of Using Preamplifier Pole Zero to Reduce Background}

An evaluation was performed for using the preamplifier pole zero to reduce the background continuum from large-area planar detectors. This was an application of a technique discussed at the DOE Lung Intercalibration Committee Annual Meeting, May 2, 1995, in Richland. Unfortunately, it was concluded that a reduction in background for the Hanford systems could not be achieved in this manner.

\subsubsection{Monitoring of Palmer Cell Structural Crack}

Monitoring of cracks discovered in 1994 in the Palmer Room continued, with no evidence of propagation or significant change. The cracks are located in the left wall of the cell near the hinges of the left door. The cracks are in iron plating (former battleship armor) fabricated over 50-years ago under wartime conditions, and may be the result of embrittlement from the hardening process; they are not necessarily recent. The room is considered safe, but surveillance of the cracks will continue.

\subsection{Supporting Programs and Studies at the IVRRF}

The following programs and studies were conducted by the IVRRF staff in 1995.

\subsubsection{DOE Phantom Library}

Operation of the DOE Phantom Library by IVRRF staff continued in 1995. Funded by DOE-HQ, this program loans state-of-the-art in vivo calibration phantoms to U.S. bioassay laboratories for calibration of measurement systems. The loans are made to DOE laboratories and other government agencies at no cost other than the shipping costs. The program also maintains records and calibration information on phantoms and provides technical assistance to others in the field of direct radiobioassay. There were 8 phantom loans to other in vivo measurement facilities in 1995.

The Phantom Fabrication Laboratory had to be relocated in 1995 due to general site downsizing and the vacating of buildings. A location for a new lab was identified in the 331 Building, with the engineering and facility modifications begun to accommodate future lab work. Lab construction will be completed and the move accomplished in 1996. 


\subsubsection{U.S. Transuranium Registry Support}

Analysis of post-mortem measurements of a USTR whole body donor (Case 269) were completed in 1995. The measurements were performed over a two-day period in late 1994, and results were reported by letter to the USTR in 1995 . The individual had incurred a significant plutonium nitrate intake approximately 30 years prior to death, and had undergone multiple chelation therapy, with no further plutonium work after the intake. The organ and body measurements reflected that intake. The data will be part of a future report by USTR on this important case.

\subsection{Project-Related Professional Activities}

Staff presentations and professional memberships during 1995 are listed in this section.

\subsubsection{Presentations}

Rieksts, G. A. Early Operating Experience with Large Area Germanium Detectors for Detecting Low Energy Photons. Presented at the DOE Lung Intercalibration Committee Annual Meeting, May 2, 1995, Richland, Washington.

Pierce, J. L., Olsen, P. C., and McDonald, J .C. Gas Scintillation Proportional Counter Development at PNL. Presented at the DOE Lung Intercalibration Committee Annual Meeting, May 2, 1995, Richland, Washington.

Perkins, B. W. Repair of Intrinsic Germanium Diode Detectors. Presented at the DOE Lung Intercalibration Committee Annual Meeting, May 2, 1995, Richland, Washington.

\subsubsection{Professional Memberships}

Lynch, T. P. Chairman of ANSI N13.35 Working Group which is writing the ANSI Standard ANSI Standard for the Bottle Manikin Absorption Phantom.

Lynch, T. P. Member of ASTM Task Group E-10.04.27 which is writing the ASTM standard Estimation of Low Energy Photon Emitters in a Wound.

Olsen, P. C. Member of ANSI N13.35 Working Group writing the ANSI Standard ANSI Standard for the Bottle Manikin Absorption Phantom.

Olsen, P. C. Member of ANSI N13.44 Working Group writing the ANSI Standard ANSI Standard for Thyroid Calibration Standard Phantoms.

Olsen, P. C., appointed an Adjunct Lecturer by Washington State University. 


\subsection{Hanford Radiological Records Project}

The Hanford Radiological Records Project (HRRP) supports RL and Hanford contractor radiation protection programs. The HRRP administers and preserves radiological exposure records for all Hanford workers and visitors, past and present, and provides specified and requested reports using these records. The program is also responsible for maintaining the Hanford Radiation Protection Historical Files. Program personnel operate the computer systems and library equipment necessary to input, store, verify, and retrieve the records and produce the required reports and downloads.

The HRRP uses the REX ${ }^{(a)}$ system, which includes a database containing the personnel radiological exposure data. These data are readily retrievable via a system of personal computers and terminals operated by the HRRP and Hanford contractor dosimetry staffs. The REX system also includes all of the supporting exposure documentation on microfilm and laser optical disk which are indexed into computer-assisted retrieval (CAR) systems. The CAR systems allow for rapid retrieval of the documents for any individual using identifiers, including payroll numbers, social security numbers, names and/or REX IDs (REX IDs are unique numbers generated by the computer for each individual to tie all of their records together). The project also uses a laser optical disk subsystem (called LaserREX). All hardcopy exposure records starting with January 1, 1992, are preserved on LaserREX. LaserREX also stores the electronic records created by the REX transaction log. Hardcopy records generated prior to 1992 are maintained on microfilm.

The Hanford Radiation Protection Historical File records include documents such as policies, procedures, reports, and important communications that define the Hanford radiological dosimetry and radiation protection programs during their history. The historical records are microfilmed and indexed into an additional CAR system. These records are retrievable by author, date or range of dates, document number (if applicable), document title, and up to three keywords.

The program is operated under the applicable sections of 10 CFR Part 835 (DOE 1993); the Hanford Site Radiological Control Manual (HSRCM-1) (RL 1994), ANSI N13.6, American National Standard Practice for Occupational Radiation Exposure Records Systems (ANSI 1972); as well as the following DOE Orders: 1324.5B, "Records Management Program" (DOE 1995a); and 231.1 "Environment, Safety and Health Reporting" (DOE 1995b). The program also complies with the applicable sections of the Privacy Act (1974) and the Freedom of Information Act (1966).

(a) A description of the REX database can be found in Lyon et al. 1994. 


\subsection{Routine Project}

The HRRP is organized into four major functional areas: data administration, data handling, report issuance, and the library. Both data handling and report issuing are performed by the Radiological Records Data Processing Center.

The database administration function performs system evaluations, troubleshooting, resolution of system and user problems, training of users, oversight of system security, liaison with the BCSR computer analysts, and initiation and testing of modifications to the databases.

Data-handling includes entering data into the REX database and validating all data entry. Validation is accomplished by reviewing field data entry, establishing audits to be matched to entries of results, resolving unmatched results, and interacting directly with contractor personnel. Data-handling also includes dealing directly with contractor personnel and data suppliers to assist them and solve data problems.

The report issuance function provides for generation and issuance of routine exposure status reports to the contractors, quarterly person rem and annual statistical reports to DOE, annual reports to employees, and special reports requested by former employees, as well as those requested by the contractors, RL, the Uranium and Transuranium Registries, and Privacy Act and Freedom of Information Act petitions. This function requires close contact with $\mathrm{RL}$, the contractors, and other personnel dosimetry functions.

The Records Library maintains individual exposure records that are not reducible to database elements and backup documentation as well as the Hanford Radiation Protection Historical Files. The library staff file and retrieve hard-copy documents, prepare documents for long-term storage, and track and account for the documents through the imaging and indexing process. The library contains the individual exposure records of all Hanford personnel since its inception (almost five-million microforms), except those individuals who transferred from Hanford when DuPont left in 1946. These and the Historical File microforms are retrievable through index systems that are maintained by the library staff.

Although the results from the dosimeter and excreta processing, as well as the in vivo counts, are received by electronic transmission, a large amount of data are entered manually by the field dosimetry organizations and the HRRP Data Processing Center staff. The hard copies are then sent to the library for preservation on the imaging systems. Table 5.1 presents CY 1995 statistical information on many of the documents that are entered into the database and indexed into LaserREX. Some documents, such as the Employee and Dosimetry Change Form may contain several pieces of information that require data entry. 
Table 5.1. Records Activity for Calendar Year 1995

\begin{tabular}{|l|c|}
\hline \multicolumn{1}{|c|}{ Document Type } & Number \\
\hline \hline $\begin{array}{l}\text { Personal Radiation Exposure History Form (used to document exposure history } \\
\text { prior to Hanford and to initiate a record for a new or rehired employee) }\end{array}$ & 2,945 \\
\hline $\begin{array}{l}\text { Employee and Dosimetry Change Forms (used to document personnel data or } \\
\text { dosimetry changes) }\end{array}$ & 11,194 \\
\hline $\begin{array}{l}\text { Employee and Dosimetry Change Forms (used to document employee } \\
\text { terminations) }\end{array}$ & 6,863 \\
\hline $\begin{array}{l}\text { Temporary Dosimeter Assignment Forms (used for issuing temporary } \\
\text { dosimeters to employees due to new hires, changes to dosimetry requirements, } \\
\text { and employees who forgot their dosimeters) }\end{array}$ & 7,749 \\
\hline $\begin{array}{l}\text { Visitor and Subcontractor Dosimeter Issue Forms (used to issue dosimetry to } \\
\text { visitors and subcontractors not completing radiological worker training) }\end{array}$ & 4,611 \\
\hline $\begin{array}{l}\text { Investigation of Dosimeter Result Forms and Change Letters (used to estimate } \\
\text { exposure for lost, damàged, or otherwise suspect dosimeter results) }\end{array}$ & 2,656 \\
\hline $\begin{array}{l}\text { Special Process Forms (used to document data for specially processed } \\
\text { dosimeters) }\end{array}$ & 6,227 \\
\hline $\begin{array}{l}\text { Requests for Exposure Summaries (summaries requested for current and prior } \\
\text { Hanford employees) }\end{array}$ & 334 \\
\hline $\begin{array}{l}\text { Letters Sent to Request Prior Exposure (to request summaries for new } \\
\text { employees with prior exposure or existing employees receiving exposure at off- } \\
\text { site facilities) }\end{array}$ & 686 \\
\hline Total number of hardcopy records scanned and indexed into LaserREX & \\
\hline \hline $\begin{array}{l}\text { (a) } \text { This total is for all of the hardcopy records scanned and indexed into LaserREX, some } \\
\text { of which are not listed in this table. }\end{array}$ & 86,153 \\
\hline \hline
\end{tabular}

The project added certain new reports, a project procedures manual, and revised the project manual, all discussed below, and purchased fireproof cabinets to complete upgrades needed to come into compliance with and provide documentation for 10 CFR Part 835 (DOE 1993). At year end the project was $100 \%$ in compliance with 10 CFR Part 835 and HSRCM-1 (RL 1994).

A major change this year was the conversion to unit pricing for all of the project's services. In most cases, each contractor will pay for their actual usage of the services. The unit pricing methodology included the following elements: 
- Each dosimeter, in vivo, and excreta bioassay record entered into REX will be assessed a charge. In addition, each dose entered from Investigation of a Dosimeter Result forms or dose correction letters would be assessed the same charge. These will be recorded and invoiced to the appropriate contractor on a monthly basis. These charges will cover the REX processing charges and the HRRP staff effort to resolve rejects and solve other specific data problems. It will also cover the cost of scanning and indexing visitor and subcontractor dosimetry forms into LaserREX.

- Each active employee and resident non-employee listed in REX will be assessed a charge. The numbers will be recorded and invoiced monthly. This charge would cover the storage of records on REX and LaserREX, processing of hardcopy records into LaserREX, project management and technical administration, data administration, and the basic maintenance of REX. This charge would also cover other services provided by the project, such as the monthly status reports for employees, visitors, and subcontractors; providing employees and former employees with exposure records; termination letters; annual exposure reports; and various other reports.

- A charge will be assessed for each dose entered from a Personal Radiation Exposure History form or off-site dose record on a monthly basis. This will cover the average time required by HRRP staff to obtain the data from off-site facilities and enter the data.

- The cost of operating the Hanford Radiation Protection Historical File will be assessed with each contractor being invoiced an equal share. The actual expenses will be invoiced monthly.

- All programming changes to REX will be billed directly to the contractors by BCSR. If the change benefits all contractors, they will be billed an equal share of the cost. If the change benefits only a single contractor they will pay the total cost.

- U.S. Nuclear Regulatory Commission (NRC) Forms 4s and associated documentation prepared for employees going to off-site assignments will be charged to the appropriate contractor by the hour for the actual time required to prepare the package.

- Requests from the RL Privacy Act/Freedom of Information Office have been invoiced to RL on an hourly labor basis for several years and will continue to be. Data supplied to the Transuranium Registry will be similarly invoiced to RL.

The DOE Implementation Guide for the External Dosimetry Program (DOE 1994b) set forth requirements for obtaining records of prior years occupational exposure required by 10 CFR 835.702(e). It requires three written requests to previous employers to constitute sufficient effort. The HRRP procedure varies in that the third letter will go to the NRC Radiation Exposure Information Reporting System Project if the subject employer is an NRC licensee. The probability of receiving a reply is higher than sending a third letter to an unresponsive employer. If the records are still unavailable, 1 rem should be assigned for each previous year for which records are unavailable and the individual may have received occupational exposure to show compliance with the lifetime dose control level. The notional 
dose levels are only for the purpose of managing lifetime exposures and should not be included in epidemiological studies, medical evaluation programs, or primary doses of record. This situation was taken to the HPDAC for discussion. Based on 10 CFR 835.702(d) the HPDAC agreed that if the individual would sign a statement listing his/her dose for the period of unavailable records, the dose could be used in REX as the individual's official dose and the 1 rem per year would not have to be entered. The project prepared a form letter to be used by the contractors for requesting the individual to complete and sign. REX was programmed so that the 1 rem per year dose added for this requirement would only show up in the lifetime column of the monthly dose status report for tracking purposes and would not be reported on the annual report or any official dose records.

The REX database performed very well all year. The majority of the Software Change Requests issued during the year were for changes and.enhancements to make the operations more efficient and data entry less cumbersome. The REX User's Group, initiated late in 1993, was instrumental in proposing and defining many of the enhancements and changes. Some of the significant changes included the following:

- Two new reports were programmed to be attached to the annual exposure reports and termination letters. These reports contained data required for individuals receiving internal doses and embryo/ fetus doses of declared pregnant workers by 10 CFR Part 835 (DOE 1993). The attachments will be prepared only for those individuals that had an intake or completed a pregnancy during the year.

- A program was written to send every visitor or subcontractor employee not completing radiological worker training that was issued a dosimeter a Visitor Exposure Report regardless whether he/she had any exposure. This is based on a new requirement in 10 CFR Part 835 (DOE 1993). Previously only visitors with a greater than zero exposure received exposure letters. This increased the number of letters from less than 200 a year to almost 5000 a year.

- The system was programmed to accept daily transfer of dosimeter results from the External Dosimetry Project. This should reduce the number of special processed dosimeters. Programming was commenced to provide these daily results to the WHC Access Control Entry System (ACES) in 1996.

- Some changes were made to accommodate the new external dosimetry system implemented on January 1, 1995. For instance, in the original design REX would send a complete external dosimetry requirements file as the Change File, which includes all the external dosimetry changes, and HEDP personnel would extract the changes for their system. Because this was not working in the external dosimetry system a new Change File was developed that sent only the changes.

- Programming was completed to allow the incorporation of a.Facility Calibration Code onto certain screens and transfer to the HEDP with dosimeter return records. This will allow the external dosimetry computer to automatically select the proper algorithm to calculate dosimeter results. 
- A program was written to allow special processed test dosimeters, which are used for a variety of non-personnel purposes, to be tracked in REX. This was a new requirement that was not a part of the original design requirements.

- Another new design requirement was met by adding a program to allow the IDP to track their spiked excreta audit samples.

- There were a number of screen changes to make the system more efficient for the users. Some examples of these changes were

- a number of changes were made allowing users to easily toggle back and forth between different screens used frequently, reducing the time required to perform certain functions

- a period ending date field was added to the Temporary Dosimeter Issue screen to allow users to identify overdue temporary dosimeters

- an organization code field was incorporated into the Visitor Dosimeter Issue screen. This will allow the users to track missing visitor dosimeters and to bill the visited organization for the dosimeter cost. This change, and the previous change, will help reduce the number of missing dosimeters requiring investigation and paperwork at the end of the year.

- a field was added to the Bioassay Results Table to store the Sent-to-Lab Date and display the field on the Bioassay Results screen. This will eliminate the need for the IDP staff to go through hard copy requests to search for the date for reports and in responding to telephone inquires. The field dosimetry personnel will be able to view the information without having to call IDP personnel.

- several screens were reorganized to be more efficient for the users.

- REX was programmed to provide an electronic report to financial staff on many unit price categories for the HRRP, HEDP, and WBCP. This program is incorporated into financial programs to produce invoices electronically, significantly reducing manual efforts.

A large number of dosimetry changes were made during 1995. The project and BCSR analyst wrote programs to make many of the changes electronically. This process considerably reduced data entry and paperwork requirements for the contractors. Each of these programs also produced a list report that could be scanned and indexed into LaserREX for documentation purposes. Examples of these electronic changes included

- dosimetry changes for approximately 13,000 individuals to accommodate the new external dosimetry system 
- ending dates were entered and the reason code was changed for approximately 850 WHC workers that were removed from in vivo and excreta bioassay schedules

- approximately 1000 workers were removed from in vivo schedules for PNNL

- updating 385 neutron dosimeter records with a new Facility Calibration Code

- approximately 2500 organization codes were changed for PNNL.

A number of upgrades to LaserREX were accomplished during the year. These upgrades included

- networking the two work stations to allow simultaneous indexing and retrieval, increasing productivity

- speeding up the scanning process by removing the view of the image with each scan

- improving the daily backup process by eliminating error messages, reducing back-up time by $75 \%$, and eliminating the need to call the consultant for assistance

- automatic printing of each clerk's indexed documents which allows for quality control checking

- implementation of a stand-alone retrieval station for the electronic transaction log records for the Data Administrator

- addition of a scanning icon which allows scanning or rescanning without backing out of other processes.

In addition, the LaserREX contractor programmed the system to automatically index the approximately 13,000 electronic records that were generated by the changes required to implement the new external dosimetry system.

\subsection{Supporting Projects}

The Hanford personnel dosimetry projects are all upgrading their QA programs. The HRRP is heavily involved in this upgrade. The first element to be completed for the upgrade was a revision of the REX Software Configuration Management Plan (PNL 1994). During 1995, the project created a new procedures manual - the Hanford Radiological Records Project Procedures Manual. (a) Sixty-seven different procedures were identified for the manual. The manual was issued in May 1995 with those procedures that were completed and approved. As more procedures were completed and approved, they

(a) Internal Manual, HRRP-01, Pacific Northwest National Laboratory, Richland Washington. 
were added to the manual. At year end all scheduled procedures except one had been approved and issued. The procedures were produced in several areas. The areas covered were 1) project administration, 2) data administration, 3) data processing, 4) exposure reporting, 5) records library, 6) report verification, and 7) quality control. If a process is completed by several different functions (e.g., a Personal Radiation Exposure History form is data verified by the Data Processing Center, is used by the exposure reporting function to request previous exposure records, and then processed into LaserREX by the Records Library) each function will have a separate procedure for their part of the process.

An additional project that was completed was a revision to the Hanford Radiological Records Project Manual. ${ }^{(a)}$ A new Technical Basis section was added that included, among other items, dose recording and calculation methodology. The completion of this revision and certain of the procedures in HRRP-01 completed the documentation of the applicable 10 CFR Part 835 (DOE 1993) and HSRCM-1 ( $R L$ 1994) requirements.

\subsection{Project-Related Professional Activities}

Staff professional memberships during 1995 are listed in this section.

\subsubsection{Professional Memberships}

Lyon, M. Chairman of the Health Physics Society Standards Committee Working Group to Revise ANSI N13.6, American Standard Practice for Occupational Radiation Exposure Records Systems.

(a) Internal Manual, PNL-MA-553, Hanford Radiological Records Project Manual, Pacific Northwest National Laboratory, Richland, Washington. 


\subsection{Radiation Standards and Calibrations Project}

The primary function of the Radiation Standards and Calibrations (RS\&C) Project is to maintain radiological standards necessary to facilitate appropriate characterizations and calibrations within the Hanford Radcon Instrumentation Services Project and HEDP. In support of this task, special instrument and dosimeter response-characterizing equipment and supplemental radiological reference fields are maintained, as necessary. This activity provides the means to characterize response to various radiation fields encountered at Hanford and ensures that calibration fields are described in accordance with recommended standards and guides. Typical project activities include

- providing traceability of the calibration sources to the NIST

- maintaining basic radioactive sources and instruments that serve as radiological standards

- reviewing calibration standards, regulations, and handbooks

- ensuring that calibration procedures are in agreement with technically accepted methods.

Project activities conducted during CY 1995 are discussed in the following sections.

\subsection{Routine Tasks}

Routine activities conducted by project personnel included maintaining 1) radiological standards and capabilities and 2) radiological reference fields traceable to national standards.

\subsubsection{Standards and Capabilities}

The radiological standards and capabilities maintained for the various entities of Hanford Radiological Protection Support Services include gamma, beta, and neutron isotopic sources and x-ray generating devices. These standards and capabilities are configured to deliver well-known and easily reproduced quantities of radiation dose or exposure to environmental or personnel dosimeters and radiological survey instruments for providing NIST-traceable calibration and/or response characterization.

\section{Gamma Ray Sources}

Available photon sources include various activities of ${ }^{137} \mathrm{Cs}$ and ${ }^{60} \mathrm{Co}$ configured in either collimatedbeam, well, or open-field geometries, and an ${ }^{241} \mathrm{Am}$ source configured for irradiation in a $2 \pi$ geometry, as listed in Table 6.1. 
Table 6.1. Available Gamma-Ray Sources

\begin{tabular}{|c|c|c|c|c|c|}
\hline Source & Geometry & $\begin{array}{c}\text { Nominal Rate/Range } \\
\text { [R(rem)/hr] }\end{array}$ & $\begin{array}{l}\text { Location in } \\
\text { Bldg. } 318\end{array}$ & $\begin{array}{l}\text { Reference } \\
\text { No. }\end{array}$ & $\begin{array}{l}\text { Primary Photon } \\
\text { Energy }(\mathrm{MeV})\end{array}$ \\
\hline \multirow{5}{*}{${ }^{60} \mathrm{Co}$} & Well $^{(\mathbf{a})}$ & $0.006-2.000$ & Rm. 121 & $318-027$ & \multirow{5}{*}{$1.17 / 1.33$} \\
\hline & Open & $2 / 7$ & Rm. 106 & $318-164$ & \\
\hline & Beam & $3-1500$ & Rm. 8 & $318-037$ & \\
\hline & Beam $^{(b)}$ & $210-57000$ & Rm. 8 & $318-353$ & \\
\hline & Beam $^{(c)}$ & $90-3000$ & Rm. 8 & $318-036$ & \\
\hline \multirow{8}{*}{${ }^{137} \mathrm{Cs}$} & Well & $10^{-4}-0.130$ & Rm. 121 & $318-031$ & \multirow{8}{*}{0.662} \\
\hline & Well & $0.026-2.700$ & Rm. 121 & $318-030$ & \\
\hline & Well ${ }^{(\mathrm{d})}$ & $0.005-25.600$ & Rm. 121 & $318-288$ & \\
\hline & Beam & $0.080-25.600$ & $\mathrm{Rm} .8$ & $318-040$ & \\
\hline & Open & $0.400 / 2.000$ & $\mathrm{Rm} .106$ & $318-001$ & \\
\hline & Beam & $1-250$ & Rm. 8 & $318-044$ & \\
\hline & Open & $1 / 8$ & Rm. 106 & $318-029$ & \\
\hline & Beam & $3 / 30$ & Rm. 6 & $318-131$ & \\
\hline${ }^{241} \mathrm{Am}$ & Open $(2 \pi)$ & 0.125 & $\mathrm{Rm} .6$ & $318-184$ & 0.060 \\
\hline \multicolumn{6}{|c|}{$\begin{array}{l}\text { (a) Source removed July } 1995 . \\
\text { (b) Source installed November } 1995 . \\
\text { (c) Source removed November } 1995 . \\
\text { (d) Source installed August } 1995 .\end{array}$} \\
\hline
\end{tabular}

The "Open" sources listed in Table 6.1 are placed in the center of a circular, aluminum table via a pneumatic air-transfer system. Exposure rates at two discrete distances to the source are typically characterized. "Beam" sources, with the exception of 318-131, provide a continuum of exposure rates via use of a detector/dosimeter positioning stand located on a sliding-rail system. Source 318-131 also includes a moveable stand, but is typically characterized and used only at the one- and three-meter distances. Device (instrument and/or dosimeter) placement for the most commonly used positions within these beam irradiation facilities is enhanced by laser alignment capabilities. "Well" sources also provide a continuum of exposure rates and facilitate instrument adjustments during irradiation without undue exposure to personnel. Source-to-detector/dosimeter distance is controlled by moving the sources, on a trolley system, up and down within the well via computer interface.

In addition to the sources listed above, a Nordion, Model GB650, "high-intensity" gamma irradiator is available within the 331 Facility which produces high-energy gamma fields from ${ }^{60} \mathrm{Co}$. This facility uses 12 sources which can be placed in a variety of geometries within tubes set in a circular pattern (Figure 6.1). The exposure rate is adjusted by selection of a particular source or combination of sources and the specific orientation of the irradiation tube(s) in proximity to the detector 


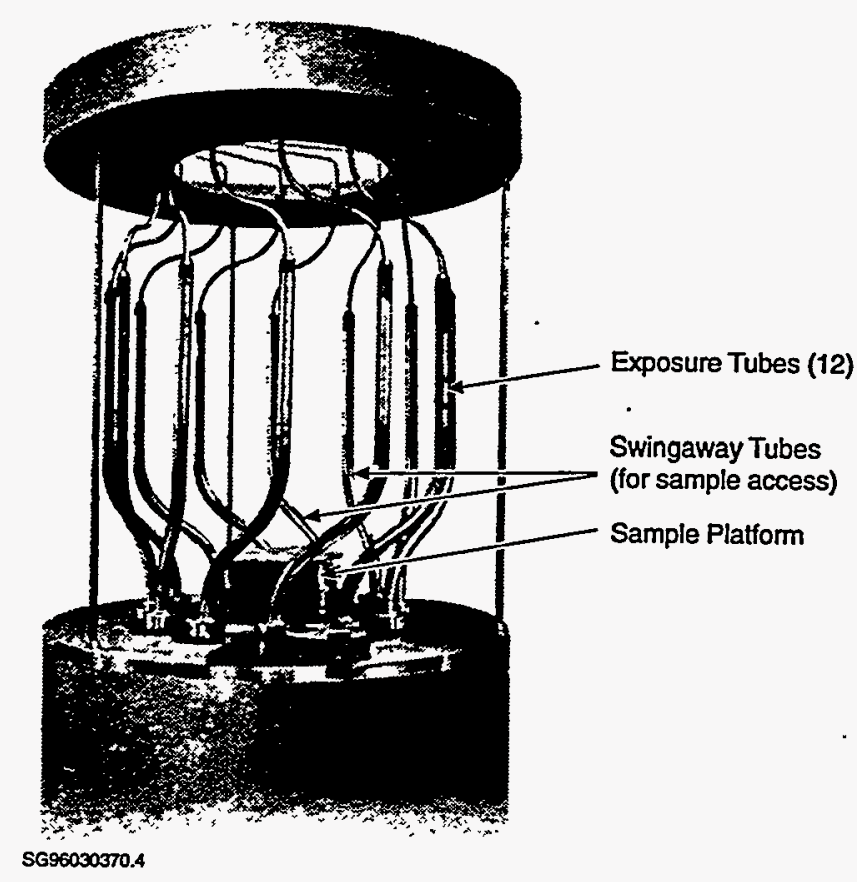

Figure 6.1. GB $6500^{60} \mathrm{Co}$ Irradiator

or other artifact being irradiated. The range of available exposure rates extends from 30 to $10^{7} \mathrm{R} / \mathrm{h}$ and has been applied to ultra high-range instrument calibration/characterization, as well as evaluations of . radiation fatigue for materials and components. The calibration of this facility is maintained traceable to the NIST through use of reference standards and methods identical to those used for the $\mathbf{3 1 8}$ sources, as described in this report.

\section{X-ray Photon Sources}

Two identical Philips Model-324 x-ray machines are currently in use in support of the RS\&C Project. One machine is used to produce Bremstrahlung (broad) photon spectra (e.g., NIST techniques $\mathrm{M} 30, \mathrm{~S} 60, \mathrm{M} 150, \mathrm{H} 150$, etc.) while the second is configured for K-fluorescence technique (narrow) secondary photon spectra (e.g., 17 and $59 \mathrm{keV}$ ) within a shielded enclosure.

Figure 6.2 shows an example spectrum of each type of $x$-ray configuration and Table 6.2 provides a complete listing of available techniques and their characteristics. Both of these systems use a laser alignment system to aid in detector/dosimeter positioning.

\section{Neutron Sources}

Two configurations of ${ }^{252} \mathrm{Cf}$ neutron sources are available. The first configuration allows the use of available sources within the pneumatic transfer system in Room 106. During use, these sources are 


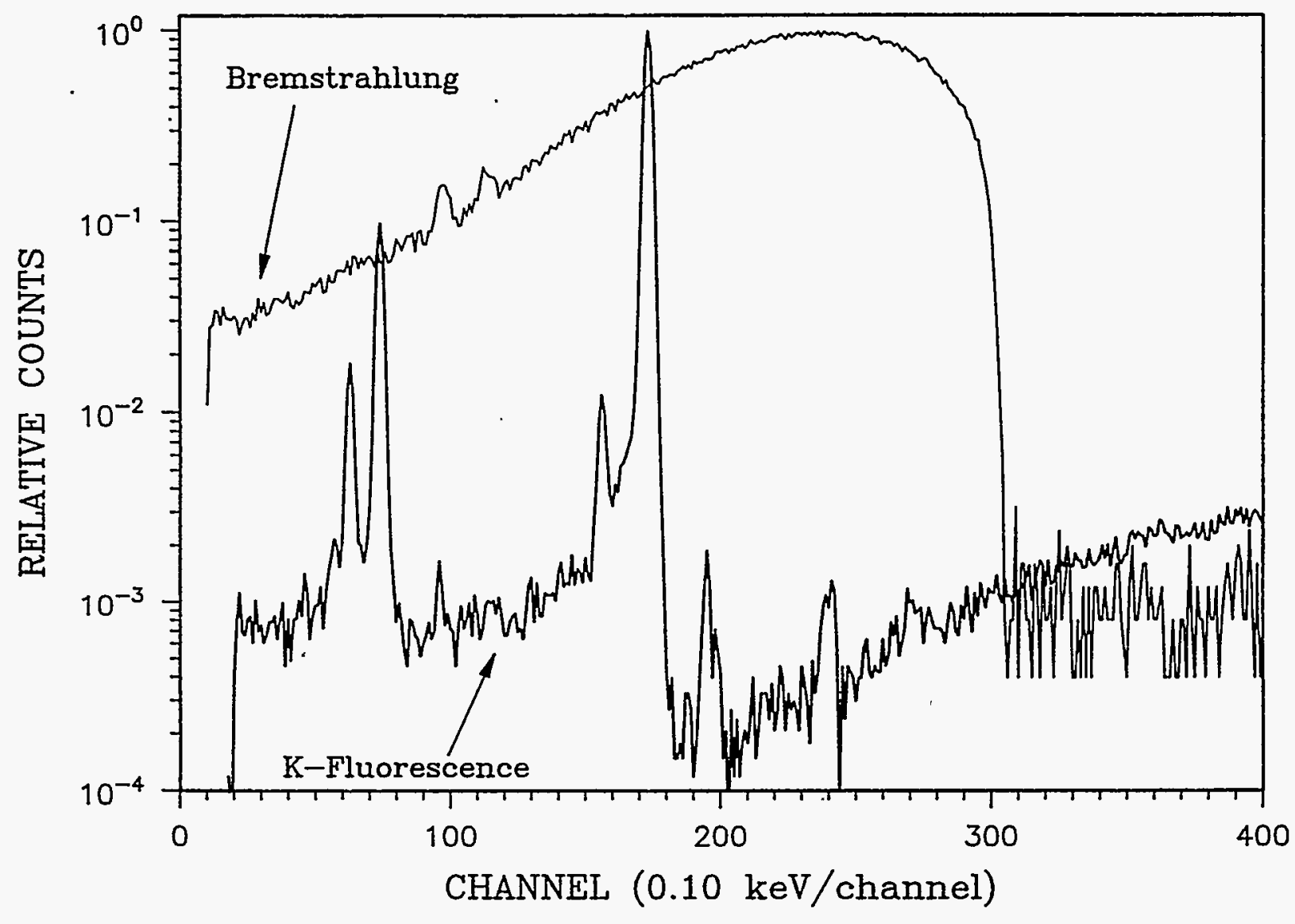

Figure 6.2. Example Spectrum of X-Ray Configurations

placed approximately at the geometric center of a room 10 meters wide, 14 meters long, and 8.8 meters high, such that a low-scatter environment is established. Both sources may be used bare or moderated by a sphere of deuterated water $\left(\mathrm{D}_{2} \mathrm{O}\right) 15$ centimeters in radius, enclosed within a thin stainless steel shell and covered by 0.051 centimeters of cadmium. These provide neutron fields useful for instrument calibrations as well as for dosimeter characterization in accordance with specifications of DOE/EH-0027, the Department of Energy Standard for the Performance Testing of Personnel Dosimetry Systems (DOE 1986), ANSI Standard HPS N13.11, Personnel Dosimetry Performance-Criteria for Testing (ANSI 1993), and International Standards Organization (ISO) 8529, Neutron Reference Radiations for Calibrating Neutron-Measuring Devices Used for Radiation Protection Purposes and for Determining Their Response as a Function of Neutron Energy (ISO 1989).

The second configuration involves a ${ }^{252} \mathrm{Cf}$ source placed in a well to facilitate easy access for instrument calibration. This source provides a fission spectra partially degraded by the significant scattering from the sides of the well; however, its calibration is established such that instrument calibrations will be referenceable to free-field conditions. 
Table 6.2. Complete Listing of Available X-Ray Configuration Techniques and Their Characteristics ${ }^{(2)}$

\begin{tabular}{|c|c|c|c|c|c|}
\hline Style & Technique & $\begin{array}{c}\text { Average/Effective } \\
\text { Energy }(\mathrm{keV})^{(\mathrm{b})}\end{array}$ & $\begin{array}{c}\text { Half Value } \\
\text { Layer (mm Al) }\end{array}$ & $\begin{array}{c}\text { Homogeneity } \\
\text { Coefficient }\end{array}$ & $\begin{array}{c}\begin{array}{c}\text { Exposure Rate/Range } \\
(\mathrm{R} / \mathrm{hr})^{(\mathrm{o})}\end{array} \\
\end{array}$ \\
\hline \multirow{15}{*}{ Bremstrahlung } & $\mathrm{M} 20$ & 14 & 0.152 & 0.79 & $2.9-288.6$ \\
\hline & \% M30\% & $2 \% 20 \%$ & \%., 0.36 & $\because 0,64 \%$ & $\div 3 / 32 \times 32611 \%$ \\
\hline & का &. & 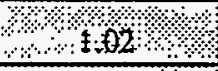 & $30.66 \%$ & $13,34,350,9$ \\
\hline & $\% \times 600$ & 35 & 1.1668. & 3 & $4 ., 32,0,0,0$, \\
\hline & MMOO & $\% \mathrm{S3}$ & 5,0 & $0,72 \%$ & $31,3 \%$;05 \\
\hline & $\mathrm{MLSO}$ & 33 & $1,10,2, \%$ & $3,0,87$ & $3,3,8391,4+$ \\
\hline & $\mathrm{M} 200$ & 100 & 14.9 & 0.95 & $4.3-431.0$ \\
\hline & $S 60$ & 38 & 2.8 & 0.75 & $0.6-119.6$ \\
\hline & S75 & 40 & 1.86 & 0.63 & $4.6-472.2$ \\
\hline & $\mathrm{H} 40$ & 33 & 2.9 & 0.94 & Not established \\
\hline & $\mathrm{H} 50$ & 39 & 4.2 & 0.92 & $0.05-9.40$ \\
\hline & $\mathrm{H} 100$ & 83 & 13.5 & 1.00 & $0.02-3.07$ \\
\hline & HHISQ & 118 & 17.0. & 1000 & $0012+165 \%$ \\
\hline & $\mathrm{H} 200$ & 162 & 19.8 & 1.00 & $0.09-9.22$ \\
\hline & $\mathrm{H} 250$ & 204 & 22 & 1.00 & $0.09-8.50$ \\
\hline \multirow{7}{*}{ K-Fluorescence } & K8.6 & 8.6 & N/A & N/A & 20.43 \\
\hline & $\mathrm{K} 17.0$ & 17.5 & N/A & N/A & 3.64 \\
\hline & $\mathrm{K} 25.3$ & 25.3 & N/A & $\mathrm{N} / \mathrm{A}$ & 3.74 \\
\hline & $\mathrm{K} 31.0$ & 31.0 & N/A & N/A & 1.55 \\
\hline & $\mathrm{K} 40.1$ & 40.1 & N/A & N/A & 1.51 \\
\hline & K49.1 & 49.1 & N/A & $\mathrm{N} / \mathrm{A}$ & 0.86 \\
\hline & $\mathrm{K} 59.0$ & 59.3 & N/A & $\mathrm{N} / \mathrm{A}$ & 0.96 \\
\hline
\end{tabular}

(a) Routine calibration maintained only for shaded techniques. All others are calibrated as needed.

(b) Nominal.

\section{Beta Particle Sources}

Beta particle sources $\left({ }^{147} \mathrm{Pm},{ }^{204} \mathrm{Tl}\right.$, and $\left.{ }^{90} \mathrm{Sr} /{ }^{90} \mathrm{Y}\right)$ are maintained primarily for dosimetry characterization. Available sources include those manufactured by Amersham-Buchler and calibrated directly by the Physikalisch-Technische Bundesanstalt (PTB), Germany's national physical standards organization, and those manufactured in the United States by Amersham and Isotope Products Laboratory. Currently 
available ${ }^{147} \mathrm{Pm}$ sources have decayed to the extent that renders them useless for most dosimeter irradiation or instrument characterization purposes. A higher activity replacement has been procured, but is still undergoing characterization prior to being accepted for use. Measurements have been made of all Amersham-Buchler sources and the Amersham-U.S. ${ }^{90} \mathrm{Sr}{ }^{10} \mathrm{Y}$ sources to verify satisfactory compliance with HPS N13.11; DOE/EH-0027; and ISO 6980, Reference Beta Radiations for Calibrating Dosimeters and Doseratemeters and for Determining Their Response as a Function of Beta Radiation Energy (ISO 1984).

\subsubsection{Traceability to National Standards}

Maintaining radiological reference fields traceable to national standards is one of the primary goals of this project. The traceability pathway has been evolving over the history of this effort and was initially discussed in the 1993 annual report (Lyon et al. 1994). Since the method of traceability is often unclear and can vary periodically, the current pathway for PNNL radiological reference fields is provided here.

Traceability infers an assurance that calibration fields are established and used in a manner consistent with national standards. There are two accepted types of consistency measurements which are commonly used to infer traceability: 1) implied consistency, which is established through the use of a laboratory standard submitted to NIST for calibration within radiation fields applicable to the laboratory; and 2) demonstrated consistency, which can be established through a measurement quality assurance (MQA) interaction with NIST. This latter method is akin to a performance test administrated by NIST and is instrumental in verifying measurement traceability, as opposed to simply obtaining or maintaining a traceable source or reference instrument (i.e., artifact traceability). A disadvantage with traceability based only upon implied consistency is the lack of demonstration which indicates that measurements made of traceable sources or using reference instruments are consistent with those made of or using national standards. Traceability based upon demonstrated consistency provides the assurance that traceable instruments and/or sources are being used properly (whether it be to calibrate additional sources [or reference fields] or laboratory instrument standards) such that traceability is appropriately extended as desired.

NIST supports the use of both techniques in maintaining traceability, but favors the practice of performing MQA interactions on a routine basis coupled with providing infrequent instrument or source calibrations. This project mirrors the NIST philosophy where possible; however, there are some limitations of the NIST capability which require a variance in the normal process. The following descriptions provide the traceability pathway for each of the radiation types applicable within this project.

Photon sources (i.e., gamma sources and x-ray techniques) are maintained traceable via both implied and demonstrated consistency verifications. Periodically, one or more selected "reference class instruments" are submitted to NIST for calibration to specific radiation fields. Prior to 1995, five air ionization chambers had been submitted for calibration to ${ }^{137} \mathrm{Cs},{ }^{60} \mathrm{Co}$, and many of the available NIST x-ray techniques, including M30, M50, M60, M100, M150, M200, H40, H50, H100, H150, H200, H250, S60, and S75. In calibrating these instruments directly to NIST "primary standard" reference fields, they are 
deemed. "secondary standards" and are used within the process of calibrating other radiological reference fields and/or reference instruments for use as tertiary or working standards. The most common traceability pathway currently in use is depicted in Figure 6.3. In some cases, secondary standard instruments have been used to calibrate or verify the constancy of working level radiation fields such as the fields associated with the well sources. This practice is not unacceptable and, in fact, tends to slightly reduce the calibration uncertainty; however, it exposes the valuable secondary standards to increased use and the potential for damage. This practice is, therefore, gradually being reduced.

To achieve demonstrated consistency, NIST has conducted MQA assessments of PNNL photon reference fields since 1984, in most cases selecting a subset of the available sources and/or X-ray techniques. During 1995, M50, M60, and $\mathrm{H} 150 \mathrm{x}$-ray and ${ }^{60} \mathrm{Co}$ reference fields were verified. The results of this intercomparison were within the NIST-specified tolerance level of $\pm 5 \%$, as shown in Table 6.3 .

The result for M50 prompted an internal evaluation of that $\mathrm{x}$-ray technique. It was identified earlier that the half-value layer for this beam had changed slightly from the prior verification. This change suggested a need to make minor adjustments to the high voltage applied to generate this field. The MQA test was performed using the original beam parameters and it is suspected that this caused the relatively higher percent difference noted in the NIST intercomparison. This $\mathrm{x}$-ray technique is no longer used on a frequent basis; however, to study the issue and gain further knowledge of the $\mathrm{x}$-ray system, the beam parameters will be adjusted and subsequent measurements performed during the upcoming year to evaluate the suspected reason for this outcome.

Currently, NIST does not maintain capabilities for K-fluorescence $\mathrm{x}$-ray or ${ }^{241} \mathrm{Am}$ reference fields. Although traceability for these fields has been established using a similar pathway as that identified in Figure 6.3, the primary reference field is maintained by the National Radiation Protection Board of the United Kingdom. Traceability for irradiations and calibrations made using these reference fields are implied.

Neutron traceability for all irradiations and measurements performed using PNNL sources is implied only. The primary pathway to NIST is through direct calibration of PNNL ${ }^{252} \mathrm{Cf}$ sources, in terms of neutron emission rate, within the NIST Manganous Sulfate Bath Facility. Dose equivalent rates are calculated for these sources in their bare and moderated configuration based on NIST recommendations provided in the National Bureau of Standards (NBS) Special Publication 633, Procedures for Calibrating Neutron Personnel Dosimeters (DOC/NBS 1982). A Nuclear Research Corporation Model NP-2 portable neutron monitor (SNOOPY) is maintained as a tertiary standard which is used to convey the dose equivalent rate in a low scatter environment to a calibration well equipped with a bare ${ }^{252} \mathrm{Cf}$ source. The calibration well is currently established as a working standard specifically for use with SNOOPY survey instruments. Use of the well for calibrating any other neutron survey instrument would not necessarily preserve any implied traceability. The traceability pathway for neutrons is shown in Figure 6.4.

During the past several years, numerous joint efforts have been made between the NIST and PNNL to establish a suitable method for neutron MQA intercomparisons in order to demonstrate traceability. 


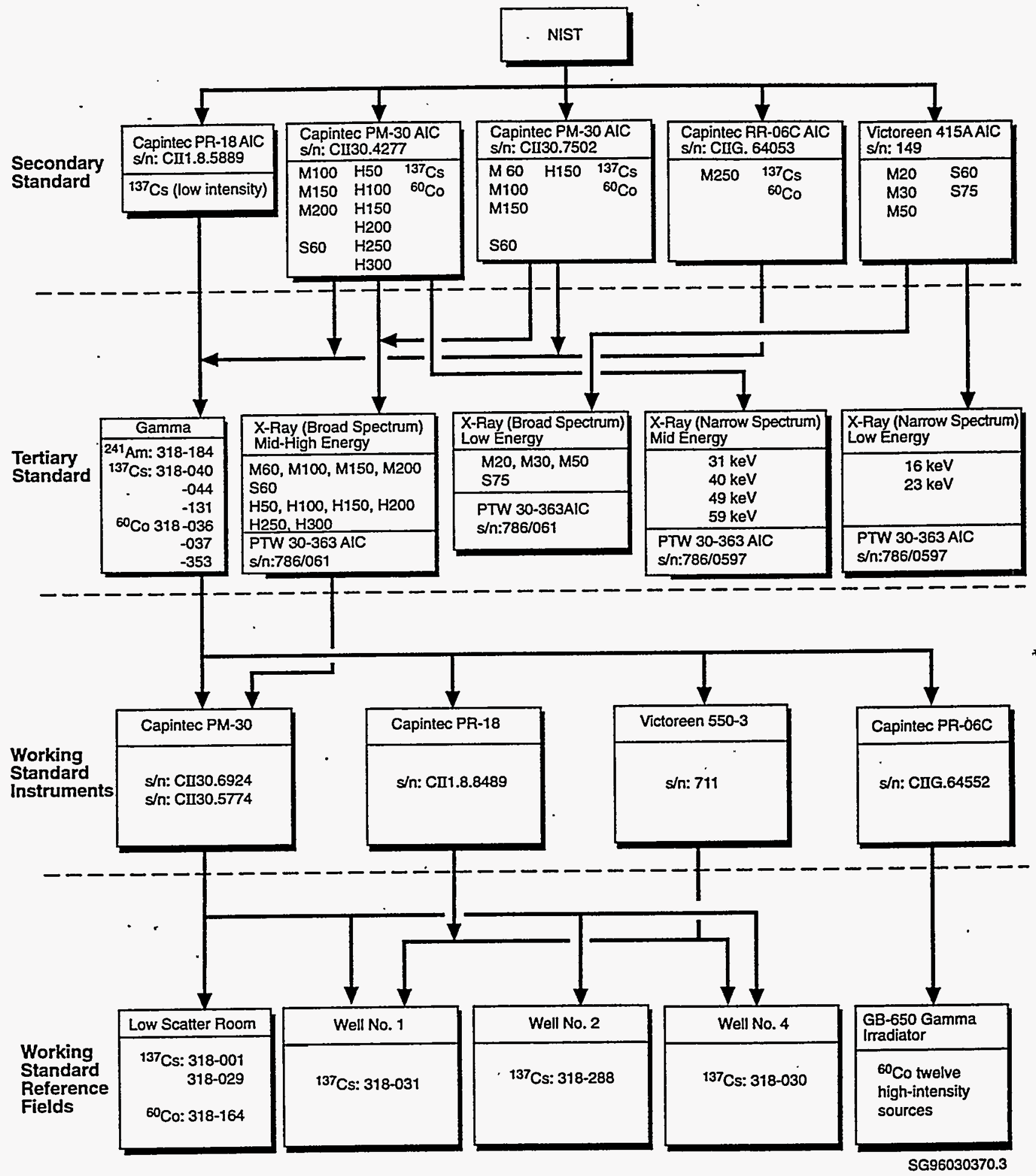

AIC $=$ Air lonization Chamber

Figure 6.3. Typical Traceability Pathway for PNNL Photon Reference Fields 
Table 6.3. Results of 1995 NIST Measurement Quality Assurance Intercomparison

\begin{tabular}{|c|c|c|c|c|}
\hline Beam Code & M50 & M60 & H150 & ${ }^{60}$ Co (318-037) \\
\hline \hline Percent Difference & -3.98 & -0.97 & -0.56 & -0.93 \\
\hline
\end{tabular}

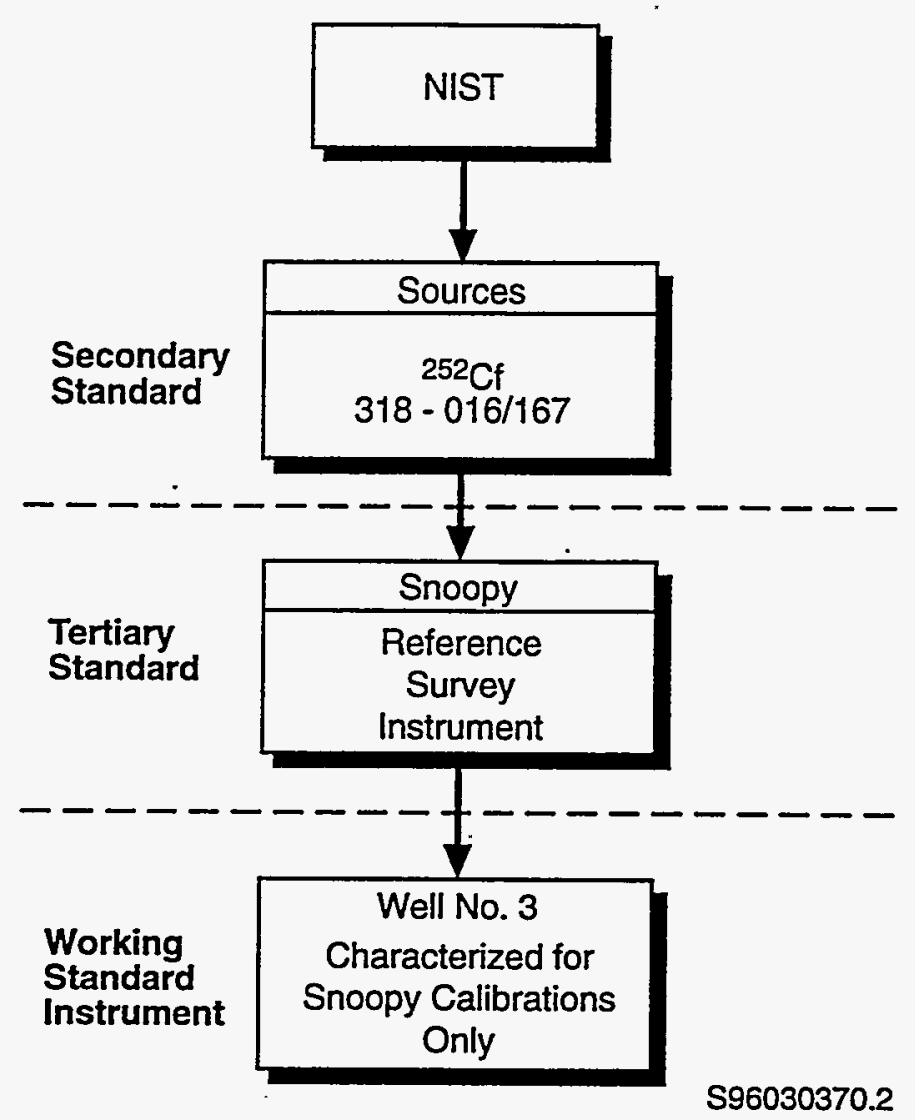

Figure 6.4. Typical Traceability Pathway for PNNL Neutron Reference Fields

These interactions are necessary to assume that various parameters are properly determined and/or are accounted for in the use of these sources. Such physical influences as room (wall, ceiling, floor) and air scatter must be properly measured. Also, source aging is a concern due to possible isotopic contaminants which are difficult to eliminate during source manufacture and are not detectable via the NIST calibration. These intercomparisons have involved various measurement devices and outcomes and, although nominal agreement has been somewhat poorer than is typically observed for beta and photon fields, the results are encouraging. No further evaluations were performed during 1995; however, NIST has tentatively planned to visit PNNL in 1996 to continue its investigation of intercomparative methods. 
The NIST-traceability of beta reference fields is based upon both implied and demonstrated consistency. Of highest order in the reference field hierarchy are the Amersham-Buchler ${ }^{90} \mathrm{Sr}{ }^{90} \mathrm{Y}(74 \mathrm{MBq}$ and $1.85 \mathrm{GBq})$ and ${ }^{204} \mathrm{Tl}(18.5 \mathrm{MBq})$ beta point sources. NIST maintains a similar set of sources at its facility which it has characterized/verified both quantitatively and qualitatively. PNNL predominantly uses the alternate (i.e., Amersham-U.S. and Isotope Products Laboratory) set of point sources of similar isotopic distribution, but with subtle differences in construction material and, in the case of the ${ }^{204} \mathrm{Tl}$, a significantly larger activity (i.e., $1.85 \mathrm{GBq}$ ). The ${ }^{90} \mathrm{Sr} /{ }^{90} \mathrm{Y}$ sources of this alternate set, commonly referred to as the ANSI N13.11 sources, were calibrated directly by NIST, the $74 \mathrm{MBq}$ source in 1986 at the NIST and the $1.85 \mathrm{GBq}$ source at PNNL by a NIST scientist using a PNNL-owned extrapolation chamber. The NIST calibration places these sources as secondary standards in the calibration hierarchy. The PNNLowned extrapolation chamber, used by the NIST scientist, is generally considered to be an absolute standard and is difficult to place in the laboratory traceability hierarchy. It is currently being used as a tertiary standard, since instead of being calibrated by NIST using primary standards, it is compared to the Amersham-Buchler sources which, through periodic MQA intercomparisons with NIST, are considered to be internal secondary standards. The traceability pathway for beta reference fields and the extrapolation chamber is shown in Figure 6.5.

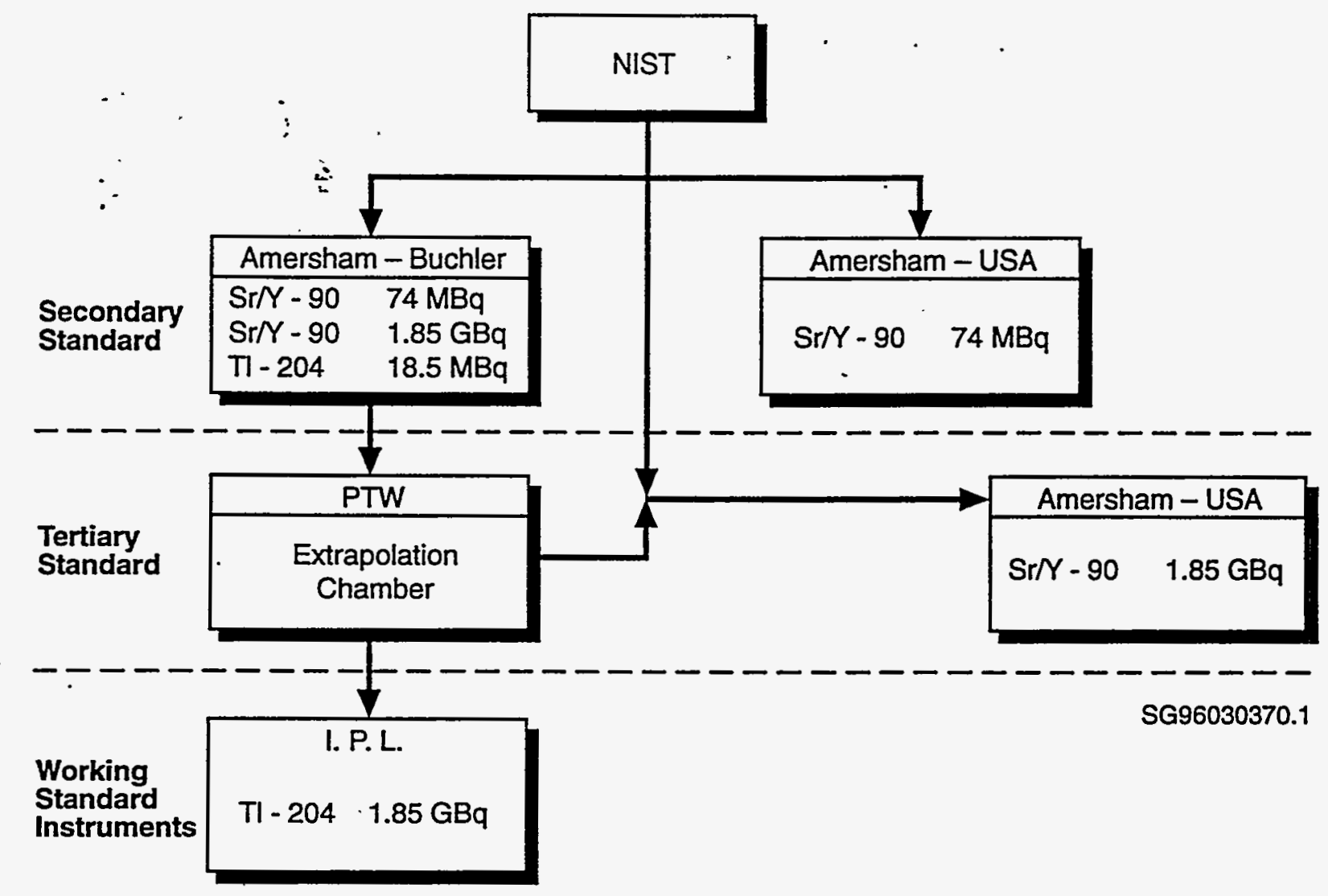

Figure 6.5. Typical Traceability Pathway for PNNL Beta Reference Fields 
The periodic MQA intercomparison NIST conducts with the PNNL calibrations laboratory involves the use of a NIST transfer standard. Intercomparisons were made in 1984-85 and again in 1991-92 between the NIST and PNNL Amersham-Buchler sources. These sources were selected to preserve similar geometry, encapsulation, and activity since it is suspected the transfer standard used for these measurements is sensitive to differences in these parameters. There were no beta MQA measurements performed during 1995.

\subsubsection{Calibrations and Constancy Checks}

Following initial or annual calibrations, periodic verification measurements are performed to assure constancy of characteristics and magnitude for most radiation reference fields maintained by the RS\&C Project. Historically, the philosophy has been to perform extensive annual calibrations and less-involved constancy verifications, typically on a quarterly frequency. The stability of reference fields demonstrated for previous years, along with a desire to reduce costs, has prompted consideration for a revision to this methodology. Although reference fields were still verified in this way during most of 1995, a gradual change has been initiated and will continue into 1996 using alternate criteria.

Under a new proposed philosophy, the frequency and rigor of measurement will be established based on several criteria. For radioactive sources, these criteria may include, but are not limited to

- the general content (including possible impurities) of the source material

- the half-life

- the age and/or historical stability

- whether an automated positioning system is used to obtain a continuum of exposure/dose equivalent rates and, if so, the stability of such a system

- the stability and/or reproducibility of the source position or positioning system

- the constancy of ambient conditions (e.g., addition of major structures, equipment or other sources of potential scatter).

For x-ray reference fields, criteria for consideration may include

- the constancy/stability of the $\mathrm{x}$-ray equipment

- the quantity of use

- the properties of the materials used within the various beam filters 
- the constancy of ambient conditions (e.g., addition of major structures, equipment or other sources of potential scatter).

Throughout 1995, the format for source verifications followed that of prior years. For beam and open geometry photon fields generated by radioactive sources in which no automated positioning system . is involved, this included an annual calibration and periodic interim checks performed, typically, on a quarterly basis. X-ray reference fields are verified at the beginning of each calendar quarter. Low scatter room neutron sources are verified on a quarterly basis as a byproduct of the quarterly verification of the SNOOPY tertiary standard. Well sources (photon and neutron) are calibrated annually to provide data for modifying the computerized exposure rate calculational program which determines programmatic instrument calibration points. Absorbed-dose rates from beta sources are verified annually using an extrapolation chamber at fixed distances to assure constancy with original calibration data. Instrument standards are intercompared annually, as necessary prior to use, including verifying the calibration factors for photon ionization chambers, assuring the proper function of the PhysikalischTechnische Werkstäten (PTW) extrapolation chamber and assuring accuracy and proper functioning of the reference SNOOPY detector (tertiary standard).

Calibration verifications of photon reference fields were completed as necessary in 1995. In general, all verifications confirmed the nominal status of reference fields and there were no significant discrepancies encountered. There were several significant changes during 1995, however, some of which affected calibration dates and the frequency. These are described below.

- During the routine calibration of the Low Scatter Room gamma sources in April $1995,{ }^{60} \mathrm{Co}$ source 318-164 became jammed within one of the pneumatic system diverter assemblies. Sufficient data had been collected to provide an adequate calibration; however, the source was locked-out pending a survey of the capsule condition. There has been no need of the source since that time and, consequently, the capsule inspection was not performed and the source remains in locked-out status. Use of this source has been temporarily discontinued.

- Colbalt-60 source $318-027$, contained in Well \#4 is normally calibrated during the first calendar quarter. Cesium-137 source $318-030$, contained in Well \#2 is normally calibrated during the second calendar quarter. Due to planned removal of 318-027 and a move of 318-030 to Well \#4, the calibration of 318-027 was eliminated and 318-030 was postponed until it was moved. To verify 318-030 in Well \#2 and justify the extension of its calibration period, an abbreviated constancy verification was performed. Upon transfer in July 1995 to Well \#4, which was refitted with upgraded and more accurate laser distance measuring equipment (DME), source 318-030 was successfully recalibrated.

- In August 1995, a new ${ }^{137} \mathrm{Cs}$ source, 318-288, was installed into Well \#2 following its upgrade to new laser DME. This source was subsequently calibrated in both the unattenuated and lead-attenuated geometries available on that well. 
- High Exposure Facility ${ }^{137} \mathrm{Cs}$ sources (318-040 and -044) and ${ }^{60} \mathrm{Co}$ sources (318-036 and -037) are normally calibrated during July. During 1995, however, two significant changes to the facility occurred in the third calendar quarter. First, the position system was upgraded, which if done after the calibration, would have mandated a repeat of the calibration. Second, source 318-036 was replaced by a new $222 \mathrm{TBq}{ }^{60} \mathrm{Co}$ source, $318-353$, and this new source required a complete calibration on the range. Therefore, a constancy verification was provided to extend the calibration period to November 1995.

Annual verification of the PTW extrapolation chamber was performed using the $1.85 \mathrm{GBq}$ Amersham-Buchler ${ }^{90} \mathrm{Sr} /{ }^{90} \mathrm{Y}$ PTB standard (source no. 318-012). The instrument responded within $0.25 \%$ of the decayed baseline dose rate provided on the source certificate. In prior years, verification of the chamber had been performed using this source, along with a $74 \mathrm{MBq}{ }^{90} \mathrm{Sr} /{ }^{90} \mathrm{Y}$ source and an 18.5 $\mathrm{MBq}{ }^{204} \mathrm{Tl}$ source so that the energy response of the instrument could also be verified. This extensive verification method has since been simplified with the justification that the energy response of the instrument would only change under the condition of a significant modification (e.g., change of the entrance window). The low current generated by these formerly used PTB sources also resulted in high uncertainties and significant measurement time. Since the primary concern is verifying the effective diameter of the entrance window and the accuracy of the micrometer which adjusts the separation of the parallel collecting electrodes, the high-activity $\mathrm{PTB}{ }^{90} \mathrm{Sr} /{ }^{90} \mathrm{Y}$ source was judged to be sufficient to complete the annual verification. In the event that significant modifications are performed on the extrapolation chamber that could effect the energy response, a complete verification using the three sources is recommended.

Annual verifications of ${ }^{90} \mathrm{Sr} /{ }^{90} \mathrm{Y}$ and ${ }^{204} \mathrm{Tl}$ sources used for most dosimeter irradiations and instrument evaluations (318-102, -103 and -192) were subsequently performed using the extrapolation chamber. Measured results were within $2.5 \%$ of decayed baseline dose rates.

The ${ }^{252} \mathrm{Cf}$ source $318-038$, contained within Well \#3, is normally calibrated during June; however, its annual calibration was postponed pending replacement of the source with 318-167, currently utilized within the Low Scatter Room pneumatic system. Instead, verifications of the source using the quarterly format have been conducted and have confirmed the continuing accuracy of the prior annual calibration conducted in 1994.

\subsection{Supporting Studies}

Two supporting studies were conducted in 1995: one to determine well calibration uncertainties and one to calibrate a ${ }^{241} \mathrm{AmBe}$ neutron reference field.

\subsubsection{Determination of Well Calibration Uncertainties}

An evaluation of the uncertainties associated with the calibration of various reference fields was initiated during 1995. The initial focus of this evaluation was associated with the measurements of 
radiation sources applied within well geometries. The methods of uncertainty analysis follow the guidance provided in NIST Technical Note 1297, Guidelines for Evaluating and Expressing the Uncertainty of NIST Measurement Results.

Identifying a single value for the uncertainty of the any exposure rate available from a selected well source provides a difficult challenge. While it could be simply resolved by stating the worst-case value, which is normally realized at the lowest exposure rate obtainable on each particular well, this could, in some cases, overstate the value by a factor of two or more. Currently, the range of the uncertainties are provided on the calibration report with the specific value at each evaluated calibration point.

The inclusion of this information provides a general improvement to the presentation of the calibration data; however, one component of uncertainty still remains to be assessed. This component, although potentially insignificant, is associated with the mathematical profiling of the exposure rates available throughout the range of source positions. The calibration of each well involves the assimilation of eighteen to thirty-seven (depending on the particular well) individual calibration points, each with their associated uncertainties, into a mathematical equation. This equation, which is determined by a commercial curve fitting software package, is the critical tool used by the automated positioning system to determine the specific source position needed to obtain a specified exposure rate, or the converse. It is the proration of uncertainties into this derived equation and the associated "goodness of fit" of the equation to the individual data points which must yet be determined to complete the assessment. This work will continue in 1996.

\subsubsection{Calibration of a ${ }^{241} \mathrm{AmBe}$ Neutron Reference Field}

A need was identified by HEDP to characterize the performance of the HCND within a high-energy neutron field specifically obtained from the compound isotopic source of ${ }^{241} \mathrm{AmBe}$. This source produces a spectrum of neutrons with a dose equivalent average energy of $4.4 \mathrm{MeV}$, significantly higher than the $2.4 \mathrm{MeV}$ dose equivalent average energy provided from ${ }^{252} \mathrm{Cf}$. Although a source with nominal activity of $555 \mathrm{GBq}$ was recently obtained, radiological controls were not in place to allow its use via manual positioning methods and to facilitate such controls was not considered cost efficient. Instead, a $111 \mathrm{Gbq}$ (nominal) source, routinely used within the instrument calibration facility to test the alarm capabilities of criticality monitors, could be accessed manually and used within the current scope of 318 Building Radiation Work Permits and Safe Operating Procedures. This source is typically used for indication only and, consequently, was not calibrated. Use of this source for dosimetry purposes required a calibration.

This source (reference number 318-286) was configured in a reproducible geometry within the Room 106 low-scatter environment. A Health Physics Instruments, Model REM-500, neutron survey instrument was selected to perform the calibration. This instrument, which uses as its base detection system, a 2.5-inch-diameter tissue equivalent proportional counter (TEPC), was favored because of its relative energy independence, gamma insensitivity, and ease of use. Also, this device had been used as a trial intercomparison device in efforts to identify a suitable method for neutron MQA interactions with NIST and, therefore, had an established link to NIST, albeit referenced to ${ }^{252} \mathrm{Cf}$. 
The instrument was first characterized for the effects of scattered neutrons from the walls, floor, and ceiling of the exposure area followed by a specific characterization of the free field dose equivalent rate at a distance of one meter. The determined neutron dose equivalent rate was $6.31 \mathrm{mrem} / \mathrm{h}$ and, although not specifically assessed, the field was postulated to be nearly void of photon influence through the combined attenuation using the intrinsic stainless steel encapsulation and an additional lead attenuator. This condition was confirmed after performing dosimeter irradiations in which only a slight indication of photon influence was noted. Future work, if justified, may include the characterization of the photon component and the neutron spectrum.

\subsection{Project-Related Professional Activities}

No professional presentations or publications were made by project staff during 1995. 
, 


\subsection{Radcon Instrumentation Services Project}

The Radcon Instrumentation Services (RIS) Project (formerly the Instrument Calibration and Evaluation Program) provides complete and reliable radiation protection instrument services for Hanford Site contractors to ensure personnel safety in the Hanford workplace. Specific tasks performed under this project during 1995 included calibration, maintenance and repair of portable instrumentation, procurement and testing of new radiological control instruments, administration and technical support of the Hanford Instrument Evaluation Committee, and maintenance of a pool of portable survey instruments available for use by site contractors. In support of site contractor radiological control organizations, the RIS Project completed an evaluation of new and existing instruments in support of 10 CFR Part 835 (DOE 1993) compliance and, at the request of DOE-RL, initiated unit prices for services offered to site contractors.

\subsection{Routine Tasks}

The operation of a complete radiation protection instrument calibration and maintenance program is an integral part of the Hanford Site Radiological Control Program. During CY 1995, the RIS Project continued to provide complete instrument services; however, as the mission and scope of the Hanford Project evolved into a more privatized, cost-efficient operation, the RIS Project made required scope and operational changes. The Hanford pool of portable radiation protection instruments was administratively separated from the calibration and maintenance of instruments. Pool and non-pool instruments are calibrated in categories based on unit-price cost to the site contractors (see Table 7.1). Maintenance is costed at an hourly rate with the required parts and labor charged to the last contractor to use the instrument. Calibration intervals were set to one year and will be shortened only if analysis of instrument returns indicates a shorter calibration interval is needed. Procurement of new instruments is initiated by the site contractors, or jointly by the contractors through the Hanford Instrument Evaluation Committee, and the procurement costs are charged to the contractor using the instruments. The Hanford Site contractors, through the evaluation, calibration, and maintenance programs of the RIS Project provide the site with quality, reliable, and accurate instrumentation capable of performing at the level necessary to ensure personnel safety as required by 10 CFR Part 835 (DOE 1993), DOE 5480.6 (DOE 1992), and HSRCM-1 (RL 1994). Calibrations are performed using the guidance in ANSI N323-1978 (ANSI 1978). The RIS Project activities fall under the base tasks that comprise the CY 1995 program: 1) administration of the Hanford Site pool of portable survey instruments; 2) calibration and maintenance service of Hanford pool, WHC, PNNL, and BHI radiation protection instruments; 3 ) evaluation and publication to the site of all site portable survey instrument environmental parameters; 4) maintenance of a calibration records database; 5) maintenance of all the necessary radiological, electronic and mechanical standards traceable to NIST; and 6) administration and technical support of the Hanford Instrument Evaluation Committee. These basic tasks and other important supporting tasks performed in CY 1995 are described in this chapter. 
Table 7.1. Calendar Year 1995 Instrument Calibrations by Unit-Price Category

\begin{tabular}{||r|r|r|c|c|c|c||}
\hline \hline Month & Portable & Non-Portable & CAM & Special & Sources & Pencils \\
\hline \hline January & 1,473 & 60 & 44 & 0 & 30 & 135 \\
\hline February & 1,301 & 81 & 27 & 0 & 19 & 553 \\
\hline March & 1,475 & 64 & 64 & 9 & 27 & 541 \\
\hline April & 1,230 & 42 & 41 & 3 & 36 & 226 \\
\hline May & 1,057 & 51 & 56 & 3 & 39 & 445 \\
\hline June & 1,480 & 95 & 60 & 6 & 34 & 351 \\
\hline July & 1,324 & 63 & 39 & 42 & 66 & 419 \\
\hline August & 1,232 & 114 & 44 & 3 & 22 & 128 \\
\hline September & 1,173 & 196 & 37 & 15 & 63 & 457 \\
\hline October & 789 & 140 & 25 & 1 & 23 & 806 \\
\hline November & 776 & 75 & 34 & 6 & 24 & 175 \\
\hline December & 727 & 172 & 58 & 1 & 12 & 428 \\
\hline Total & 14,037 & 1,153 & 529 & 89 & 395 & 4,664 \\
\hline
\end{tabular}

\subsection{Project Improvements in Calibration and Maintenance Operations}

As part of the ACE Breakthrough evaluation of the PNNL RIS Project, core instrumentation calibration and evaluation needs of the Hanford Site have been identified; a new, highly defined project scope was developed in response to these needs; and a unit-priced operating budget was established. The streamlining of PNNL instrument calibration services, resulting from the breakthrough process, has produced significant ( $\sim 40 \%$ ) savings to the site and has provided the RIS Project with a competitive position in the marketplace.

In support of the ACE driven changes in project philosophy, operational developments designed to automate equipment tracking, improve procedural accuracy, increase operational efficiency and capture manpower and parts costs associated with routine RIS Project calibration operations have been successfully advanced during 1995 .

Bar coding of instruments, using a new numbering system that naturally groups and maintains instruments of the same type together and facilitates database queries and instrument evaluations, was 
successfully developed and implemented to increase productivity. Bar coding automation will save costs by significantly simplifying the tasks of accurately logging and tracking calibrated pool instruments.

To accomplish this automation, all laboratory and instrument-shop work stations have been fully equipped with computer terminals and bar code readers, and this equipment has been fully integrated into the RIS Project's calibration database system. These new work-station/database links allow detailed manpower and parts costs information associated with routine instrument maintenance to be automatically logged and costed. Accounting for specific instrument maintenance costs is an important, integral component of the RIS Project's unit-priced operating budget.

To further reduce project record management costs, all PNL-MÁ-563 procedures have been revised to include a complete, stand-alone, fully traceable calibration data sheet. The newly adopted system for maintaining instrument calibration records promises to significantly improve record management productivity while readily providing the means of supplying customers with calibration information that is normally provided by commercial vendors. Moreover, the newly adopted bar code numbering system also provides a unique basis for electronically filing instrument calibration data.

Specifically, bar code mnemonics will provide the basis of an easily understood and navigable directory structure within which electronic calibration records will be stored and easily retrieved. The year of calibration and a bar code number will be the only parameters required to extract a complete, signed calibration record for any instrument processed by the RIS Project personnel.

\subsubsection{Instrument Evaluation and Testing}

The Hanford Instrument Evaluation Committee (HIEC) was established to provide a Hanford intercontractor information exchange mechanism to assure that the highest quality portable and semiportable radiological protection instrumentation program is maintained at Hanford. Responsibilities of the committee include the following:

- discuss and propose solutions to ongoing or potential radiological instrumentation problems and needs on site

- identify new radiological instrumentation available from manufacturers that may be useful to the Hanford Site operations

- oversee the procurement of the instruments, and review the evaluations of the performance by contractor organizations

- establish or review minimum acceptable operational criteria for portable and semi-portable radiological instrumentation used for safety on the Hanford Site 
- promote information exchange between contractors on radiological protection instrumentation usage and problems/resolutions.

Representatives from all of the Hanford contractors and a representative of DOE are on this committee.

During 1995, the committee continued to perform evaluations on instruments identified as needing further evaluations before approval and placement on the "approved instrument list." The "approved instrument list" was developed to meet Hanford Site Radiological Control Manual (HSRCM-1) (RL 1994) requirements that only approved instruments may be used on site.

\subsection{Supporting Investigation and Studies}

Two supporting investigations were conducted in 1995. Each is described in the subsections below.

\subsubsection{Testing to Qualify Site Instruments for Use in the Hanford Environment}

In support of the site contractors' requirements for 10 CFR Part 835, all instruments used on site were evaluated for compliance with the required qualification and documentation of being appropriate for use in the Hanford Site environment. Any missing tests for qualification were performed, and the environmental parameters for all instruments were published for site operations.

\subsubsection{Stack Monitoring Systems Technical Assistance}

During FY 1995, the RIS Project has provided significant assistance to PNNL Facilities in maintaining and calibrating stack monitoring systems installed at the 324 and 325 Buildings. To meet new State and Federal requirements for measuring and tracking radiological stack emissions, PNNL facilities recently installed new sophisticated monitoring systems at both these facilities. Unfortunately, the only instruments that could meet the stringent regulatory performance requirements were fabricated by a German company that had only recently been acquired by a U.S. firm. Although the fundamental components of the system were and are sound, significant system electronic design problems resulted when the vendor integrated these components into the requested stack monitor. Since the U.S. firm was unable to diagnose and remedy the very significant, nightmarish operational problems that beset both monitoring systems after they were installed, the RIS Project's assistance was requested and all problems were successfully overcome. Both monitors have been calibrated and are currently undergoing operational evaluations.

\subsection{Project Related Professional Activities}

Staff presentations and professional membershhips during 1995 are listed in this section. 


\subsubsection{Presentations}

Johnson, M.L. 1995. "Battelle Northwest Instrument Testing Capabilities." Presented to the GOCO Health Physics Instrument Committee, March 14-16, 1995, Cocoa Beach, Florida.

Johnson, M.L. 1995. "Evaluation of the SAIC PD-3 Electronic Dosimeter." Presented at the SAIC User's Group Meeting, September 11-13, 1995, Monroe, Michigan.

\subsubsection{Professional Memberships}

Johnson, M.L. Chairperson of Working Group for ANSI N323B, "Radiation Protection Instrumentation Test and Calibration - Air Monitoring Instruments"

Johnson, M.L. Member of Working Group for ANSI N323A, "Radiation Protection Instrumentation and Calibration - General Requirements and Portable Instruments"

Johnson, M.L. Member of Working Group for ANSI N323C, "Radiation Protection Instrumentation and Calibration - Fixed Instruments." 



\subsection{References}

American National Standards Institute (ANSI). 1995. "Performance Testing of Extremity Dosmeters." ANSIN13.32, Health Physics Society, McLean, Virginia.

American National Standards Institute (ANSI). 1993. Performance Criteria for Radiobioassay. ANSI N13.30, New York.

American National Standards Institute (ANSI). 1983. American National Standard for Dosimetry Personnel Dosimetry Performance - Criteria for Testing. ANSI N13.11, New York.

American National Standards Institute (ANSI). 1978. Radiation Protection Instrumentation Test and Calibration. ANSI N323, New York.

American National Standards Institute (ANSI). 1972. American Standard Practice for Occupational Radiation Exposure Records Systems. ANSI N13.6, New York.

Dirkes, R. L., R. W. Hanf, and R. K. Woodruff, eds. 1994. Hanford Site Environmental Report for Calendar Year 1993. PNL-9823, Pacific Northwest National Laboratory, Richland, Washington.

Freedom of Information Act. Public Law 89-487, July 4, 1966.

International Standards Organization (ISO). 1984. Reference Beta Radiations for Calibrating Dosemeters and Doseratemeters and for Determining Their Response as a Function of Beta Radiation Energy. ISO 6980, Geneva.

International Standards Organization (ISO). 1989. Neutron Reference Radiations for Calibrating Neutron - Measuring Devices Used for Radiation Protection Purposes and for Determing Their Response as a Function of Neutron Energy. ISP 8529, Geneva.

Lyon, M., D. E. Bihl, J. J. Fix, T. J. Froelich, R. K. Piper, and P. C. Olsen. 1994. Hanford Radiological Protection Support Services Annual Report for 1993. PNL-10047, Pacific Northwest National Laboratory, Richland, Washington.

Privacy Act, 44 Federal Regulations 510772 (1974).

Strenge, D. L., R. A. Peloquin, M. J. Sula, J. R. Johnson. 1990a. Code for Internal Dosimetry (CINDY), Part 1: Conceptual Representation, PNL-7493,Pt.1, Pacific Northwest National Laboratory, Richland, Washington. 
Strenge, D. L., R. A. Peloquin, M. J. Sula, J. R. Johnson. 1990b. Code for Internal Dosimetry (CINDY), Part 2: Users Guide, PNL-7493,Pt.2, Pacific Northwest National Laboratory, Richland, Washington.

Sula, M. J., E. H. Carbaugh, and D. E. Bihl. 1991. Technical Basis for Internal Dosimetry at Hanford. PNL-6866.R1, Pacific Northwest National Laboratory, Richland, Washington.

U.S. Department of Commerce/National Bureau of Standards (DOC/NBS). 1982. Procedures for Calibrating Neutron Personnel Dosimeters. NBS Special Publication 633, Washington, D.C.

U.S. Department of Energy (DOE). 1986. Department of Energy Standard for the Performance Testing of Personnel Dosimetry Systems. DOE/EH-0027, Washington, D.C.

U.S. Department of Energy (DOE). 1991. Quality Assurance. DOE Order 5700.6C, Washington, D.C.

U.S. Department of Energy (DOE). 1992. Safety of Department of Energy-Owned Nuclear Reactors. DOE Order 5480.6, Washington D.C.

U.S. Department of Energy (DOE). 1993. Occupational Radiation Protection. 10 CFR 835, Washington, D.C.

U. S. Department of Energy (DOE). 1994a. Implementation Guide for Use With Title 10, Code of Federal Regualtions, Part 835, Occupational Radiation Protection, Internal Dosimetry Program. G-10 CFR 835/C1 - Revision 1, Washington, D.C.

U. S. Department of Energy (DOE). 1994b. Implementation Guide for Use With Title 10, Code of Federal Regulations, Part 835, Occupational Radiation Protection - External Dosimetry Program. G-10 CFR 835/C2, Rev.1, Washington, D.C.

U.S. Department of Energy (DOE). 1995a. Records Management Program. DOE Order 1324.5B, Washington, D.C.

U.S. Department of Energy (DOE). 1995b. Environment, Safety, and Health Reporting. DOE Order 231.1, Washington, D.C.

U.S. Department of Energy Richland Field Office (RL). 1994. Hanford Site Radiological Control . Manual. HSRCM-1, Revision 2, Richland, Washington. 


\section{Distribution}

No. of

Copies

\section{OFFSITE}

12 DOE/Office of Scientific and Technical Information

DOE Albuquerque Field Office

R. Enge

Battelle Pantex

Pantex Plant

P.O. Box 30020

Amarillo, TX .79120

R. J. Blum

Mound Laboratory

EG\&G

Mound Applied Technologies

P.O. Box 3000

Miamisburg, $\mathrm{OH} 45342$

J. M. Graf

Los Alamos National Laboratory

P.O. Box 1663

Los Alamos, NM 87545

S. Baker

Kaiser-Hill

Rocky Flats Plant

P.O. Box 464

Golden, CO 80402-0464

DOE Chicago Field Office

C. Schopfer

Technical Support Section

Brookhaven National Laboratory

P.O. Box 5000

Upton, NY 11973
No. of

Copies

Manager, Radiation Protection

Argonne National Laboratory

9700 South Cass Avenue

Argonne, IL 60439

DOE Headquarters

C. R. Jones, Director

Office of Health Physics and Industrial

Hygiene Programs

U.S. Department of Energy

$4011 / 270$

Washington, D.C. 20585

R. T. Bell, Director

Health Physics Programs Division

U.S. Department of Energy

4007/270

Washington, D.C. 20485

DOE Idaho Field Office

G. Courtney

LITCO

P.O. Box 4000

Idaho Falls, ID 83404

DOE Nevada Field Office

C. T. Bastian

Bechtel Nevada

P.O. Box 98521

Las Vegas, NV 89193

DOE Oak Ridge Field Office

J. S. Bogard

Oak Ridge National Laboratory

Martin Marietta Energy Systems, Inc.

P.O. Box 2008

Oak Ridge, TN 37831

Distr.1 
No. of

Copies

J. B. Hunt

Y-12 Plant

Martin Marietta Energy Systems, Inc.

P.O. Box 2009

Oak Ridge, TN 37831

DOE San Francisco Field Office

C. T. Prevo

Lawrence Livermore National Laboratory P.O. Box 808

Livermore, CA 94550

DOE Savannah River Field Office

K. W. Crase

Westinghouse Savannah River Company

Savannah River Plant

P.O. Box 616

Aiken, SC 29802

\section{ONSITE}

3 DOE Richland Operations Office

T. L. Aldridge

R. M. Rosselli

D. E. Trader

4 Environmental Restoration Contractor

T. M. Brun

D. E. Gergely

J. D. Moroney

J. E. Tarpinian
No. of

Copies

Hanford Environmental Health Foundation

S. McInturff

2 Westinghouse Hanford Company

L. R. McKay

D. B. Ottley

Washington State University (Tri-Cities)

R. L. Kathren

48

Pacific Northwest National Laboratory

D. E. Bihl (2)

D. M. Brehm

R. A. Buchanan

E. H. Carbaugh (2)

J. J. Fix (2)

T. J. Froelich (2)

M. E. Hevland

E. E. Hickey

D. P. Higby

G. R. Hoenes

M. P. Long

M. Lyon (15)

T. P. Lynch

J. C. McDonald

P. C. Olsen

R. K. Piper (2)

K. H. Pryor

B. A. Rathbone

R. I. Scherpelz

K. L. Soldat

R. A. Walters

Technical Report Files (5)

Radiation Protection

Historical Files

(c/o V. L. Berndt) (2) 